Portland State University

PDXScholar

1979

\title{
A Study of Multnomah County community support services for the chronically mentally ill
}

\author{
Karen Albers \\ Portland State University \\ Barbara Bransford \\ Portland State University \\ Diane Bunn \\ Portland State University \\ Joyce Kilpatrick \\ Portland State University \\ Ann Kramer \\ Portland State University
}

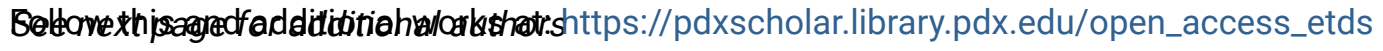

Part of the Psychiatric and Mental Health Commons, and the Social Work Commons Let us know how access to this document benefits you.

\section{Recommended Citation}

Albers, Karen; Bransford, Barbara; Bunn, Diane; Kilpatrick, Joyce; Kramer, Ann; McLin, Douglas; Patella, Elly; Pittman, Barbara; Pulliam, Rod; Rickert, Janet; Rosenbaum, Deena; Ruonavaara, Alanna; Weston, Nancy; and Widerburg, Clarence, "A Study of Multnomah County community support services for the chronically mentally ill" (1979). Dissertations and Theses. Paper 3408.

https://doi.org/10.15760/etd.5294

This Thesis is brought to you for free and open access. It has been accepted for inclusion in Dissertations and Theses by an authorized administrator of PDXScholar. Please contact us if we can make this document more accessible: pdxscholar@pdx.edu. 


\section{Author}

Karen Albers, Barbara Bransford, Diane Bunn, Joyce Kilpatrick, Ann Kramer, Douglas McLin, Elly Patella,

Barbara Pittman, Rod Pulliam, Janet Rickert, Deena Rosenbaum, Alanna Ruonavaara, Nancy Weston, and Clarence Widerburg 


\title{
A STUDY OF MULTNOMAH COUNTY COMMUNITY SUPPORT SERVICES FOR THE CHRONICALLY MENTALLY ILL
}

\author{
by \\ KAREN ALBERS, \\ BARBARA BRANSFORD, \\ DIANE BUNN, \\ JOYCE KILPATRICK, \\ ANN KRAMER, \\ DOUGLAS MCLIN, \\ ELLY PATELLA, \\ BARBARA PITTMAN, \\ ROD PULLIAM, \\ JANET RICKERT, \\ DEENA ROSENBAUM, \\ ALANNA RUONAVAARA, \\ NANCY WESTON \\ AND \\ CLARENCE WIDERBURG
}

A practicum submitted in partial fulfillment of the requirements for the degree of

MASTERS OF SOCIAL WORK

PORTLAND STATE UNIVERSITY 
APPROVED:

June A. Dunn

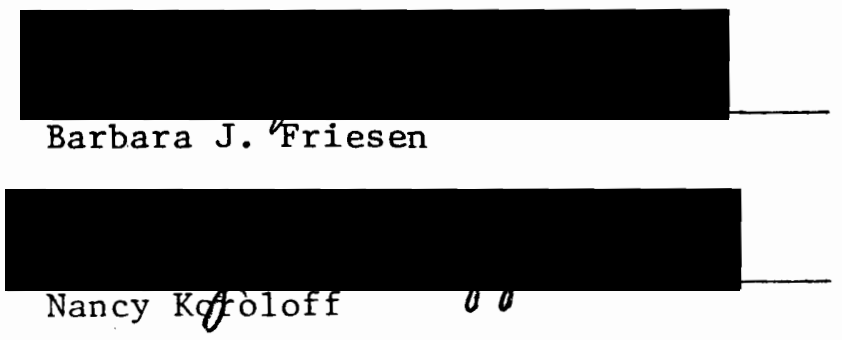




\section{ABSTRACT}

In recent years attention has been given to the problems of the chronically mentally $i l 1$ in regard to the effects of deinstitutionalization and a need for community supports. In this study, 77 service providers to the chronically mentally ill of Multnomah County (Portland), Oregon were interviewed to assess the components of the existing community support system for this population, as well as to identify the strengths and weaknesses of the system. Ten chronically mentally ill clients were interviewed in a similar manner.

Although a multitude of problems were reported, service providers most frequently mentioned the need for residential situations, for case management and services coordination, and for financial resources. Clients, on the other hand, most frequently mentioned the need for employment for financial resources, and for transportation. Special problems of minority groups were reported by half of the service providers. While service providers most frequently spoke of the community as being neutral towards, or rejecting of the chronically mentally ill,.clients tended to view the community as accepting.

There were differences of opinion among service providers regarding the existence of interagency cooperation and case management. Existing case management and services coordination were reported to be, for the most part, on an informal basis. While the majority of service providers said that case management should be the responsibility of one agency, 
problems were anticipated in the development of greater interagency case management.

Varied degrees and types of professional training were reported by service providers, although the majority reported at least one deficit in training of staff. Service providers and clients offered suggestions for improvements in service delivery. 
TABLE OF CONTENTS

Abstract

Page

Abstract

List of Tables

vi

Preface

vii

\section{CHAPTER}

I. LITERATURE REVIEW

Introduction 1

Historical Overview 2

Background of Community Support Project 6

Clients in the Community 9

Identification of the Chronically Mentally Ill 9

Community Attitudes 10

Living Arrangements \& Daily Activities 12

Service Delivery 16

General Description $\quad 16$

Interagency Cooperation $\quad 17$

Case Management 18

Innovative Responses $\quad 20$

Service Needs $\quad 25$

$\begin{array}{ll}\text { Training Needs } & 27\end{array}$

II. THE COMMUNITY SUPPORT PROGRAM

Background 29

Types of Data to be Collected 30

Definition of the Target Population 31

III. PROJECT METHODOLOGY

Purpose of the Research 33

Participants in the Study 34

Interview Schedule $\quad 35$

Service Provider Interview $\quad 35$

Client Interviews 36

Data Collection $\quad 37$

Analysis 37

Limitations 38

IV. MULTNOMAH COUNTY

County Characteristics 39

Basic Population Characteristics 41

V. SERVICE PROVIDER INTERVIEW FINDINGS
Definition of Chronic

Client in the Community $\quad 44$

Problems of the Chronically Mentally Ill 44

Residential Situations 45

Case Management/Services Coordination 45

Financial Resources $\quad 46$ 
Employment

Isolation/Loneliness/Need for Social and/or Emotional Support Out-patient Resources/Services

Transportation

Activities

Miscellaneous Categories

Problems of Minority Groups

The Client's Day

Where the Chronically Mentally Ill Cluster

Community Attitudes

Service Delivery

Interagency Cooperation

Case Management

Training

Suggestions for Improvement

Special Skills Needed

Training Received

Deficits in Training

Staff Time and Utilization Data

Additional Comments

VI. CLIENT RESULTS

Clients in the Community

$\begin{array}{ll}\text { Problems } & 82\end{array}$

Time in the Community $\quad 84$

Places in Community Where Respondents Spend Time 85

Attitude of the Community $\quad 87$

Service Delivery $\quad 88$

Services Utilized by Respondents $\quad 88$

Referral Sources $\quad 90$

$\begin{array}{ll}\text { Interagency Cooperation } & 90\end{array}$

VII. SUMMARY OF THE REPORT OF FINDINGS IN MULTNOMAH COUNTY 94

Introduction $\quad 94$

Strengths of the System $\quad 94$

Client in the Community 95

Problem Areas $\quad 95$

Problems of Minority Groups $\quad 96$

The Client's Day 96

Where the Chronically Mentally Ill Cluster 97

Attitude of the Community $\quad 97$

Service Delivery $\quad 97$

Interagency Cooperation $\quad 97$

Case Management Issues 98

Suggestions for Improvement of the Service Delivery System 99 Barriers

Resources $\quad 99$

Training . $\quad 99$

Attitudes $\quad 100$

$\begin{array}{ll}\text { Case Management } & 100\end{array}$ 
Bibliography

Appendices

A. Interview Instruments and Checklist

B. List of Participants and Checklist Results

C. Statistical Sources

D. Description of Housing and Urban Development Program

E. Basic Population Characteristics 


\section{LIST OF TABLES}

Page

TABLE

I. Most Frequently Mentioned Problems of the Chronically 44 Mentally III in the Community.

II. Frequency of Responses to a Question Concerning Problems 49 for Minority Groups Among the Chronically Mentally I11.

III. Perceived Community Attitudes Towards the Chronically 59 Mentally Ill.

IV. Responses to a Question Concerning Interagency Cooper- 60 ation to Meet the Needs of the Chronically Mentally I11.

V. Suggestions for Improvement in Service Delivery. 


\section{PREFACE}

A group of graduate students from the School of Social Work at Portland State University became interested in a project of studying the status of the chronically mentally ill. Since this is an area of state-wide concern, the Community Support Project and the Multnomah County Mental Health Division were also involved in examination of this population. A research project was planned and implemented in cooperation with these agencies to determine the needs of this group of Oregon's citizens.

The review of the literature traces the treatment of the chronically mentally $i 11$ in America and the effects of deinstitutionalization upon this population. A description of the Community Support Project is presented.

The findings of this project examine the current needs of the chronically mentally ill in Multnomah County and the strengths and weakness of the service delivery system as it currently exists. 


\section{CHAPTER I}

\section{LITERATURE REVIEW}

\section{Introduction}

In a special message to the United States Congress on February 5, 1963, President John F. Kennedy outlined a national mental health program suggesting it was time for a "bold new approach" towards critical mental health problems facing the nation. Subsequently Congress enacted legislation which would implement Kennedy's recommendations, and it was thought the reforms undertaken would revolutionize the delivery of mental health services. Particularly important to this community support research emphasis was placed on the release of the chronically mentally ill from state hospitals and return to communities for rehabilitation. Smith and Hart (1975, p. 582) note:

Theoretically, if persons received vigorous, early treatment (crisis intervention) close to home and could stay in the community with the help of medication, chronic mental illness would disappear. It was assumed there would be no need for long-term hospitalization, and large state hospitals would be closed.

In the ensuing years, as the community mental health emphasis expanded, the population of state mental hospitals has been reduced; however, there now is increasing concern about the welfare of the deinstitutionalized chronically mentally ill. Bassuk and Gerson (1978, p. 46, 48) write of :

- . the number of discharged but severely and chronically disturbed former patients consigned to bleak lives in nursing homes, single-room occupancy hotels, and skid-road rooming 
houses. For thousands of hospitalized patients released haphazardly to a non-system of community aftercare, deinstitutionalization has meant real hardship and even tragedy.

Zaitz, in the Portland, Oregon, Oregonian (October 17, 1978, p. B3) reported, "Health professionals conceded in interviews that the government's mental-health systems are missing up to $75 \%$ of the chronically mentally 111 who need treatment." That the supportive systems are not serving large numbers of the chronically disturbed raises considerable concern. Reasons for the problems which have developed as a result of the deinstitutionalization process are being explored by many in the mental health field. Keith (1978, p. 317) writes:

Mental health workers, who tended to be either vehemently opposed or complacently approving of the migration of patients to the community, made little effort to adopt the existing community services delivery system to the special needs of the large population of discharged patients that suddenly confronted them.

According to Ozarin (1976, p. 70):

Aftercare or continuing care resources have not always been available to assist the patients leaving hospitals or those who enter community alternative facilities. . . The result is often a social or psychiatric crisis, resulting in rehospitalization.

Many of the chronically mentally: ill patients apparently are not having their needs adequately met by the mental health system. This research study is an examination of the history of the treatment of the chronically mentally ill and an exploration of the current services available to this population.

Historical Overview.

The care of the chronically mentally ill appears to have been of little significance until the mid-nineteenth century. Up to this time, 
asylums provided for the custodial care for the poor of any and all circumstances with prisoners, beggars, and the mentally ill of ten housed in the same institutions, possibly in the same cell. Living conditions were deplorable. The mentally ill were of ten chained in dungeons and care of their physical needs, as well as their mental health was virtually non-existent.

Establishment of state hospitals for the mentally ill began as a protest against these conditions. Through the work of Dorothea Dix and other reformers, seventy-five state-supported mental hospitals were established between 1840 and 1880, and the American people had been awakened to the need for the state to take more responsibility for the care of its mentally disabled. Patients were moved out of the jails and into the hospitals, care was improved, and there was an air of optimism that many patients would recover (Marshall, 1937). Hospitals became overcrowded and understaffed, and funds were inadequate for either proper treatment or training of staff. As a result, recovery rates declined, and the hospitals once again became the focus of custodial care for the chronically mentally ill.

Thus, in the hundred years between 1845 and 1945, the United States saw the establishment of almost three hundred state mental hospitals, nearly all of which -- after an initial flurry of enthusiásm and hope -- quickly lapsed into vast storehouses for some of the most disabled and miserable people in the county. (Bloom, 1977, p. 9-20)

After the end of World War II, developments took place which began to alter the care of the mentally ill and reduce the hospital population. Bloom lists three significant changes: the advent of tranquilizers, adoption of the concept of the "therapeutic community," and the geographic decentralization of many mental hospitals. Through 
the use of tranquilizers, the length of hospital stays was shortened considerably, and many patients who previously would have required hospitalization were able to be cared for in their home communities. The philosophy of the "therapeutic community" consists of both patients and staff in the hospital setting cooperating in forming a democratic community to create a "conflict-free, warm, encouraging, reassuring environment with a minimum of stress for the patients." (Pasamanick, Scarpitti and Dinitz, 1967, p. 16). The goal of this approach was to encourage positive interpersonal relationships and to provide a setting similar to what patients would encounter after hospital discharge. They were given opportunities to test their behavior against the realities of community living.

The third change was the inauguration of the concept of geographic decentralization. The result of this shift was the movement of the seriously mentally ill out of the "back wards" where they had been less accessible to treatment, and to facilitate improved working relationships between the hospital and the community.

Changes were also being made during this period in the administration and funding of state mental hospitals. The federal government enacted its first major mental health legislation in 1946, with the passage of the National Mental Health Act (Public Law 79-487). The purpose of the act was to finance research concerning psychiatric disorders, to promote training of personnel in the mental health field, and to encourage and assist the states in their development of mental health facilities. The bill also provided for the creation of the 
National Institute of Mental Health (NIMH), which would assist the states in administration and funding of mental health programs, thereby improving the quality of care. The act stressed the need for states to establish their own mental health agencies to act as authorities for that state (National Mental Health Act, 1946).

In 1955 Congress passed the Mental Health Study Act (Public Law 84-182), which created the Joint Commission on Mental Illness and Health. The Commission's task was to analyze and evaluate the resources and needs of the mentally ill, and to make recommendations for national programs (Mental Health Study Act of 1955). The final report, the result of a five-year study, was presented to Congress and President John F. Kennedy in 1961. The Commission stressed the federal government should substantially increase its financial commitment to provide for research, training, and to expand services, particularly programs for the chronically mentally ill (Action for Mental Health, 1961).

The recommendations made by the Commission formed the basis of President Kennedy's national mental health program presented to Congress in 1963. The major part of his proposal was the establishment of comprehensive mental health centers in major communities so all Americans would have access to mental health care. Congress responded to Kennedy's proposal, and in 1963 passed the Community Mental Health Centers Act (Public Law 88-164). Among the essential services required by this act were in-patient and out-patient care, as well as pre-care and after-care services -- programs which were designed to meet the needs of the chronically mentally ill. According to Bassuk and Gerson (1978,p. 48) the community mental health centers would offer "comprehensive and 
coordinated treatment and rehabilitation services" to the chronically disturbed, and these new services would replace the custodial functions of state hospitals. Further, these new innovative programs were to be conducted in the least restrictive setting, which generally was the community rather than the hospital. The goal for deinstitutionalization was a 50 percent reduction in mentally 111 hospital patients within the first 20 years.

The goal of reducing the population in the state mental hospitals has been reached, although new trends have developed in the length of hospital stay and the rate of re-admission. Bassuk and Gerson (1978) report in 1955 there were 178,000 admissions to state mental hospitals; in 1972, 390,000; and in 1974, 375,000. There has been a significant increase in the number of re-admissions (64\% of the total admissions in 1974, for example). Between 1940 and 1975, the total admissions increased $129 \%$. On the other hand, the rate of hospitalization (number of days in the hospita1) has shown a 65\% decrease in the years from 1940 to 1975 . Further, there was a corresponding $65 \%$ decrease in the census of residents in state hospitals from 559,000 in 1955 to 193,000 in 1975. These figures indicate a trend towards short-term hospitalization with re-admission as a frequent occurence.

Background of Community Support Program.

Within the past few years, several developments have occurred which address and seek solutions to the problems of treatment of the chronically mentally ill. The 1975 Community Mental Health Centers Act Amendments enabled NIMH to create and improve community mental health centers by providing services directed towards the chronically mentally ill. These 
services include after-care, community living programs, and screening of potential inpatients in order to provide alternatives to institutional care when appropriate. Congress provided new funding sources to implement these new programs intended to fill the gaps in the service delivery system (Ochburg, 1976).

A further development was the July, 1977 publication of a General Accounting office report on the status of the deinstitutionalization program (GAO Report, 1977). This document details a study made of deinstitutionalization and is generally critical of the outcome of the program. Regarding the services of community agencies, the report states:

Increased services available from the community mental health centers and clinics have not always reduced unnecessary admissions to mental health hospitals or provided services to people released from mental hospitals. Medication was the only service provided to many patients.

(GAO Report, p. iii)

The report contends at the Federal Level:

The lack of a planned, well-managed, coordinated and systematic approach to deinstitutionalization at the federal level has caused or contributed to the . . problems. A better planned, more coordinated, and more aggressive effort by the Federal government could help facilitate deinstitutionalization, and make sure that mentally disabled persons eligible for or receiving federally supported benefits receive appropriate services in the appropriate setting. (GAO Report, p. 25)

The resultant problems of deinstitutionalization were seen as a need for comprehensive services such as housing, income support, employment, vocational training, and physical and mental health supervision. Among the recommendations made to Congress in the report was the requirement of states to concentrate on coordination of support services at the local level. A recommendation to the Secretary of 
Health, Education, and Welfare was to "determine how to make sure that State and local agencies administering HEW-supported programs develop and implement effective case management systems for people being released from public institutions," (GAO Report, p. ix). The ultimate finding of the GAO Report indicates that intergovernmental coordination is virtually non-existent.

A third development which occurred during this period was formation of the NIMH Community Support Program, designed to improve the services described as inadequate in the GAO Report. The Community Support Program is an effort to coordinate interagency planning at the Federal level, as well as contracting between NIMH and State mental health agencies to improve services to the mentally ill. According to Herbert (1977, p. 1),

- . the target group includes many who have been turned out into unprepared communities as a result of deinstitutionalization and who receive unsuitable care or no care at all, as well as thousands who remain in unnecessarily restrictive settings such as mental hospitals or nursing homes because they have nowhere to turn.

The Community Support Project will encourage the formation of comprehensive community support systems to more adequately meet the needs of the chronically disabled.

The ultimate goal of CSP is to assure that clients have access to relevant services --continuing mental health care, a place to go or someone to call on in times of crisis, decent living arrangements with as much independence as possible, a chance to work or participate in other meaningful activities, and opportunities to develop life satisfactions. (Turner and TenHoor, 1978, p. 338)

Mental health professions (Herbert, 1977; Bassuk and Gerson, 1978) are encouraged to have the Federal government assert more leadership in the care of chrnoically mentally 111 , and to assume some of the responsibility 
for services to this underserved population. Hexbert (1977, p. 4) states:

On the one hand, the CSP calls for intensified interagency planning at the federal level, and, on the other, for a fiscal partnership involving federal, state and local agencies in guaranteeing direct services -- both mental health services and a full range of 'mainstream' services,-- to the chronically 111 . . . CSP marks a major departure. The program's explicit message is that the mental health field is ready to assume leadership responsibility for securing not only mental health services, but also long-term support and rehabilitation services in the community.

In conclusion, NIMH has designed and implemented a pilat program to explore the current service delivery problems which affect the chronically mentally ill as a result of the process of deinstitutionalzation. An examination of the literature in regards to this population, and its adjustment to community living, follows.

Clients In The Community

Identification of the Chronically Mentally Ill.

Since programs need to be geared to a specific population, it is important to investigate the concept of "chronic mental illness" as determined by mental health professionals so that means of identification of this population are understood.

The term 'mental illness' is one of recent origin. It was coined by people who were humane in their inclinations and who wanted very much to raise the station of (and the public's sympathies toward) the psychologically disturbed from that of witches and 'crazies' to one that was akin to the physically ill. (Rosenhan, 1973, p. 254)

The literature reviewed (Kittrie, 1971, Szasz, 1973, Crown, 1975, Weiner, 1975, Rosenhan, 1973 and Mechanic, 1969) noted the definition of mental illness is subjective, fraught with controversy and constant change. Determination of mental illness often relies on highly subjective criteria, such as variation in values from culture to culture 
(Kittrie 1971, Crown, 1975) interpretation of normality and abnormality (Rosenhan, 1973 ), models of mental illness adopted including the traditional disease or medical model, the "personality disturbance" model, and the "problems in living" model (Mechanic, 1969 and Szasz, 1973).

Although much disagreement in the literature about the concept of mental illness exists, there is recognition that such controversy and questioning does not: ". . . deny the existance of the personal anguish that is often associated with 'mental illness.'" (Rosenhan, 1973, p. 250).

The literature reveals a paucity of information regarding the concept of "chronic mental illness." The American Heritage Dictionary (1975,p. 240) defines "chronic" as "(1) of long duration, continuing, constant. (2) Prolonged, lingering, as certain diseases." Applied to the concept of mental illness, the definition of a "chronically mentally ill" individual would be one whose disturbance has been of an extended period of time. Chronic mental illness should also to be defined in behavioral terms. Test and Stein (1971, p. 3, 351) list some characteristics of the chronically mentally ill as high vulnerability to stress, need for basic coping skills necessary for daily living, extreme dependence, difficulty in working in the competitive job market, and difficulty with interpersonal relationships. Turner and TenHoor (1978, p. 319) define this "particularly vulnerable population" as "adult psychiatric patients whose disabilities are severe and persistent."

In summary, the chronic psychiatric patient is one whose emotional disabilities are so serious and persistent that without special support he or she is unable to maintain a stable adjustment to community life. (Test and Stein, 1977, p. 351)

Community Attitudes

Historically, the mentally ill have been viewed negatively by the 
community; however, a review of current literature shows these attitudes are beginning to be changed by a more accepting society.

Dohrenwend and Chin-Shong (1967 found a growing tolerance of deviant behavior in both low-status and high-status groups. Low-status groups tend to maintain positive attitudes until overtly threatened by a mentally ill individual. High-status groups appear to have positive attitudes as a result of their generally liberal orientation rather than through their understanding of psychopathology.

Sarbin and Manusco reported the public is sympathetic toward persons who have been labelled mentally ill. However such individuals are relegated to a "childlike non-person role." (Sarbin and Manusco, 1978, p.168). In a study of members of the United Auto Workers Union in a large metropolitan area, researches concluded "there is no evidence in this study of extreme rejection by blue-collar workers of the mentally ill." (Grocetti, et al, 1971, p. 1126). Schwartz and her associates studied relationships between former mental patients and their relatives in an effort to measure social distancing. They found the more overt symptoms of psychosis "were of lesser importance than neurotic symptoms such as anxiety, depression, and somatic concerns in explaining social distance." (Schwartz, et al, 1974, p. 332). Segal noted public attitudes towards the mentally $i l l$ are improving, and a broader range of behavior than in the past is being viewed as "mental illness." Acceptance of a mentally ill individual is determined by behavior the individual displays; when former patients assumed roles in which they most likely would be perceived as "normal", they were treated as such (Segal, 1978). A study regarding former mental hospital patients' experience 
indicates they felt a slight tendency towards improvement in their position in the community, a strong tendency for improvement in relationships with cohabitants following hospitalization, and a general feeling of satisfaction about the hospital experience. These findings run counter to the societal reaction theory in so much as the process of labeling patients "mentally 111 " did not result in impairment in effective functioning in normal social roles (Gove and Fain, 1973).

\section{Living Arrangements and Daily Activities.}

Bassuk and Gerson (1978, p. 53) state the matter of living arrangements needs to be of primary concern.

The first task is to provide decent places of habitation -- of asylum (which is a humane term in spite of its association with the old label 'insane asylum'). Treatment within a community may in concept seem better than hospitalization does. Actually, however, the quest for treatment may obscure a more basic responsibility: the responsibility to provide living conditions that offer refuge to individuals who seek such refuge themselves or are demonstrably unable to manage their lives independently.

Living arrangements for discharged patients vary greatly. Some individuals are able to return to their families. Rapoport and Rapoport (1961). find that those former patients who return to their families do so with varying degrees of success. However, very little guidance for these situations is available in most communities. Reich and Siegal (1973, p. 36) write:

Less noticed and less publicized, an even more oppressive and appalling state of affairs is unfolding as rooming houses, foster homes, and run-down hotels take the place of former back wards. Here the discharged patients are frequently clustered -- unsupervised, unmedicated, uncared for.

A review of the findings regarding boarding homes shows a wide range of care exists. Many owners and operators tend to see their facility as a quasi-hospital that dispenses medication and encourages residents 
to keep doctor's appointments. They do not see themselves or their homes as part of a cummunity mental health system. Due to a lack of follow up on the part of the releasing institutions, the boarding home owners sense a lack of support and interest in the patients after discharge. As a result,

With few exceptions, there is no planned program of activities for them, and they sit about aimlessly watching television or remain isolated in their bedrooms. That such conditions are an improvement on the back wards of the state hospitals is debatable. (Jones, 1975, p. 95)

The nursing homes where many former patients are sent are becoming the community equivalent of the earlier "back wards". Nursing homes more commonly have a locked ward.

That fact reinforces the impression that nursing homes are tending to become custodial institutions; disturbed patients are being cared for by staffs who have little or no training in psychiatry, and the emphasis is still on medical rather than psychiatric care. (Jones, 1975, p. 96)

Patients are also discharged to foster care as a form of home placement where a responsible person is paid to care for one or more discharged patients. Questions have been raised about the appropriate number of persons in foster care homes. Varying degrees of supervision from a hospital or outpatient clinic staff may be available. Chouinard (1975) describes a demonstration project in which he found when only one or two people are placed in a home, a more intense relationship develops with the operator than is found in most halfway houses. However, Sculthorpe (1960) reports many positive values are associated with multiple placements in a home.

Halfway houses are intended to help the client participate as fully as possible in community life with the expectation that he can, after a period of time, move to a more independent living arrangement. These homes 
serve those who cannot function adequately in the community without assistance. Occasionally these houses are utilized as alternatives to hospitalization, or more rarely, as a permanent placement.

Qther living arrangements whereby patients can share an apartment closely related to a mental hospital or rehabilitative facility are possible. Richmond (1969) calls these "post halfway house accomodations." One of the best known examples is Fountain House in New York City. Apartments in the community are leased, renovated, and then made available to groups of two or three "members" (usually former mental patients) who share the monthly rent as well as day-to-day housekeeping tasks. Members are allowed to live in the apartments for indeterminate periods. Occasionally they are able to assume the lease and maintain the apartment on their own (Beard, 1976).

Some homes are oriented to specific work for their residents and are given special labels. The two earliest established transitional residences, Spring Lake Ranch and Gould Farm, are called "work camps" by Wechsler (1961). He noted more of the life space of the residents is encompassed by a work camp than by a halfway house. Not only is the work usually farm chores, performed on the premises, but most of the soctal life of the house members takes place there as well.

Other houses are called "lodges" after the prototype established by Fairweather and his associates in Palo Alto, California (Fairweather, et al,1969). Here the residents live together with a minimum of supervision from professionals and successfully run their own business-- in this case, a janitorial service.

Shean (1973) discusses a slightly different approach in Williamsburg, Virginia, where woman clients who live together have formed a 
corporation. The clients work at various jobs and their employers form contracts with, and pay the corporation rather than the employees. Satellite housing programs, whereby individuals can maintain ties with a mental health program or the discharging hospital, are another type of living arrangement. Programs in San Mateo, California, St. Louis, Missouri, and Topeka, Kansas, uses a concept of graduated independent living settings, moving residents of halfway houses into their own rental units. They are described in the literature by Richmond (1969; Sandal1 (1975) and Bowen and Fry (1971).

A most unusual type of housing for the chronically mentally ill, dating back 600 years to the town of Gheel, Belgium, (Aring, 1974) is the mobilization of entire towns to receive discharged patients into their community. In New Haven, Connecticut, and Troy, Missouri, families were recruited by the St. Louis State Hospital to sponsor either home care or apartment living for patients. A high quality of life including social reintegration for the patients, as well as community satisfaction with the project, was reported (Keskiner and Zalcman,1974).

Most chronically mentally ill individuals are not involved in community-based programs providing services for them during the day. The literature describes programs including resocialization and community survival programs, day treatment, and aftercare services (Lamb, 1976, Kraus,1970, Fairweather,1969). A post-hospital resocialization program, described by Brandon, stresses the establishment of contacts with community persons viewed as potential helpers for chronically mentally ill persons by virtue of likely contact with them. These persons include employers, ministers, landlords, bank personnel and merchants. 
A dearth of information exists concerning how the chronically mentally ill spend time, day in and day out. In part this is due to the difficulties inherent in obtaining information which requires either extensive observations or reporting by the mentally ill person. The New York Times Magazine attempted to gather such information and presented a grim description of a "typical" day of a chronically mentally ill man (Koenig, 1978).

Service Delivery

General Description.

Although the need for continuity of care is evident to mental health professionals, a search of the literature reveals little concerning current programs, or proposed changes, in the delivery of mental health services focused on continuity of care. Former patients' need for assistance from social service agencies is high, yet they often have an extremely difficult time identifying and locating the appropriate agencies, and in continuing to seek assistance once contact has been made with an agency. As a consequence, a psychotic or social crisis may occur resulting in rehospitalization.

The following ideas from Ozarin (1976) specifically delineate and discuss service delivery and needs. The necessity of adequate follow-up care with the availability of transitional and supportive living arrangements needs to be stressed if the chronically mentally ill are to have a realistic chance of adjusting in the community. Closer working relationships between the various social support agencies and the state mental health hospitals are needed. Clients able to work need the planning assistance of vocational rehabilitation and departments of education. State and local programs for the aged should 
also be involved in offering aftercare assistance to post-hospital clients. Local health programs and the public health nurses, especially, have already proven themselves invaluable in offering immediate, compassionate, and competent assistance. Financial aid is necessary for those without adequate resources. This necessitates welfare departments to be part of this cooperative effort. Other services offered by welfare offices should provide additional assistance. Local hospitals and clinics must meet the medical needs of clients in the comunity. The police must also be involved in emergencies or crises concerning the chronically mentally ill and should be trained to handle these situations with understanding and support. Other agencies need to be involved in direct and indirect aftercare. The Department of Housing and Urban Development can provide housing and recreation. Zoning authorities and licensing agencies are important in arranging for halfway facilities. Post-hospital clients who return to the community have four general needs: financial, medical and psychiatric, employment, and social/recreational. Agencies which offer these kinds of services must be brought together through an information-sharing, education, joint planning and decision making. A pattern of interagency coordination and communication is absolutely essential, as no one service provider is likely to be able to meet all of the needs of a client.

Interagency Cooperation.

Mental health professionals agree social support agencies need to work together to better serve the chronically mentally 111 , but there is controversy about the nature of such collaborations. 
Problems of agency domain, institutional inertia, and professional specialization are some of the forces that have preserved impermeable boundary lines and forestalled effective cooperation. (Baker, 1971, p. 16)

Within this new emphasis on interorganizational relationships, a major focus is on continuity of care: the easy movement of clients between services according to their needs. While eminently desirable, the barriers to such continuity are formidable . . While everyone is in favor of coordination, nobody really wants to be coordinated. (Feldman, 1972, p. 7)

Long (1974) presented the following model for increasing interagency cooperation. One agency would be assigned the responsibility for coordinating client services. This agency would do central intake and needs assessment, and then assign the client to an appropriate second agency responsible for management of the client's therapy and follow-up services. The case management agency would have a contract with the central agency to assume responsibility for quality of service to the client. The central agency would maintain control through evaluations and monetary rewards or incentives for a job well done.

\section{Case Management.}

An individual client negotiating the maze of increasingly formalized and complex agencies may find a complicated and frustrating experience.

Brattler (1977, p. 120) describes the situation:

Many mental health, educational, legal and governmental institutions have become so complicated and impersonal that individuals no longer have direct access to them.

Agency personnel also experience difficulty maintaining contact with the client. Sometimes a client, especially a chronically mentally ill person, experiences "falling between cracks", receiving no services or support. The Task Force on Services for the Chronically Mentally Ill recognizes the need for: ". . a link between the chronically disabled person and the complicated, fragmented state service system," (Mental Health Association 
of Oregon, 1978, p. 5).

Case management is a proposed solution to the problem of adequately meeting the needs of the chronically mentally ill. As described by the Joint Commission of Accreditation of Hospitals (JCAH, 1975, P. 23):

Case management services are activities aimed at linking the service system to a consumer and at coordinating the various system components in order to achieve a successful outcome. The objective of case management is continuity of service.

Jacobson (1973, p. 63) writes:

It would seem appropriate to have the same staff group responsible for patient and family care throughout the person's career as a patient. In this way, responsibility would be clearly defined, and continuity of care assured.

The Accreditation Council for Psychiatric Facilities of the JCAH lists five basic activities involved in case management: " . . assessment, planning, linking, monitoring and advocacy (case-specific and class-specific)," (JCAH, 1975, p. 21). Several models of case management are found in the literature. All have the common theme of assigning primary responsibility to one source, usually an agency within the system (Aiken, et al, 1975; Datel and Murphy, 1975; Jacobson, 1973; Ozarin, 1976; and Dunn, 1978). An important aspect of case management emphasized is the client's involvement in the five activities throughout the process (Date1 and Murphy, 1975).

Ideally, with good case management, clients would be less likely to become "lost" within the system and interagency cooperation and coordination would be promoted (Aiken, et al, 1975; and Jacobson, 1973). Aiken, et al, (1975) mention the issue of potential conflict arising from attempts towards interagency coordination and cooperation. of particular significance is the determination of who will have primary responstbility for case management. Another related issue is whether or not case management 
and the provision of other services should be carried out by the same agency.

- a single organization can do the case management for a multi-problem client or do the therapy, but not both. In general, we believe that the single organization is best suited for case management with purchase of necessary services, especially when the multi-problem client has a wide variety of needs that are met by a number of different agencies. (Aiken, et al, 1975, P..158)

A problem facing case management is the need for services to maintain the chronically mentally ill person in the community. Townsend. (1978, p. 2-4) feels this problem is compounded when the case manager attempts to advocate for a particular client, leading to conflict with other staff, though the case manager is mandated to provide system integration.

To overcome this inbuilt dilemma in the role of the case manager, it behooves us in the community support systems business to start exploring, developing, and evaluating some practical clinical, administration and organizational mechanisms of service integration which will augment the integrative function of the case manager. (Townsend,1978, p. 4)

The Mental Health Association of Oregon (October, 1978) recommends:

The Department of Human Resources should provide case management to guarantee that every chronically ill individual receives quality mental health care and supportive services.

\section{Innovative Responses.}

Review of the literature reveals innovative programs encompassing other facets of a client's life such as employment, socialization, and the development of living skills. These programs utilize the case management concept, though often in a more restrictive setting than the community.

Fountain House, besides offering post-half-way house aćcomodation, is a prototype for many other aftercare agency programs. The program has staff and "members" work side by side in the various aspects of the organization - food service, club house, thrift shop, pre-vocational 
training in community work situations, newsletter, administrative clerical office, academic preparation, research, apartment and building maintanance, and outreach to members and those still in the hospital. Brown (1977) summarizes the development of psycho-social rehabilitation programs modeled after Fountain House, such as Horizon House, Philadelphia; Center Club, Boston; Hill House, Cleveland; Thresholds, Chicago; Bridgehaven, Louisville; Prospect House and Friendship House, New Jersey; and Fellowship House, Florida.

The Fairweather program, as discussed in Sanders (1972), is also a well-known model. Institutionalization of chronic mental patients is counteracted by forming autonomous, task-oriented, self-help groups of patients;

\begin{abstract}
- . the concept of patients determining their fate through peer groups may be a way of remedying the inadequate use of an existing resource (the patient himself), rather than focusing attention on the need for additional finances, facilities, and manpower; (Sanders, 1972, p. 51)
\end{abstract}

Small problem-solving groups are organized in the hospital to create a reference group for members' social support, develop mutual responsibility among members, and enhance independent decision-making. Staff provide continuous feedback on decision-making and problem-solving. The group then moves into the community together as a complete living and working unit. Members are trained as janitors and later as gardeners. Units are self-governing and self-run. Staff do not live-in, but are on call 24 hours a day and provide consultation at members' request. The original self-help groups in the hospital and community were found to decrease hospital recidivism, and improve community functioning in comparison with control group. 
Kantor describes the development of a non-traditional aftercare program in a rural area. An aftercare coordinator meets the patient at the hospital, and concrete plans are set before discharge. An aftercare planning committee (representatives of community agencies) helped the linkage of services.

Referrals to community agencies were continuously monitored so the aftercare coordinator could be aware of the services being provided each patient and determine whether the patient's adjustment necessitated service modifications. In addition to meeting with individual agencies, the coordinator chaired multi-agency conferences to assure that services were consistent and well-integrated. (Kantor, 1978, p. 49)

The program was considered a success, but was merged with the county community mental health clinic after one year due to need for funds.

The Harlem Valley Psychiatric Center (Sorenson,1977) serving Westchester and Putman counties in New York state is unique in the scope of services offered. In the areas of housing and employment, a series of graduated alternatives exist providing varied degrees of supervision and independence. Housing alternatives range from hospital wards to settlement in autonomous residences. A wide variety of vocational training and employment opportunities is offered, including pro-vocational training centers, sheltered workshops, a cottage industry program, onthe-job training, supported work placements, and others. All services of the program are comprehensive and wel1-coordinated.

A multi-disciplined approach is offered in the Greater Vancouver, Canada area. Eight direct service teams are assigned to specific geographic areas to provide a wide range of both traditional and innovative services to former patients. Evaluative research has substantiated that this program reduces the amount and duration of hospitalization, the cost of care, and provides a higher quality of life which includes 
client control over time and 1ife, interpersonal contacts, staff concern, and self-esteem (Bigelow, 1977).

Vancouver's Mental Patlent's Association (MPA) also offers an alternative services including a drop-in center and five cooperative residences. All facilities are run primarily by the ex-patient association membership. The MPA elects and pays coordinators for six-month terms as administrators, researchers, and as resources for the drop-in center and residences. All facilities are in residential neighborhoods in Vancouver; funding is provided from all levels of the Canadian government; program needs and services are determined by the ex-patients; and all participation is voluntary (Chamberlin, 1978).

Since 1972, the Training in Community Living Program at Mendota Mental Health Institute in Madison, Wisconsin has also used multidisciplined teams in an effort to keep in the community those requesting hospital admission. The teams work assertively with clients and their families in their own homes and with the community. Brief hospitalization is only used when absolutely necessary. Independent living situations are located for all appropriate clients. The staff teach basic living skills and assist in locating employment or placement in a sheltered workshop and in working on the job with the clients when necessary. Members of the team also involve the clients in social and recreational activities in the community, and accompany them until they are able to function independently.

Throughout the . . program, we felt that our assurance of constant avallability -- always followed through by action -was one of the most important ingredients in gaining and maintaining good community rapport. (Test and Stein,1977, p. 13) 
Community Organization for Personal Enrichment (C.0.P.E.)

was developed by South Arizona Mental Health Clinic and members of a local church. The program is based on the assumption that some of the problems of the chronically mentally ill are due to a need for social skills and knowledge, as well as the fact many clients have small and strained kinship supports. The program created mini-communities composed of volunteers referred by the church and chronically mentally ill living in the community. The goal for all persons involved was to "establish friendships of quasi-kinship relationships" (Cutler, 1978, p. 5) through meeting three mornings a week and engaging in recreational and craft activities. Clients continued to receive treatment at a mental health center.

To augment traditional aftercare services, Longview State Hospital in Cincinnati and the Clermont County Community Mental Health Center in Batavia, Ohio, trained volunteers to function as therapists for persons formerly in the hospital. The volunteers followed clients in the community, ensuring use of medication and follow-through on appointments, aiding in locating housing and employment, and providing support counseling. Agency staff continued their regular aftercare services; follow-up continued up to two years (Katkin, 1975).

Southwest Denver Community Mental Health Services has developed, as an alternative resource to hospitalization, a program whereby numerous community families take into their homes one or two clients who need intensive short-term treatment. The clients stay an average of ten days, have their own rooms, and are regarded as guests. Families receive ongoing training and support, are guaranteed a monthly salary 
for use of a continually available bed, and have up to thirty days' paid vacation a year. The husband and wife must desire involvement as the family home needs to offer a warm, accepting environment and a consistent family structure. In many instances, informal contact between the family and client continued after the crisis period. Staff is available to the homes on a 24-hour basis and has regular involvement with the client. Clients needing further care may stay up to three months in an apartment supervised by agency staff. In addition to increasing client support during aftercare and crisis, the program has extended the communities' knowledge and acceptance of mental health problems (Brooks, 1976).

A former hospital patient wrote the following os his aftercare in a structured comprehensive program:

All of us have something to contribute . . which others can see and can appreciate. We just need to be in a place where there are 'thank-you's' for what we do . . . I wish that everyone who believes that chronic patients are totally chronic could see all the things our members do each day and hear all the things they have to say . . . people can be more hopeful and not use the word 'chronic' for anybody, at least until we have given them the opportunities they and all people need if disability is to be avoided (Peterson,1978, p. 5 and 11).

\section{Service Needs.}

Many persons remain in, continue to enter, or re-enter institutions because of the lack of appropriate community services, and many others have been turned out of institutions without sufficient planning, with few or no supportive services and with no adequate follow up. (Moore,1979, p. 1)

A broad overview of needs of the chronically mentally ill centers on service needs to fill the gaps of the present mental health system in the community. Some issues involved include the need for further development of services and community resources, strengthening of 
existing services, and integration and coordination of services and resources for the chronically mentally ill (Lamb, 1976, President's Commission on Mental Health, 1977, Bassuk and Gersun, 1978, Polak and Jones, 1973, Place and Warner, 1974). Requisite services for this population in the community include provision of basic subsistance needs, such as sheltered living facilities, medication maintenance, monitoring of appropriate mental health care, opportunities for leisure time, and supportive services for the chronically mentally ill person as well as the family and the community (Bous, 1978, Place and Warner, 1974). Included in supportive services is the need to provide aftercare programs, mandated by federal legislation for community mental health centers, and other alternatives for hospitalization (Bous, 1978, President's Commission on Mental Health, 1977). A need for the development of community resources outside of the mental health system, such as natural helpers, to assist in integrating the chronically mentally ill person into the community also exists (Lamb, 1976; Polak and Jones, 1973).

An important overall service need is "linkage" or liaison between state hospital and community facilities, and among the community facilities themselves, to work toward integration and coordination of service elements to provide continuity of care (Bassuk and Gerson, 1978, Grenny and Cranda11, 1973). Case management as described in a previous section, is recognized as an overall service need entailing coordination and integration of services on behalf of the client (President's Commission on Mental Hea1th, 1977).

In general, the values and assumptions underlying these service needs emphasize the bringing about of a humanistic view towards mental health care (Polak and Jones, 1973). The overall philosophy of mental health 
service needs can be best summed up as; "A responsive mental health system should provide the most appropriate care in the least restrictive setting." (President's Commission on Mental Health, 1977, p. 16) Training Needs

Hand in hand with service needs is the need for trained and skilled personnel to administer and provide the services (Lamb, 1976, Bassuk and Gersun, 1978, Jones;, 1975, Blank, 1964, Bous, 1978).

We can build a network of comprehensive services and provide people with the means to pay for the services but accomplish little in the absence of skilled personnel to meet the diverse needs of those requiring care. (President's Commission on Mental Health, 1977 p. 35).

Training needs for mental health staff working with the chronically mentally ill are extensive and cover a wide range of service areas, some of these services areas are not traditionally thought of as pertaining to mental health, partly due to the shift of emphasis on community mental health. These areas include basic activities of daily living and personal care, medical and psychiatric care, vocational rehabilitation, sheltered employment, job referrals, financial assistance, recreation, socialization, and transportation (Bassuk and Gersun, 1978).

Also reflected in the literature is the need for mental health personnel to become more involved in advocacy for the chronically mentally ill. This requires an understanding of the total mental health service system, institutional and community attitudes towards the chronically mentally $i l l$ and efforts at the community and legislative level to bring about changes (Jones, 1975). Related to advocacy is case management requiring staff trained to assess the on-going and changing needs of the chronically mentally ill individual, and knowledge of service provided by public and private agencies. 
The ability to connect the chronically mentally ill person with the appropriate service(s), and to assist the client in becoming a part of a supportive system in the community, either formal or informal are also necessary skills (President's Commission on Mental Health, 1977).

Another need is for mental health personnel skilled in consultation and education to work in the community to develop and/or enhance and strengthen community services and resources for the chronically mentally ill (Polak and Jones, 1973). A training need for mental health personnel is in the area of program evaluation, not only in terms of the cost accountability of programs, but also in terms of effectiveness of services for the chronically mentally ill for overall program planning (Bous, 1978, Bachrach, 1976). Yet another need is for the training of mental health professionals, including psychiatrists, in the field of administration for community mental health programs (Blank, 1964). Overall staff training needs can be best summed up by the following statement: "The quality of mental health care depends ultimately on the knowledge, skills and sensitivity of those providing it." (President's Commission on Mental Health, 1977, p. 35) 
CHAPTER II

THE COMMUNITY SUPPORT PROGRAM

\section{Background}

The Community Support Program (CSP) is an NIMH funded project. The project staff are housed in the State Mental Health Division. The CSP has been assigned thirteen tasks, one of which involves the collection of baseline data and assessment of existing community support services in the state of Oregon. The goal of the project is to develop and assist the implementation of a three year Statewide CSS Action Plan. Guiding and assisting the CSP staff in their completion of tasks are a Steering Committee, composed of seven Department of Human Resources administrators or their designees, and a Technical Advisory Committee, composed of thirty individuals from around the state who have a broad base of experience with and knowledge of the chronic mentally and emotionally disabled.

The Oregon concept of a Community Support System as guided by NIMH has been described in the following way:

A community support system (CSS) is a network of caring and responsible people committed to assisting a vulnerable population to meet their needs and develop their potentials without being unnecessarily isolated or excluded from the community. The people in this network must have appropriate skills, facilities and resources at their disposal in order to accomplish this goal. Such a system must have the following basic characteristics

-the population(s) at risk must be identified

-the needs of the population(s) must be known 
-there must be legislative, financial and administrative arrangements to guarantee that appropriate forms of help are available

The following ten components of a CSS are seen as essential for this target population:

1. Identification of the population, whether in the hospital or in the community, and outreach to offer appropriate services.

2. Assistance in applying for benefits, e.g. social security, welfare, etc.

3. Crisis stabilization services in the least restrictive setting possible, with hospitalization available when other options are insufficient.

4. "Psychosocial rehabilitation services"--including transitional living arrangements, socialization and vocational rehabilitation.

5. Supportive services of indefinite duration--including sheltered living arrangements, supportive work opportunities, and age appropriate, culturally appropriate daytime and evening activities.

6. Medical and mental health care.

7. Backup support to families, friends and community members.

8. Involvement of concerned community members in planning, volunteering and offering housing or work opportunities.

9. Protection of client rights, both in hospital and in the community.

10. Case management, to assure continuous availability of appropriate forms of assistance.

Types of Data to be Collected

In order to provide baseline data for future planning, the CSP staff will collect information on costs, sources of funding, utilization patterns, quality and appropriateness of CSS components. The staff will also assess existing CSS resources by determining need for improvement through such activities as:

1. Finding out where the target population presently lives and what kinds of problems they have;

2. Finding out why inappropriate placements have taken place in either institutions or communities;

3. Identifying gaps, coordination problems and other inadequacies in the system.

Definition of the Target Population

The definition of the target population as stated by NIMH is:

The Community Support Program will focus solely on improving 
opportunities and services for one particular client group: severely mentally disabled adults whose primary disability is emotional and for whom 24 hour nursing care would be inappropriate. A more precise definition is as follows:

Adults with a severe or persistent mental or emotional disorder that seriously limits their functional capacities relative to primary aspects of daily living such as personal relations, living arrangements, work, recreation, etc.

While many elderly persons are included in this definition the problems of nursing homes and of the elderly per se, are outside the scope of the program.

The Community Support Program has added an operational definition to more clearly identify the target population. This definition can be found on the following page.

In addition, the Community Support Program has asked participants in the study to share their own definitions of the target population. A discussion of the definitions given by participants in Multnomah County can be found at the beginning of the section on Findings. Definition of Target Population for Community Support Systems

The Community Support System Strategy Development Project will develop an action plan for improving opportunities and services for chronic mentally disabled adults, ages 18 and older, whose primary disability is mental or emotional and for whom 24-hour nursing care is inappropriate. These people are further defined as follows:

I. Mental or Emotional Disability (must meet at least one criterion)

A. ( ) Has had a single episode of hospitalization of at least six (6) months duration for treatment of a mental or emotional disturbance between 1973 and the present.

B. ( - Has had a total of twelve (12) months of hospitalization for treatment of a mental or emotional disturbance between 1973 and the present. 
C. (_) In the opinion of an experienced clinician, is chronically mentally disabled.

\section{$\underline{A N D}$}

II. Impaired Functioning in the Natural Environment (must meet at least two criteria)

A. ( I) Is unemployed with markedly limited job skills and/or a poor work history.

B. ( I) Is employed in a sheltered setting.

C. ( Is unable to perform basic household management tasks without assistance.

D. ( ) Exhibits inappropriate social behavior which results in rejection by the community and requests for intervention by the mental health or judicial/legal system.

E. (-) Is unable to procure appropriate public support services without assistance.

F. (_) Requires public financial assistance for out-of-hospital maintenance (SSI, General Assistance, etc.).

G. ( ) Severely lacks social support systems in the natural environment (no close friends, lives alone, no group affiliations, highly transient).

H. ( ) Is placed in a nursing home setting because of financial considerations and/or because a less restrictive suitable environment isn't currently available. 
CHAPTER III

METHODOLOGY

\section{Purpose of the Research}

The purpose of this study is to assess existing services for chronically mentally ill adults in Multnomah County, Oregon. Research was conducted by graduate students of the School of Social Work of Portland State University with the guidance of faculty advisors June Dunn, Barbara Friesen and Nancy Koroloff.

The study was done in collaboration with the Multnomah County Mental Health Division and the Oregon Statewide Community Support System Strategy Development Project. The Community Support Project (CSP) has conducted similar research in Umatilla, Marion, and Clackamas Counties within Oregon.

Final reports from these studies will be utilized by the Oregon Mental Health Division, the Department of Human Resources of Oregon, and the National Institute of Mental Health. The findings will be used by the Oregon Community Support Project to develop a three year action plan. Data collected will be used to identify strengths and weaknesses in existing community support systems for chronically mentally ill adults.

This study was conducted in relation to guidelines provided by the Community Support Project which call for comprehensive planning efforts to meet the needs of the chronically mentally ill through a broad range of health, mental health, and human service programs. 
These guidelines were taken into account in selecting persons to be interviewed for this study. Effort was made to focus on client needs in both formal and natural support networks and to gain information regarding issues of interagency cooperation. Participants in the Study

The research group, with the aid of CSP personnel, compiled a list of agencies and individuals providing services to the chronically mentally ill in Multnomah County. Public and private agencies were identified as well as natural helpers within the county. Agencies selected included 1) federal, state, and local agencies sanctioned with primary responsibility for providing service to the chronically mentally ill, and 2) those agencies which are most likely to be involved in community support systems.

An attempt was made to include a wide range of agency personnel working with the target population such as day treatment staff, county mental health professionals, staff from private hospitals and emergency rooms, correction and police personnel, a private psychiatrist and social worker, and operators from room and board facilities.

After the initial list of potential interviewees was completed, it was reviewed by personnel from both the Community Support Project and the Multnomah County Mental Health Program. Other names were added at this point. A few participants were identified at the suggestion of other interviewees.

A total of 77 service providers were interviewed during the months of December, 1978 and January, 1979. (see copy of interview schedule in appendix A) 
Ten persons who fit the definition of chronically mentally ill who live in Multnomah County were also interviewed in December, 1978 and January, 1979. (see appendix A) Most clients were initially contacted by their therapist, informed of the purpose of the interview, and asked to participate. Those who wished to participate were asked to sign a consent form (appendix A) and were assured that their identity would remain confidential. One client not involved in a structured program was included.

Interview Schedule

The interview schedule utilized by the study, originated from the Community Support Project. The graduate students involved in the research participated in two training sessions which focused on interviewing skills and probing techniques. The interview process was reviewed by the total research group to insure that each member was clear about the intent of every question. The group also spent time clarifying the role and expectations of the interviewer during the interview. Each student conducted two practice interviews prior to interviewing service providers.

Two interview schedules were utilized, one was administered to agencies which provide services to the target population; the second schedule was used to interview persons identified as chronically mentally 111. The second instrument covered similar content as the first, with wording revised to eliminate technical vocabulary. A few items were removed because they were relevant only to service providers. Service Provider Interview

Interviews were conducted in a face-to-face setting with selected agency staff. In five interviews, more than one agency staff member 
participated in the interview.

Prior to presentation of interview questions, researchers explained the purpose of the project and answered any questions that interviewees had. Interviewers assured agency staff of complete confidentiality and mentioned that quotations used in the report would not identify individuals or agencies. Interviewees were then asked for their definition of the chronically mentally ill in order to assure that questions would be answered in terms of the target population.

The next step was to collect checklists which were mailed to the interviewee prior to the interview (see appendix B for checklist results). Interviewees were asked to respond in terms of two categories: 1) services provided by their agency for the chronically mentally ill population, and 2) services provided for this population by other agencies in the county.

Finally, sixteen open-ended questions were asked. Interviews took approximately ninety minutes to complete.

\section{Client Interviews}

Ten client interviews were conducted, taking approximately one hour each. Members of the project felt strongly that the report should contain information obtained directly from the target population. The client interview schedule was designed to allow input from clients so they could share their feelings and experiences about services in the community, and provide a better understanding of their lives and a greater perspective regarding the strengths and weaknesses of services for chronics in Multnomah County. Items on the questionnaire were also designed to obtain information regarding client lifestyles. 
At the time of the interview, interviewers explained the intent of the project and answered any questions. Before proceeding, clients signed a release form which indicated that data would be used for this project and that they could refuse to answer any question. Nine questions were asked pertaining to problems experienced in living in the community the way they spent their time, the quality of services received and perceptions of how they are treated in the community.

After interviewing clients and service providers, interviewers recorded their impressions of the interview. Any unusual events during the interview, such as interruptions, were also recorded. Data Collection

Letters explaining the purpose of the research project and the affiliation with CSP were sent to each person. This letter included the name of the interviewer who would be contacting the agency, the check list, and a copy of the goals and philosophy of the Community Support Project. (see appendix A) Each interviewer was assigned service providers and/or natural helpers to interview. Each respondent was contacted by phone and a time for the interview was arranged. Analysis

Fixed-response data collected from the interviews were tallied. Open-ended data was organized into general categories before tallying. The 77 interview schedules from service providers were divided into eight groups for the purposes of analysis. These are: group care facilities, corrections, natural helpers, government agencies, community mental health programs (including county sub-contract agencies), private organizations, psychiatric inpatient facilities and miscellaneous organizations. 


\section{Limitations}

Service providers interviewed are not a representative sample, but were selected purposefully for the services their agencies provide. Certain perspectives may be underrepresented or omitted. An attempt was made to set up interviews with persons working closely with clients, but some interviews were carried out with administrators or managers. Because of time limitations, it was difficult to identify and obtain permission of clients to interview. For this reason, a limited number of clients were interviewed and those interviewed came predominantly from mental health affiliated programs. Members of the target population not affillated with mental health programs are not represented.

The interview schedule was constructed to relate to csp priorities and therefore may have narrowed the scope of information that could have been collected.

Because of the number of interviewers used and time limitations on training, questions may not have been asked in a consistent manner nor recorded in the same format.

Once all interviews were completed, they were grouped into broad service provision categories. Because interviewees were not selected to represent these categories initially, the size of the categories are unequal. Due to the open-ended nature of the interview, some of the information collected was categorized retrospectically and may have reflected the perspective of the researchers rather than that of the respondents. 
CHAPTER IV

MULTNOMAH COUNTY

\section{County Characteristics}

Multnomah County, covering an area of 457 square miles, is located in the northwest portion of the State. The county borders on Washington County to the west, Clackamas County to the east, and the Columbia River and the State of Washington to the north. Multnomah County is composed of the City of Portland (which extends 80 square miles in the western region), surrounding suburban communities, and a large rural area in the east. This rural portion includes agricultural land, Bull Run Water Reserve, and a part of Mt. Hood National Forest. 1

There are approximately 549,000 persons residing in the county. Portland, the most populous city in the state, has a population of 366,650 . Smaller incorporated cities include Gresham with 30,280 residents, Troutdale with 3,520 residents, Wood Village with 2,410 residents, Fairview with 1,850 residents, and Maywood Park with 985 residents. 2

The county is divided into four geographic regions - west, north/ northwest, southeast, and east, that correspond to planning and service districts for human resource agencies, and reflect common citizen designation. Each area has distinctive characteristics. The downtown business section and residential areas are located in the western portion of the county. A variety of individuals live in this district including families, many

\footnotetext{
${ }^{1}$ Community Mental Hea1th Plan, 1977-78, Multnomah County, Mental Health Division, p. 23.

2 Population Estimate, July, 1978, Center for Population Research and Census, Portland State University, Portland, Oregon.
} 


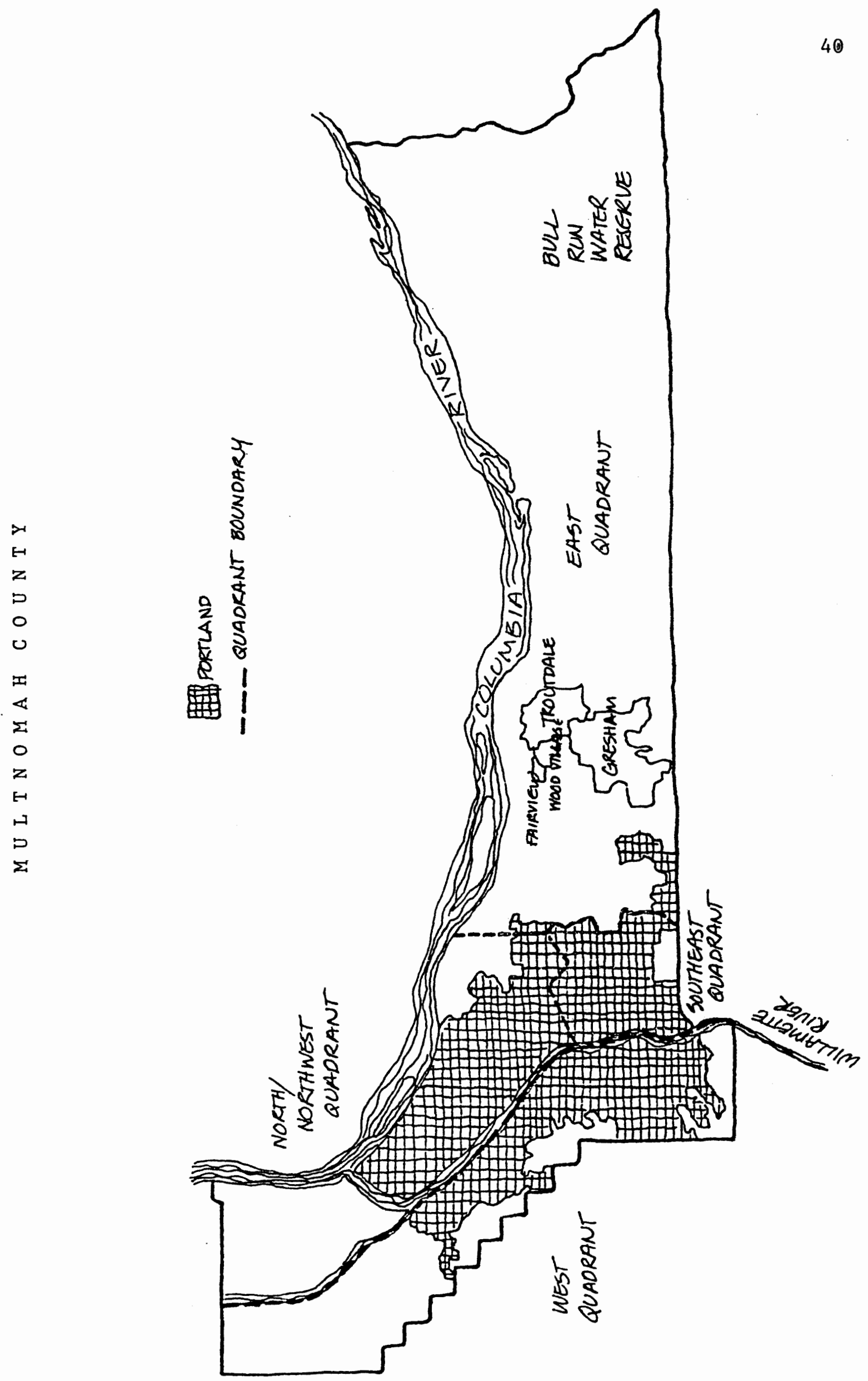


elderly persons with low incomes, and a transient population with substance abuse problems. North/northeast is composed of numerous residential neighborhoods interspersed by small business districts; some of the highest and lowest income residents of the county live in this section. In addition to having the largest proportion of non-white persons, this area has the most stable population of the four districts. The southeast is also an area of residential neighborhoods and commercial districts. Residents have a range of income levels and include a high percentage of disabled or handicapped individuals. The eastern region composed of suburban and rural districts is the largest and most populous of the four areas. The families and unrelated individuals living here have the highest median income and lowest proportion of persons below the poverty line. ${ }^{3}$

Basic Population Characteristics 4

Percentages are based upon total county population except where noted.

AGE

17 and under

$18-64$

65 and older

SEX

Male

Female

RURAL/URBAN

In cities

Not residing in cities

ETHNICITY APPROXIMATE

White

Black

Spanish Heritage

Asian American and Native

American
$26.3 \%$

$61.0 \%$

$12.7 \%$

$48.3 \%$

$51.7 \%$

$74.2 \%$

$24.8 \%$

$93.0 \%$

$4.0 \%$

$1.5 \%$

$1.5 \%$

${ }^{3}$ Community Mental Health Plan, 1977-78, Multnomah County, Mental Health Division, p. 28-39.

${ }^{4}$ See Appendix C for statistical sources. Appendix E presents the "Basic Population Characteristics" section in the same format as the other CSP county studies for the purpose of direct comparison. 
ECONOMIC

Median Family Income

$\$ 17,914$

Average employee earnings

11,988

Residents living below poverty level

$11.1 \%$

Monthly average unemployed in labor force

$7.5 \%$

ADULT EDUCATION LEVEL

4 th grade education or less

8 th grade education or less

Have not finished high school $46.1 \%$

PUBLIC ASSISTANCE

Supplemental Security Income:

Total adult recipients (number

of disabled adult recipients

greater then number of aged or blind adult recipients)

$1.28 \%$

old Age Assistance (monthly average)

$0.2 \%$

General Assistance (monthly average by case)

$0.58 \%$

Aid to the Blind and Disabled (monthly average)

$0.6 \%$

Food Stamp Recipients

(monthly average)

Congregate Care Recipients

(monthly average)

$7.6 \%$

$.32 \%$

\section{HOUSEHOLDS}

Majority include husband and wife $28.6 \%$ headed by individuals other

than married couple

Most are single household

Most are privately owned

DISABLED PERSONS

Individuals in need of alcohol services

$6.4 \%-14.1 \%$

Individuals in need of drug services

Individuals in need of services for mental retardation or developmental disabilities

Individuals in need of services for mental and emotional disablities $\quad 13.4 \%-19 \%$ 
CHAPTER V

\section{SERVICE PROVIDER INTERVIEW RESULTS}

\section{Definition of Chronic}

All service providers were asked for their definition of chronic mental illness in order to establish a common understanding of the characteristics of the population the interviewee would be discussing. Two interviewees declined to give a definition of chronic. One stated that the term was hard to define, while the other reportedly does not use the term. In the instance that the service provider's definition was not in keeping with the Community Support System Strategy Development Project's two-part variable criteria definition of the chronic mentally ill, the latter was discussed with the interviewee.

Approximately 70 different criteria were given by the interviewees. The most common theme of the definitions, found in 35 of the 77 interviews, was a person with a long term mental or emotional problem requiring continuing care. A condition necessitating hospital or institutional care was mentioned 30 times. Seventeen interviewees mentioned a diagnosis of mental illness as a criterion of chronicity. Other items noted more than ten times were dangerous to self or unable to care adequately for self, inability to hold a job for a sustained period of time, and inability to cope with the demands of society. Mentioned five times were dangerous to others, exhibiting deviant or inappropriate behavior, on psychotropic medication, and unchangeable 
or incurable condition.

Over 60 other criteria were present in the definitions, but occurred fewer than five times. Of the 11 criteria listed by the Community Support Project, only placement in a nursing home setting because of financial considerations was not mentioned in the data collected.

\section{Client in the Community}

Problems of the Chronically Mentally Ill.

A multitude of client problems were mentioned in the interviews. The eight problem areas mentioned most frequently are presented in Table I. The number of responses are presented by type of service provider, with totals recorded by problem area.

Table I: Most Frequently Mentioned Problems of the Chronically Mentally I11 in the Community.

\begin{tabular}{|c|c|c|c|c|c|c|c|c|}
\hline 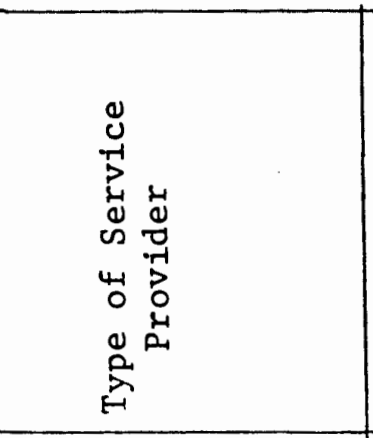 & 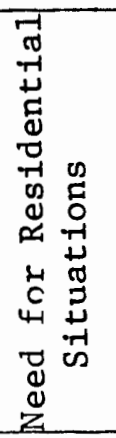 & 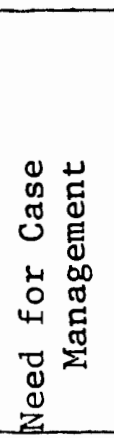 & 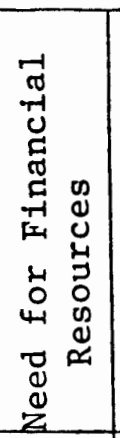 & 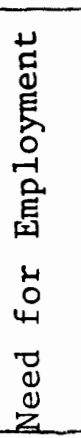 & 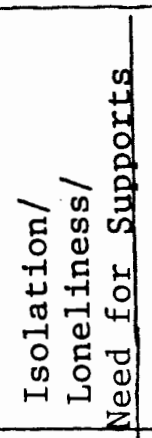 & 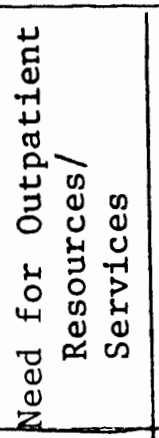 & 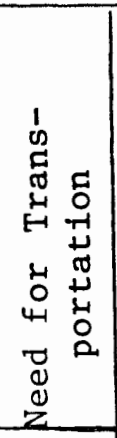 & $\begin{array}{l}0 \\
0 \\
01 \\
+1 \\
0-1 \\
3 \\
0 \\
0 \\
0 \\
4 \\
0 \\
0 \\
4 \\
0 \\
0 \\
0 \\
0 \\
z\end{array}$ \\
\hline $\begin{array}{l}\text { Group Care } \\
\text { Facilities } \mathrm{N}=7\end{array}$ & 4 & 5 & 3 & 2 & 1 & 1 & 2 & 1 \\
\hline Corrections $\mathrm{N}=8$ & 4 & 5 & 4 & 2 & 2 & 3 & 0 & 0 \\
\hline $\begin{array}{l}\text { Natural Helpers } \\
\mathrm{N}=4\end{array}$ & 2 & 2 & 3 & 1 & 1 & 0 & 2 & 1 \\
\hline $\begin{array}{l}\text { Government } \\
\text { Agencies } \mathrm{N}=10\end{array}$ & 4 & 6 & 7 & 3 & 3 & 1 & 2 & 1 \\
\hline $\begin{array}{l}\text { Comm. Mental } \\
\text { Health Prog. } \mathrm{N}=14\end{array}$ & 10 & 9 & 7 & 8 & 7 & 3 & 4 & 4 \\
\hline $\begin{array}{l}\text { Private Organ- } \\
\text { izations } \mathrm{N}=20\end{array}$ & 13 & 11 & 8 & 7 & 4 & 6 & 5 & 1 \\
\hline $\begin{array}{l}\text { Psychiatric } \\
\text { Inpatient } \mathrm{N}=8\end{array}$ & 7 & 6 & 4 & 2 & 1 & 4 & 2 & 1 \\
\hline Misc. $\mathrm{N}=6$ & 3 & 1 & 1 & 2 & 1 & 2 & 0 & 2 \\
\hline $\begin{array}{l}\text { Total Number } \\
\mathrm{N}=77\end{array}$ & 47 & 45 & 37 & 27 & 20 & 20 & 17 & 11 \\
\hline
\end{tabular}


The three most frequently mentioned problems were need for residential situations, need for case management and need for financial resources. Specific comments were sometimes noted. These can best be delineated and described by problem area.

Residential Situations.

Forty-seven respondents considered this a problem for the chronically mentally ill. Five responses referred to a need for transitional living situations, or halfway houses for the mentally or emotionally disturbed. Five interviewees mentioned a need for residential situations with built-in support systems; residential and treatment situations were combined by five respondents in explaining another type of need. A need for structured living situations was mentioned twice, as was the need for more group homes. These responses appear to indicate that the chronically mentally ill are in need of more living situations with some type of built-in support.

Most of the remaining comments referred to the need for appropriate, adequate or good housing. Two interviewees mentioned the restriction of insufficient financial resources in obtaining adequate shelter.

\section{Case Management/Services Coordination}

Among the 45 respondents who mentioned case management as a problem, need for follow-up was the most often recorded comment (13 responses), followed by need for advocacy (6 responses). Other specific comments referred to need for coordination of services (3 responses) and need for monitoring (1 response).

For those who considered case management/services coordination a problem, the general consensus, as reflected by recorded comments, 
was that clients returning to the community from an in-patient facility tend to "fall through the cracks" because of inadequate follow-up. Comments indicated that the chronically mentally ill need help obtaining services and resources once they have returned to the community, and that there is a need for coordination of in-patient and out-patient services.

\section{Financial Resources.}

Thirty-seven respondents considered this a problem for the chronically mentally ill; few comments were recorded pertaining to this problem area. Recorded comments referred to the lack of funds for food, clothing, shelter, personal expenses, medical expenses, emergencies and specialized treatment. Two people mentioned that those receiving Social Security for the disabled (SSI) are responsible for their own medical expenses. One interviewee also mentioned that SSI does not provide for a service payment to group homes, making a group home situation inaccessible without additional personal funds. The same respondent reported that there are disincentives toward family helping in that family assistance is taken as income and consequently deducted from welfare payments.

\section{Employment.}

As noted in Table I, twenty-seven respondents mentioned a need for employment as a problem. Of the comments recorded for this area, three mentioned the need for vocational training and three mentioned a need for supportive, sheltered or protected work opportunities. Miscellaneous comments included the need for meaningful work, for sultable employment, and for an alternative work experience. Not 
counted in this problem category are the responses which pertained to the "inability to hold a job". (5 responses) for various reasons.

Isolation/Loneliness/Need for Social and/or Emotional Supports.

Twenty respondents mentioned this problem in some form. "No support systems", "loneliness", "isolation", "no sustained contact with one person, agency or institution" were typical responses that fell into this category. As one interviewee put it, ". . They seem to get it together in some of the better institutions, but then things start to fall apart because they have no support systems after leaving the institution."

\section{Outpatient Resources/Services.}

Twenty interviewees mentioned need for outpatient resources and/or services as a problem for the chronically mentally ill. "Lack of resources", "lack of suitable resources", "lack of proper resources" constituted the bulk of comments in this area. Five responses referred to the need for mental health centers and/or services and three respondents specifically referred to a need for day treatment.

\section{Transportation.}

Few recorded comments dealt with this issue so little information can be discerned here except to say that 17 respondents mentioned transportation as a problem.

\section{Activities.}

Eleven respondents mentioned social and/or recreational activities as a significant problem of the chronically mentally ill. This response is supported by the answers recorded in a following question pertaining to how a chronically mentally ill person spends his/her time in the community. Many respondents said that in essence the chronically mentally ill engage in passive or solitary activities. It is interesting to 
note that even though sixty respondents mentioned this, only eleven respondents considered it a problem.

Miscellaneous Catagories.

Other problems mentioned more than once include the following:

Number of responses

$\begin{array}{ll}\text { food/clothing/shelter } & 6 \\ \text { medical care } & 5 \\ \text { inability to hold a job } & 5 \\ \text { lack of crisis facilities/ } & 4 \\ \text { services } & \\ \text { poor diet or malnutrition } & \\ \text { apathy toward the chronically } & \\ \text { mentally ill } & 3 \\ \text { access to services } & 3 \\ \text { lack of community understanding/ } \\ \text { education }\end{array}$


unwillingness on part of

2

client to use agencies for

assistance

\section{Problems of Minority Groups.}

Responses to the question concerning special problems for any

minority groups within the population of the chronically mentally ill

are presented in Table II.

Table II: Frequency of Responses to a Question Concerning Problems

for Minority Groups Among the Chronically Mentally I11.

\begin{tabular}{|c|c|c|c|}
\hline $\begin{array}{c}\text { Type of Service } \\
\text { Provider }\end{array}$ & "Yes" & $\begin{array}{l}\text { "No"/"Don't } \\
\text { know"/"No } \\
\text { minority pop." }\end{array}$ & Total \\
\hline $\begin{array}{l}\text { Group Care } \\
\text { Facilities }\end{array}$ & 3 & 4 & 7 \\
\hline Corrections & 2 & 6 & 8 \\
\hline $\begin{array}{l}\text { Natural } \\
\text { Helpers }\end{array}$ & 2 & 2 & 4 \\
\hline $\begin{array}{l}\text { Government } \\
\text { Agencies }\end{array}$ & 5 & 5 & 10 \\
\hline $\begin{array}{l}\text { Comm. Mental } \\
\text { Health Program }\end{array}$ & 11 & 3 & 14 \\
\hline $\begin{array}{l}\text { Private Or- } \\
\text { ganizations }\end{array}$ & 9 & 11 & 20 \\
\hline $\begin{array}{l}\text { Psychiatric } \\
\text { Inpatient }\end{array}$ & 5 & 3 & 8 \\
\hline Miscellaneous & 2 & 4 & 6 \\
\hline Total Number & 39 & 38 & 77 \\
\hline
\end{tabular}


Approximately half (39) of all respondents recognized special problems for minority groups within the target population. Interviewees from community mental health programs identified such problems most frequently. Specific problems mentioned and recorded include the following:

\section{Number of responses}

Discrimination/racism/anti-Semitism
$\begin{aligned} & \text { Do not use or relate to existing services } \\ & \text { Lack of understanding by or insensitivity }\end{aligned}$
$\quad$ of service providers
Lack of services/resources
$\begin{aligned} & \text { Minority status contributing to mental } \\ & \quad \text { illness }\end{aligned}$
$\begin{aligned} & \text { Language barriers } \\ & \text { Inability to compete for jobs }\end{aligned}$
$\begin{aligned} & \text { Effect of cumulative prejudices/problems } \\ & \text { Cultural differences/problems } \\ & \quad \text { "Typical minority problems" }\end{aligned}$
$\begin{aligned} & \text { Alcoholism among the Native Americans } \\ & \text { Lack of access to resources }\end{aligned}$
$\begin{aligned} & \text { Class differences between clients and } \\ & \text { service providers }\end{aligned}$

Minority groups specifically mentioned were:

Blacks

Native Americans

Poor

Elderly 


\section{Number of responses}

Russian-speaking population

Women

Spanish-speaking population

Jewish people

Retarded people

Gay people
3

2

2

1

1

1

Twenty-five of these responses refer to racial or ethnic characteristics.

Twelve involve other criteria for minority status, namely, income, age, sex, mental capacity, sexual preference.

\section{The Client's Day.}

The bulk of responses to the question regarding how the chronically mentally ill spend their time in the community referred to passive or solitary activities. Sixty interviewees made comments such as "doing nothing", "being isolated", "sitting in their rooms", "just sitting", "wandering", "hanging around."

Following is a list of the activities mentioned:

\section{Number of responses}

Watching television

Participating in program/agency activities/ services

Drinking or going to bars

Participating in family activities

Smoking

"Agency hopping"/telephoning agencies

Drinking coffee, in coffee shops or otherwise

Visiting friends or relatives
29

13

9

5

4

4

4 


\section{Number of responses}

Shopping

Taking drugs

Going to pool halls

Going to church or participating

in church activities

Working

Going to inexpensive restaurants

Acting bizarre
2

2

2

2

2

2

2

Activities mentioned once include participating in group home activities, going to parks, participating in community group activities, viewing films at the library, mating, listening to the radio, listening to the stereo, looking for food and shelter, hoarding, playing cards, and being victimized by those in the street culture.

Programs and agencies specifically mentioned as those in which the chronically mentally ill participate were mental health clinics (6 responses), day treatment (6 responses), David's Harp (2 responses), Errol Heights (2 responses), Volunteers of America Drop-In Senior Center ( 1 response), Loaves and Fishes ( 1 response), Open Heart ( 1 response), the Senior Center at Friendly House (1 response) and Vocational Rehabilitation ( 1 response).

Those interviewed generally viewed the chronically mentally ill population as inactive, with television apparently filling more time than anything else. The chronically mentally ill are "existing on their thumbs, doing nothing. They're non-productive--the vast majority," one interviewee was quoted as saying. Another respondent was more specific 
in saying that there are "a lack of opportunities for a variety of activities for healthy self-esteem and some degree of independence." Where the Chronically Mentally Ill Cluster.

Interviewees were asked, "Do the chronically mentally ill tend to cluster in any geographic areas in the community?" Fifty-four of the total interviewed reported that the chronically mentally ill do cluster in certain areas. Twenty-three said "no", "uncertain" or "not aware". Geographic sections of Portland were mentioned, as well as eating or drinking establishments, hotels, specific streets. The geographic location of these sites was discerned with the aid of the phone book and a map of Portland. Responses fell into four geographic areas: northwest, northeast, southeast, and downtown Portland. Totals are as follows:

Area

Northwest

Southeast

Northeast

Downtown

\section{Number of responses}

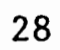

17

13

12

Over half of those who reported clustering thought the chronically mentally ill cluster in northwest Portland. Almost one third of those who reported clustering mentioned southeast Portland; approximately one fourth were aware of clustering in northeast Portland; and over one fifth mentioned downtown Portland.

Responses referring to northwest Portland somewhat overlapped with responses referring to downtown Portland because of their geographic proximities. For purposes of differentiation, the specific responses of "Burnside area", "downtown northwest", "lower northwest", "O1d Town", 
"east of 24th Street" ("between 18th and 24th") and "between Burnside and Thurman" were included in the total of responses for northwest Portland. The tally for downtown Portland was strictly limited to the responses of "downtown", "central" and "the Park Blocks". Of those respondents aware of clustering, 33 reported clustering in northwest, downtown, or both areas of Portland. The northwest and downtown areas combined still constitute the smallest geographic area of Portland. The overwhelming majority of more specific responses involve the Burnside area in northwest Portland and the Albina area in northeast Portland. Eleven respondents mentioned "low-income", "low-rent", "poor" or similar areas. Also, eight respondents mentioned hotels, and four mentioned room and board, group and/or foster homes. Other responses included "east county", north Portland, mental health programs/agencies, homes for the aged, pool halls, taverns, inexpensive restaurants, stores and parks.

When asked what attracts the chronically mentally ill to the area(s) mentioned, 34 of the 54 respondents aware of clustering said the availability of residential situations was one of the primary attractions. Of these 34 respondents, 27 mentioned "low-income", "inexpensive" or "cheap" housing and 10 mentioned the availability of/or placement in room and board or group homes. The total list of attractions to the area(s) is as follows:

\section{Number of responses}

Residential

Social/recreational

Tolerance/acceptance

Inexpensive eating 


\section{Number of responses}

Availability/accessibility of services 3

Hotels

Camaraderie

Stimulation by observing others

Anonymity

Close to town

Access to restaurants and stores

Items mentioned once include activities, availability of drugs, availability of "community care givers", clustering of Native Americans, fewer children present.

The general theme of responses appears to be that the chronically mentally ill cluster where they do because of economic reasons and that they live in low income or low rents areas. However, 12 respondents mentioned social/recreational opportunities and 11 acknowledged tolerance or acceptance of this population as primary attractions to certain areas. In addition to asking if the chronically mentally ill cluster in any geographic area(s) in the community, interviewees were further asked if their respective agencies placed any special emphasis on working with people in those areas. Of the 54 respondents aware of clustering, 32 answered "no". Of the 22 interviewees who answered "yes", six mentioned servicing a certain geographic area, which did not necessarily correspond to the geographical area(s) mentioned as clustering sites. Eight mentioned that they are serving entire populations with no real "special emphasis" on the chronically mentally ill in any geographic area. Ten of those who said "yes" to this question focused their attention on the chronically mentally ill. Of those who reported that their agencies place a special 
emphasis on working with people in the areas mentioned, most reportedly do so either because their agencies happen to be in those areas or because clients, the chronically mentally ill included, seek out the services/resources offered.

\section{Community Attitudes.}

The service providers who were interviewed reported a cross section of community attitudes toward the chronically mentally ill. The attitudes that were reported included accepting, neutral, rejecting and a combination of these. A tabulation of these responses is contained in Table III.

The following were the responses most frequently cited regarding rejection. Nine of those interviewed felt that the community was fearful and mistrustful of this population. This was especially true when it was overtly apparent that a person was a danger or threat to the community. Difficulty in building and opening residential care facilities in neighborhoods was reported as being a problem by nine people interviewed. As one agency representative told us, "Nine out of ten times if a group home is proposed to be started, the neighborhood will oppose it." Five people reported that the community doesn't understand people who do not conform to community norms. This was seen as a particular problem if an individual exhibited behavior that was obviously strange and different. One agency person expressed the community's attitude toward those that are different in the following way: "Most people get angered quickly toward the chronically mentally ill; they don't want to be inconvenienced or deal with people who are different from them." other examples of rejection included difficulties in finding jobs. A hesitancy to hire people with a history of mental illness was noted by three people. Finding places to live was also mentioned as a problem. 
Three people reported a lack of funding and programs for this population. Other representatives verbalized the community's rejecting attitude with the following: "An indicator of community lack of tolerance is who police bring to jall.", "If the community where individuals were going to reside were made part of the treatment, the chronically mentally 111 would be well received.", "If the chronically mentally ill are in jail, you know support systems (parents, friends) have not worked."

Twenty-three interviewees indicated that the community had a neutral attitude toward this population. "If they don't bother me, I won't bother them," exemplified the neutral attitude that so many people expressed. Six people stated that this group was ignored and that the community was generally indifferent and ambivalent toward them. Six people suggested that if this population stays out of trouble and keeps a low profile, they can go unnoticed.

Accepting attitudes were reported by 15 respondents. Six people identified the Burnside community and the northwest area as being more accepting of this population than the suburbs or other areas of Portland.

The quotations that follow are indicative of accepting attitudes. "It's getting more accepting in the community with newer medications; these people are more appropriate," said one agency representative. "Communities can be accepting of one person but not of a group home." "They can accept the person on an individual basis when they know the family."

Interviewees were asked, "Are there any community organizations providing services or showing an interest in this population?" of the 156 total responses, 76 indicated at least one interested organization. 
Responses were grouped retrospectively into the following categories.

\section{Category}

Churches and Church Organizations

Self Help Groups

Senior Citizen Groups

Social and Political Action Groups

Fraternal Organizations

Social Service Agencies

Private Businesses
Number of responses

21

8

8

7

2

2

1

Interviewees were asked to identify citizens who are advocates or could become advocates for the chronically mentally ill. of the 105 total responses, 66 mentioned at least one citizen or group who could advocate for this group.

\section{Category}

Social and Political Action Groups

Boards

Mental Health Facilities

Churches

Social Service Agencies
Number of responses

\section{0}

5

4

3

3

Although there is interest in this group, the responses show that the interest is scattered throughout the community. 
垔望

年

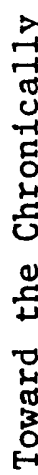

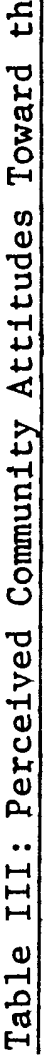

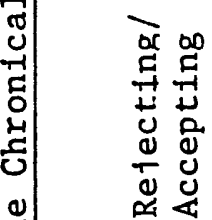

\begin{tabular}{l|l}
0 & \\
0 & 0 \\
3 & 0 \\
0 & 0 \\
0 & 0 \\
0 & 0 \\
0 & 0 \\
0 & 0 \\
0 & 0 \\
2 & 0 \\
0 & 0 \\
7 & 0
\end{tabular}

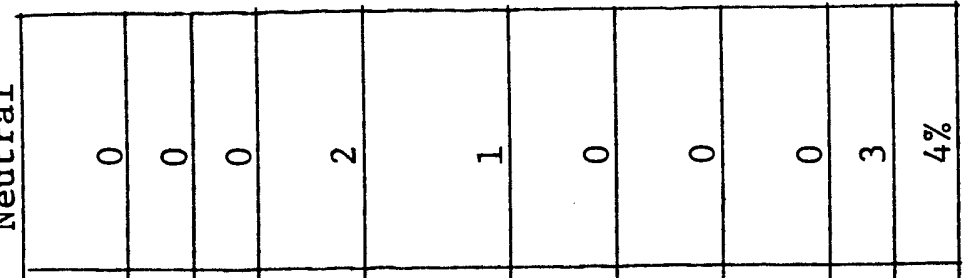

先

营

苞

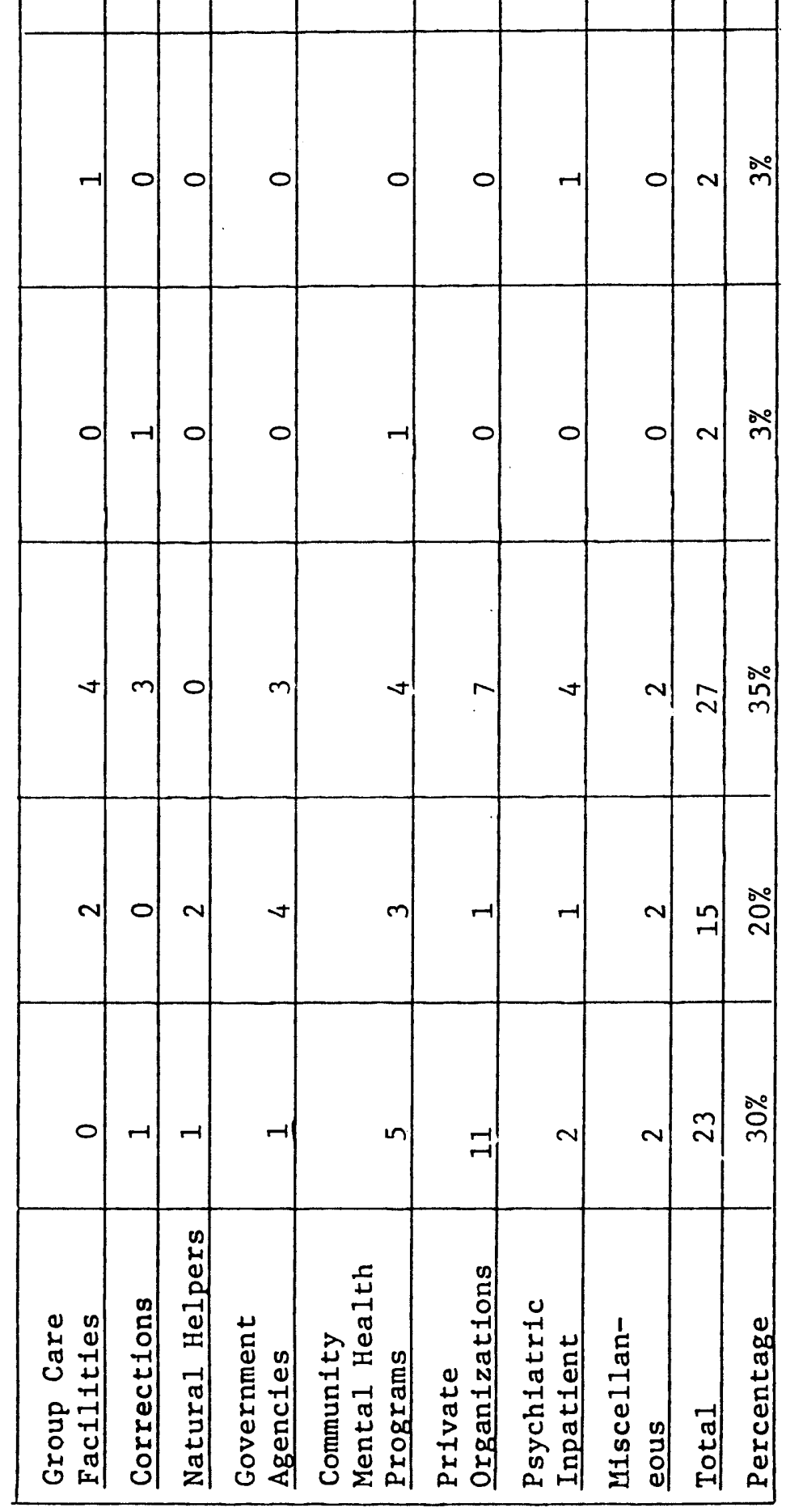


Service Delivery

Interagency Cooperation.

According to the 77 respondents, interagency cooperation in Multnomah County ranges from "good" to "it doesn't exist". Table IV groups the responses by agency type into the following four categories: (1) moderate to good cooperation, (2) poor cooperation, (3) little or no cooperation, (4) did not know or did not answer. These four categories were developed retrospectively from comments to an open-ended question.

of 77 respondents, 30 indicated there was no, little, or poor interagency cooperation; whereas 35 indicated cooperation was moderate to good. In the moderate to good category, 20 respondents indicated cooperation was mostly informal, consisting primarily of phone calls between individual workers. In contrast, 15 respondents indicated cooperation proceeds primarily through formalized networks of interagency executive arrangements, regular interagency meetings, or community channels.

Table IV: Responses to a Question Concerning Interagency Cooperation to Meet the Needs of the Chronically Mentally Ill.

\begin{tabular}{|c|c|c|c|c|c|c|c|c|c|}
\hline $\begin{array}{l}\text { Degree of } \\
\text { Cooperation }\end{array}$ & 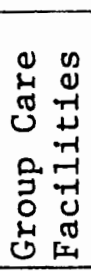 & 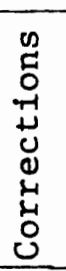 & 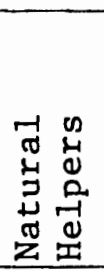 & 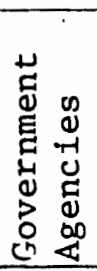 & 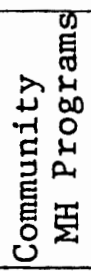 & 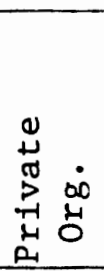 & 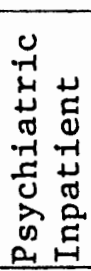 & $\begin{array}{c}j \\
0 \\
0+1 \\
\sum\end{array}$ & 元 \\
\hline Good to Moderate & 2 & 0 & 0 & 7 & 9 & 10 & 5 & 2 & 35 \\
\hline $\begin{array}{l}\text { Poor/ Little } \\
\text { Or None }\end{array}$ & 5 & 7 & 1 & 1 & 4 & 7 & 2 & 3 & 30 \\
\hline $\begin{array}{lll}\text { Did Not } & \text { Know/ } \\
\text { Did Not } & \text { Answer } \\
\end{array}$ & 0 & 1 & 3 & 2 & 1 & 3 & 1 & 1 & 12 \\
\hline Total & 7 & 8 & 4 & 10 & 14 & 20 & 8 & 6 & 77 \\
\hline
\end{tabular}

There were several comments by agency interviewees on the positive rapport and open communication between various agencies. Such responses 
as "we work well together" and "we have a good working relationship" were representative of the responses from this group. The following quotes are examples of how agencies work together on both an informal and formal basis. "We do a lot of telephone work, telephone consultation, we share materials, discuss reports and social histories" and "telephone contacts and agency visits are the usual ways we work with other agencies." Lack of cooperation was blamed on (1) insufficient funding and staff, (2) too much red tape, or (3) lack of a coordinated system. Some respondents related to the lack of a coordinated system mechanism to insufficient funding and staff. Some respondents in this group reported that the potential for cooperation exists, but has not been developed. The remaining respondents citing lack of mechanism gave no reason. Comments were that interagency cooperation depended greatly on the initiative of individual workers and their knowledge of how the system works. Many responses indicate that the quality of interagency cooperation and client service depends on the integrity, knowledge, and energy of the individual worker, rather than on formalized agreements between agencies.

Following are responses grouped by agency category:

Community Mental Health Programs. Nine of 14 respondents indicated cooperation was good to moderate. Interagency contacts were described as mostly informal and primarily by telephone. Three interviewees mentioned formalized cooperation with mental hospitals.

\section{Psychiatric Inpatient. Five of eight respondents indicated} cooperation was good to moderate. Cooperation mainly consisted of making referrals informally and by phone.

Government Agencies. Seven of ten respondents reported cooperation 
was good to moderate. Three interviewees cited a formalized process of cooperation. This relatively higher proportion of formalized contacts may result from mandated rules and regulations.

Corrections. Seven out of eight respondents indicated "little", "poor", or "no" cooperation.

Group Care Facilities. Five of seven providers reported "little", "poor", or "no" cooperation. A common theme found in responses was difficulty in obtaining appropriate services for clients.

Natural Helpers. This group was comprised of staff from two hotels and two restaurants. Three did not provide an answer and one indicated cooperation was poor.

Private Organizations. Ten of the 20 respondents indicated good to moderate interagency cooperation. One respondent said, "We're doing better all the time".

Because "improved interagency cooperation" and "improved advocacy" were mentioned less frequently, these categories are described in a general way, rather than by specific agency type.

Responses concerning improved interagency cooperation noted the need for a central referral system. Comments indicated a need for more information sharing, more coordination and communication, improved understanding, and more information about what is available.

In summary, little, poor or no cooperation was the most frequent response of interviewees from corrections and group care facilities. A predominance of good to moderate cooperation was indicated by respondents from community mental health programs, psychiatric inpatient agencies, government agencies and private organizations. 


\section{Case Management.}

When interviewees were asked if case management is occuring for the chronically mentally ill, 39 interviewees stated that it is not occuring, 32 stated that it is occuring and six replied that they did not know. Twenty-eight interviewees stated that case management services are inadequate; 31 remarked that interagency case management is done on an informal basis, often as the result of personal contacts. Twelve interviewees stated they perform interagency case management. The opinion that planning, coordination and follow-up occurs only or mainly for the involuntarily committed after discharge from a hospital was expressed by eight interviewees.

Several reasons for the lack of case management were mentioned. These included the opinions that it is difficult to provide case management because of the lack of funding. Another reason given was that case management does not occur because of the lack of training and commitment on the part of staff who work with the client. One social worker remarked,"Patients get lost. If they find a good social worker, they're in luck." Other reasons mentioned for the lack of case management include large caseloads and the size of Multnomah County's population and geographic area.

Some interviewees identified organizations, other than the one they were zepresenting, which are providing case management services. These organizations are the Involuntary Commitment Program, the Veterans Administration, Dammasch Hospital, Adult and Family Services and Vocational Rehabilitation. Several interviewees stated that Multnomah County Mental Health is not doing case management. One interviewee from a private agency stated that Multnomah County Mental Health is limited to maintenance 
and crisis intervention. Other sources of case-management mentioned included families, private psychiatrists and special one-time-only demonstration projects.

The opinions expressed by interviewees did not vary greatly according to the type of service provider represented. However, respondents from corrections organizations stressed that case management and follow-up services need to be improved.

There are differences of opinion concerning how to develop and operate a formal case management system. Fifty-four interviewees stated that case management should be the responsibility of one agency; fifteen feel that it should not be the responsibility of one agency and eight did not know.

\section{Agency Suggested for Case Management Role}

Mental Health Division

Adult and Family Services

A state agency (not necessarily an existing one)

A private agency

A new agency which would do case management only

City of Portland

Involuntary Commitment Program

Public Guardian

Dammasch Hospital
Number of Responses

23

6

6

3

2

1

1

1

1

Additional comments related to the assignment of one agency to do case management were:

The agency responsible for case management should not provide direct services.

The Mental Health Division should concentrate on coordination, rather than be involved in direct services. 
Case management should not be the responsibility of one agency but of people in the community.

Neither the medical profession nor the State Mental Health Division should have responsibility for case management.

Centralizing case management in one agency or creating a new agency would divert too much money from services to administration and would create just another bureaucracy.

It should be noted that, in many instances, it could not be determined from the data whether the interviewees were referring to Multnomah County Mental Health or the State Mental Health Division. Eight of the interviewees specifically mentioned "Multnomah County Mental Health".

When asked for suggestions on how to develop and operate a case management system, the following responses were noted.

\section{Suggestions}

Number of responses

Agencies could refer directly to other agencies and meet with each other on a regular basis to do case planning and improve communication

Hospitals could assign a coordinating caseworker to each patient at discharge.

Case management could be mandated by a central authority

Case managers could advocate for patients. 6

Caseloads could be decreased. 4

Case managers could perform outreach, including offering transportation to clinics and other services.

Computers could be used to collect data on patients. 4

Extensive training in case management could be provided.

All services could be located in one building. 4

One or more agencies could be given custodial 


\section{Suggestions}

Rewards or incentives to staff who do case management could be provided.

There could be one central intake system

for each geographic area.

Volunteers could be used to follow patients on a daily basis.

A broker system or a network of cooperating agencies could be developed.
Number of responses

1

The interviewees were asked what problems might be anticipated in the development of interagency case management. The most frequently anticipated problem was non-cooperation resulting from a desire on the part of agencies to protect their domains of "turf". Twenty-seven interviewees stated that there would be conflict over clients, resources and geographic areas. Thirteen additional interviewees expressed the same problem of non-cooperation in terms of an inability to develop good working relationships because of personality problems or refusal to release information. Five interviewees stated that the lack of integrated goals and standards along with differences in philosophies and methods would create problems. Other needs and anticipated problems include:

\section{Number of responses}

Need for increased funds to do case management

Need for increased staff time to do case management.

Need for increased numbers of staff.

There could be problems relating to confidentiality.

A new agency might create just another bureaucracy and too much money might be spent on administration. 7

Need for trained, qualified personnel. 


\section{Number of responses}

Need for additional resources in the community.

There might be difficulty finding an agency with the leadership potential to do case management.

There might be a need for integrated goals along with differences in philosophy and methods.

A case management system could become a "dumping ground" for clients with whom no agency wanted to work.

Staff turnover could disrupt continuity.

Case management might create a "Big Brother" watching over the clients; the potential is there for the abuse or power.

Case management might encourage deinstitutionalization which might have negative consequences for clients. 1

Staff might prefer to do therapy rather than case management.

Case management might create duplication of service.

Non-cooperation was expressed as a potential problem by respondents from all categories of service providers. The fear of creating another bureaucracy was expressed mainly by interviewees from the private organizations.

In summary, those interviewed said that:

Interagency case management is not being provided or is inadequate. Most interagency case management is done informally.

There is some intraagency case management.

Interagency case management should be the responsibility of one agency and that agency should probably be the Mental Health Division. 
The best way to provide case management is for agencies to work more closely together in an open, cooperative manner.

The major problems are domain protection and the lack of resources including funding, services, time and staff.

\section{Suggestions for Improvement.}

General Results. Responses in regard to improved delivery of services to the chronically mentally ill were often related to areas already identified as problems and were categorized retrospectively as follows: (1) case mangement, (2) improved expanded services of other agencies, (3) "in-house" changes, (4) improved interagency cooperation, and (5) advocacy and changes in attitudes. Table V shows the breakdown into these categories of suggestions made by the 77 respondents. Improvement or expansion of services in other agencies was the most commonly cited need ( 47 responses). This was followed by an almost equal number of citations for improvements in case management (29 responses) and "in-house" changes (28 responses). The least cited categories were improved interagency cooperation (12 responses) and improved advocacy and changes in attitudes (10 responses).

The following sections present the suggestions for improvement in case management, improved/expanded services of other agencies, and improved "in-house" services by agency type. Responses related to improved interagency cooperation, advocacy and attitudinal changes are summarized later in this section.

Group Care Facilities. Respondents from group care facilities focused on improvements needed in other agencies and within-house.

Comments concerning other agencies cited the need for increased funding, for staffing, better facilities and improved training. One respondent cited the need for a major change in welfare funding to assure 
proper psychiatric care as well as physical care for the chronically mentally ill.

Desired "in-house" improvements included 24-hour respite care, more physical therapy services, and a decrease in paper work.

Corrections. All comments concerning case management cited the need for improved follow-up. One respondent specified that follow-up in the community should assure that a discharged person takes medication, has housing, and spends money wisely.

Responses suggesting improvements in the services of other agencies centered on the need for more hospital inpatient space for crisis situations. The need for more nursing homes equipped to handle the target population was also reported. One interesting comment concerned police-hospital relations. The respondent believed some hospital personnel treated police like second class citizens who are depriving people of their rights, and that some hospital personnel did not listen to police.

Ideas for improvement within correction agencies focused on the need for more training to utilize staff abilities more fully. One respondent felt that police are now some of the best educated and most flexible people in the county. With proper training, such individuals could do a fair amount of community counseling. Another respondent noted that corrections programs, as of October, 1978, provide funding for established mental health services.

Natural Helpers. Only a few comments were made by the four natural helper respondents. The responses covered the need for housing, employment tralning, and better follow-up.

Government Agencies. The comments of governmental agency respondents concerning case management focused on follow-through. One respondent 
suggested that each agency should assign one individual to meet with the patient's caseworkers. The selected worker could then form a "network within a network" by meeting regularly to discuss issues and problems.

The most frequent comment regarding improved/expanded services concerned the need for more group home facilities. The need for structured facilities was cited specifically for those who are acting out. Needs for job finding and the maintenance of job services were also noted.

Changes desired within the respondents' own agencies included more training, simplified regulations, and improved access to services. Training in gerontology was mentioned. One respondent stated, "I would put emphasis on training members of this agency and other agencies with regard to ways of working with the chronically mentally ill, approaches to be used, more of an emphasis on mental health problems and what problems the mentally 111 are up against."

Community Mental Health Programs. Respondents from these agencies made only a few comments concerning case management. These involved the general need for more follow-up and a standardized case management system. Improvements desired in other agencies included more appropriate residential facilities, day treatment centers, and increased socialization services. Frequent responses were made concerning how the mental health clinics have very large caseloads. One respondent said, "All the agencies are understaffed."

Comments on "in-house" improvement included the need for more adequate housing, an intensive crisis program, psychological services given by permanent staff, a physician familiar with psychotropic 
medications to prescribe on a short term basis, and the general need for smaller case loads and more trained professionals. One response stated the need to aim services to the families of the target population, especially the high risk children of this population.

Private Organizations. Comments concerning case management noted the need for better organization, but reflected different opinions about which agency should take responsibility. One respondent thought case management responsibility should reside with field representatives from Dammasch. Another thought responsibility should be assigned at large to the Oregon Department of Human Resources.

Suggestions for improvements in other agencies focused on the need for structured housing for the chronically mentally ill. The need for development of drop-in facilities and recreational programs was also cited. In addition, one respondent suggested more flexible regulations regarding the use of state money "so that innovative programs could be started and tested--if they don't work, go on to something else." Another respondent suggested the development of structured programs based on a non-medical model, a "non-hospital based approach" for treating the mentally ill.

A variety of "in-house" changes were desired by private agency respondents. These included the need for general training, outreach programs, day treatment centers, residential treatment centers, and crisis intervention programs. One respondent noted that "chore services are needed to round out existing services." Chore services would consist of going to the client's house to clean up, make repairs, and other similar tasks. 
Psychiatric Inpatient. Comments concerning case management centered on being more responsive to ". . . Eind out what happened and didn ' $t$ " to the client. One respondent stated that "Many chronics hospital-hop from emergency room to emergency room with no continuity of care." The need for more staff for follow-up was cited.

The predominant comments concerning improved services focused on the need for (1) more and better organized halfway houses, and (2) expanded day treatment services. One respondent indicated that lack of housing causes people to be hospitalized longer than necessary because there is no available housing. Another stated there is need to "set up halfway houses that are truly therapeutic" being structured 24 hours a day. The need for improved programming in day treatment centers was also noted. One respondent cited a different need for simplifying the process the client must go through in order to obtain services. Changes desired within respondents' agencies included more awareness, better outreach, and more follow-up. One respondent stated,"Our agency is real specific--short term crisis hospitalization. People come in here and are filtered out. We need better follow-up in the community after hospitalization."

Miscellaneous. The six respondents of "Miscellaneous" agencies provided some interesting comments. There were several citations of the need for increased support services. One comment concerned outreach. "It doesn't matter how good your services are if you can't get the community to take them--it won't work to know what's available and when there is an opening." Another respondent cited a need for an information bank on housing providing information regarding the availability of low-cost housing in the public and private sectors. 
Another respondent stated there was a need for increased competency and efficiency of the referral system.

In a different vein, two respondents cited the need for improved cooperation between police and other agencies, and between hospitals and mental health centers. Noting a lack of coordination, one respondent said, "People are shuffled. It's the 'Officer Krupke' syndrome of West Side Story. The psychiatrist says it's the individual. The social worker says it's the environment. The police say he's a criminal. Meanwhile, the person is lost."

Citations of the need for improved advocacy and changes in attitudes were of three types. Concerning advocacy, the basic theme was that improved public relations are needed to cause the public to view the client in a more compassionate way. One respondent suggested that a legislative lobbyist be hired. Another suggestion was that more advocacy is needed so people working in the system become more aware of the problems of the chronically mentally ill.

Need for attitudinal changes were mentioned with regard to both the public and agency staffs. One respondent indicated that workers often do not like these clients; workers need to know how to relate better and not be emotionally hurtful. Another respondent cited the need to change society's attitudes towards the mentally ill. Another interviewee stated, "It's easy to pass off responsibility to an institution, but the community should assume more responsibility."

Training

Interviewees were asked three open-ended questions with regard to training needed to help the chronic mentally ill population. 


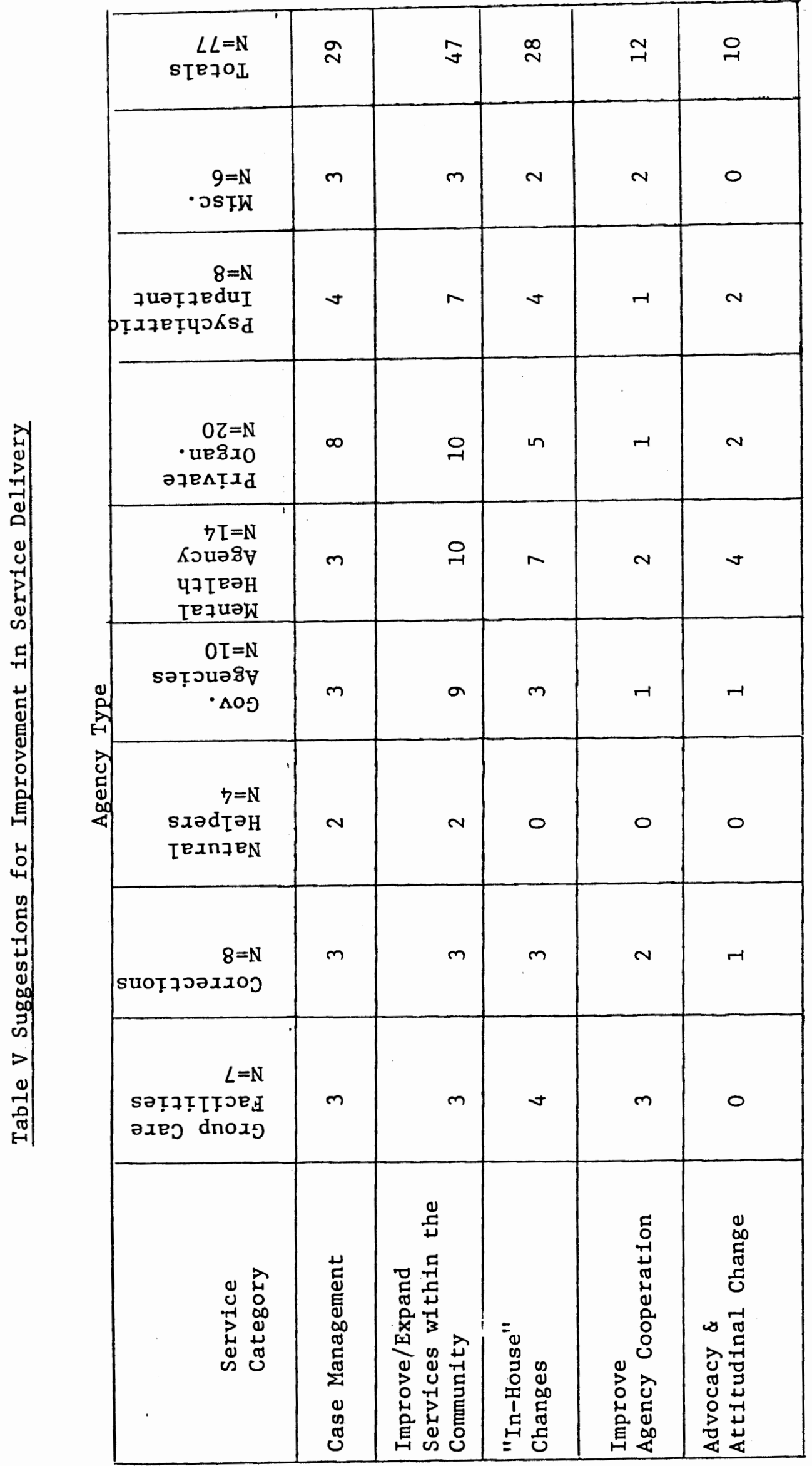


Special Skills Needed.

Interviewees were asked, "What special skills do you feel are needed by your agency staff in order to serve this population?" Responses appear to indicate a variety of skills, knowledge, and personal attributes are needed by agency staff. These have been grouped in general categories, developed retrospectively, and are listed in descending order of frequency:

\section{Number of responses}

Personal traits 30

Knowledge of mental illness and behavior science 25

Knowledge of community resources

Professional training

Interviewing/listening skills

Knowledge of medical treatment and effects of medication

Diagnostic and assessment skills

Consultation and supervision skills

Occupational therapy and job placement skills 5

Community relations and education 5

Crisis intervention $\quad 4$

Behavioral management skills 4

In-service paraprofessional training skills 4

Ability to recognize mental illness 3

Skills in group process 3

Knowledge of legal process 3

Advocacy skills 2

Self-defense skills 2 
Other responses receiving a single mention were daily-living skills, reality-orientation training skills, fiscal management, outreach, ongoing follow-up, grant writing, special skills for the handicapped, recording, ability to deal with family violence, social work skills, media skills, specialized cultural knowledge, ability to make treatment plans, attitudinal-training skills, and data-gathering regarding client movement through agencies.

The category of personal traits includes responses which appear to be personal qualities needed by workers, rather than specific skills. The words "acceptance" and "understanding" were each mentioned three times. The word "empathy" was mentioned twice.

Other responses listed in the category personal traits include assertiveness, experience sensitivity, ability to relate to people, ability to deal with personal frustration regarding failure of clients, ability to integrate knowledge with skill, lack of prejudice against men, ability to cope with institutions, good timing, patience, persistence, good judgment, tolerance, humor, believing in the Lord, creativity, ability to change, ability to relate to youth, ability to set limits, and ability to set realistic goals.

\section{Training Received.}

Interviewees were asked, "What kind of training does your staff receive in regard to this population?" They were asked to respond in terms of four categories:

Pre-service Training. Twenty-three of the 77 interviewees said their agencies required pre-service training. Some of the respondents may have referred to general mental health training and also to other more specific categories. 
Orientation. Nineteen of the 77 interviewees said their agencies' orientation included training regarding mental illness.

In-service Training. Thirty-five of the 77 interviewees said their agencies provided in-service training.

Academic Training. Seventeen of the 77 interviewees said their agencies had some connection with the academic world. Respondents mentioned workshops, internships, and students working in their agencies. Deficits in Training.

Interviewees were asked, "What are the deficits in existing training?" Forty-six of the 63 interviewees who responded mentioned at least one need regarding training. Responses, listed in categories, were:

\section{Number of response}

Need for training

Finances for training

Resource knowledge

Community relations skills

Time and staff

Training regarding mental illness and behavior

Crisis-intervention training

Follow-up

Assessment skills training

Training regarding minorities

Funded workshops

Consultation

Collaboration opportunities

Training and resources for the handicapped mentally ill 


\section{Number of response}

Professional training

Staff coverage for training
2

2

Single responses to this question indicated a need for training in specific areas. These include: housing, outreach, occupational therapy, medical knowledge, goal-setting, treatment, domestic violence, personal coping skills, attitudinal development, and training in agency policy and philosophy. Other single comments related to mobility of trainers, the need for better interagency cooperation, increased coordination of training between agencies, and increased management support for training. Other problems noted were lack of space, lack of formal education, orientation deficits and inadequacies in paraprofessional training. Staff Time and Utilization Data

Thirty-six respondents, or less than half of those interviewed, responded to a question regarding the amount of staff time the agency gives to working with the chronically mentally ill. Eighteen agencies gave interviewers printed data with a variety of information to supplement the interview. The information received is rather limited because some agencies reported a percentage without giving the number of staff involved. Other agencies reported the percentage of their clientele who are chronic without reporting total number of clients served. Figures for those who responded indicate that, on the average, approximately forty-eight percent of agency staff time goes to the chronically mentally 111 and that approximately thirty percent of clients served by the agencies are chronically mentally ill.

With regard to the characteristics of the people they serve, 15 interviewees said they do not differentiate among the types of persons 
they serve. Four interviewees said they serve persons described by the legal definition of insanity, whereas three respondents reported that they serve only the chronically mentally ill and seven respondents reported that the information was confidential. Three interviewees said there were no data available, and an additional two respondents said the question was not applicable.

In summary, there was less than a fifty percent response rate regarding both staff time and utilization data questions. This indicates the difficulty encountered when attempting to obtain this type of information about service providers.

\section{Additional Comments}

Interviewees were given the opportunity to make additional comments. Several interviewees stated that they were pleased with the efforts of the Community Support Project and indicated hope that the planning efforts will result in better service coordination. Some of the specific comments included: "The chronically mentally ill are a very underserved population." "We need to do more for them." "I feel very positive about the emphasis on the chronic population." "The chronically mentally ill have the greatest need."

Negative comments regarding the interview were also present, though much fewer in number than positive comments. Some of these comments include: "I feel some of the questions were biased towards a certain kind of service delivery. Case management is only one way to go." "It is important to move away from the planning stage to the action stage. Planning is a way of avoiding the dirty work." "We have been talking about more of this and more of that, when there isn't money to support existing services to do a top notch job with what they have." 
There were several comments supporting or promoting specific programs and giving a description of their unique role in service delivery in Multnomah County. One interviewee offered services if at the end of the study we should find a need for them.

Some additional problems mentioned were: medication to control behavior is over-used, patients are released too early, society is spending a lot of money on people who don't need it and misuse the system, families are ignored, neglected, and not consulted, services are overcrowded, staff don't have enough time, the welfare system provides no psychiatric care for those 21 to 65 years of age, large sums of money are spent on hospitalized patients but little money is allocated after discharge, the eligibility rules for service hinder many persons with identified needs from getting the service they need, and community education programs are not geared toward the emotionally deprived.

Several interviewees mentioned concern that this population of ten uses the whole spectrum of human services and that government spending directly affects those services. When money is cut back, the services tend to suffer in all areas.

Suggestions were made several times for a national health insurance plan to insure equal availability of mental health care for all. Comment was alıo made that we are the last of the modernized nations which does not have national health plan. Frequent comments referred to lack of services and coordination. Many interviewees mentioned that this increases the frustration and sense of failure for workers dealing with the chronically mentally ill. 
Additional comments included: "There is not enough public awareness of the daily problems of the chronic mentally ill in our community. These problems should be specifically pinpointed so people will be aware." "We need change in comnunity attitudes." "The chronic mentally ill have few advocates." "I have a strong feeling that we have a lack of professionals taking a stand."

Perhaps a simple comment from an interviewee sums up the situation. "There is a crying need that needs to be met. I don't know how to go about meeting it. I'd hate to be the guy who has to come up with the answer." 


\section{CHAPTER VI}

\section{CLIENT RESULTS}

Ten client interviews were conducted. It is important to note that clients were located primarily through agencies serving them and are not a representative sample of the target population.

\section{Clients in the Community}

Problems.

Members of the target population identified numerous problems that face those returning to the community after hospitalization. The following problems were reported:

\section{Number of responses}

Lack of employment 7

Limited financial resources 6

Lack of transportation

Lack of residential situation

Loneliness/lack of friends/discomfort around others 3

Depression

Unsatisfactory conditions in living situation

Limited follow up after hospital discharge

Difficulty with bus routes

Overuse of medication

Not being informed of need for specific treatment received 


\section{Number of responses}

Preferential treatment for the young

1

Difficulty completing housework

Difficulty obtaining bus pass

Fear of returning to the hospital/shock treatment

Nervousness
1

1

1

1

The three most frequently mentioned problems were lack of employment, limited financial resources, and lack of transportation. Two respondents specifically stated lack of employment as the "biggest problem." Two individuals identified the issue of employers' attitudes; one stated, "Once they (the employers) hear you've been in (a mental hospital), they won't want you." Lack of employable skills and difficulty in finding a desirable job were noted.

Three individuals specified that limited finances made it difficult to pay for personal items and bus transportation. Of those citing lack of transportation as a problem, two persons stated the cost of bus fare as a problem. Limited bus service on weekends was also noted.

Concerning lack of residential situations, one interviewee identified landlord/landlady attitudes as the problem, "Some places you go to rent, if they knew you had been in (the mental hospital) they wouldn't rent." One respondent noted that lack of adequate living arrangements caused longer stays at the hospital.

Two important concerns were raised in relation to all the above problems. The first is a lack of acceptance by others due to the individual's having been in a mental hospital. The second is the recurring comments throughout the interviews concerning financial limitations. Interviewees noted problems in paying for transportation, entertainment, 
schooling, apartments, and personal items.

When asked if there were special problems for minority groups, respondents did not agree. Three reported that there were special problems. Four said there were not and three did not know. Each of the following problem areas was identified by one respondent:

Black persons face housing discrimination

Gay persons can be isolated

Women have fewer opportunities

Low-income minorities have particular difficulties (unspecified)

Time in the Community.

When asked how they spent their time in the community, respondents reported a range of activities. All individuals interviewed listed a minimum of four activities and the average number enumerated per person was almost five. Below is a list of all activities mentioned:

\section{Number of responses}

Participate in a program/agency activities

Visit with friends or relatives

Watch TV

Do housework

Frequent coffee shops

Listen to the radio

Go to shopping centers and look around

Sit around the house

Go drinking with friends

Go out with boyfriend

Play music

Walk to the store

\section{9}

7

6

5

2

2

2

2

1

1

1

1 


\section{Number of responses}

Engage in a hobby

1

Go to inexpensive movies

Pursue interest in musical history

Play solitaire or other card games

Go dancing

Ride the bus

Take walks

Attend school to obtain GED

Attend job training program

Play pool
1

1

1

1

1

1

1

1

1

Places in Community Where Respondents Spend Time.

Respondents identified several types of establishments where they spent time. These were:

\section{Number of responses}

Restaurants

Programs/agency services

Shopping Centers

Friends/relatives' homes

Church

Park

Tavern

Shops
5

4

2

2

1

1

1

1

The places mentioned were located in all four areas of the county (east, north/northeast, southeast, west). Two persons commented on the need for inexpensive places and three individuals noted going to all the parks in the county. 
When specifying what attracts them to these settings, the following were mentioned:

\section{Number of responses}

Social/recreational

Eating

Acceptance of neighborhood

Friends and people with similar interests
8

4

1

1

Four individuals reported that they liked to be around other people, whether in restaurants, shopping centers, or in homes. Getting support and sharing interests with friends were important to one individual. Another indicated, "I feel like I'm free and on my own . . " when at a relative's house. One individual described neighborhood acceptance as "tolerance, where eccentricity is tolerated."

Two persons commented on the need for activities to be inexpensive.

All interviewees use the bus for all or a portion of their transportation. Specific arrangements are:

Number of responses

Bus/walk

Bus only

Bus/friend or others transport in car 4 3 3

One individual indicated walking as the primary mode of travel, another reported walking only in good weather. A third responded that he walked due to lack of funds.

Regarding satisfaction with their means of transportation, respondents stated: 


\section{Number of responses}

Satisfied

4

No response

Partially satisfied

Dissatisfied

\section{Attitude of the Community.}

When asked about how people in the community feel toward people who have been in mental hospitals, respondents reported:

\section{Number of responses}

$\begin{array}{ll}\text { Accepting } & 4 \\ \text { Neutral } & 2 \\ \text { Accepting and neutral } & 2 \\ \text { Rejecting } & 1 \\ \text { Accepting and rejecting } & 1 \\ \text { In clarifying his perception of an accepting community attitude, }\end{array}$

one interviewee remarked that his friends had been sympathetic. Another indicated, "They (friends) work with me and give me friendship." A third respondent reported that people in the neighborhood spoke to him. A rejecting community attitude was noted by one person who remarked that community people are fearful of the target population being violent.

Four persons perceived attitudes as mixed. One individual commented that people can be friendly at times and rejecting at others. Another noted that community reaction depends upon how you describe "your illness" --you have to do it "with diplomacy." A third stated, "I think it is really hard for society to accept mental illness. A lot of people who should know better say that there is no such thing as mental illness, because they have had no experience with it personally." 


\section{Service Delivery}

Services Utilized by Respondents.

Respondents received a variety of aid from social service agencies. The following identified types of services are currently being utilized by the interviewees.

Vocational Training/Placement (5 responses). Three different agencies were identified as providing this service. One interviewee specified terminating services as his needs were not met. Two individuals indicated satisfaction with services received and one person reported being dissatisfied. Electronic training and silver polishing were two types of occupational training specified.

Financial Aid (9 responses). Nine respondents receive financial aid from a public agency. Three different sources of support were mentioned. Two persons commented that the amount allotted for personal expenses is inadequate. One client sopke of the problems encountered when a support payment arrives late. Another client expressed a desire to get off public support as soon as possible.

Therapy/Counseling ( 7 responses). Seven respondents are currently receiving therapy or counseling from a mental health clinic or affiliated program. Group and individual counseling provided one interviewee the opportunity to talk about problems.

Residential Placement (6 responses). Six of the clients reside in supervised living sttuations. This includes two who live in group homes and one in a boarding home. Two persons expressed a desire to change their setting: one noted the difficulty of finding an apartment while finances are limited. One respondent conveyed appreciation for the 
residence operator's help in providing emergency housing for a relative in need.

Transportation (1 response). Only one interviewee indicated receiving help from an agency concerning transportation.

Daily Living Skills (5 responses). Five individuals presently

are receiving trafning in this area. Two respondents are learning such skills in their living situation and three through mental health programs. One interviewee expressed satisfaction with training received at his place of residence.

Socialization and Recreation ( 9 responses). All but one of the respondents is participating in socialization and recreational programs. One person stated, "They (program staff) help you feel good enough about yourself, so you can do something. You know you are doing all right." These additional comments were made:

"The program is very helpful."

"It gets me out of the house."

"It's good for me, it's helped me quite a bit."

Medical Care and Medication (9 responses). A11 interviewees but one receive medical care and medication. Mental health agencies are providing this service for seven of the respondents.

Education ( 2 responses). Two persons are presently engaged in educational activity. One is taking a math class offered through a socialization program, the second is enrolled in a community college and working to complete a GED. This individual commented on having to use personal monies for part of the GED program.

Lega1 Service (2 responses). Two people are currently utilizing legal services; one of these specified obtaining Legal Aid assistance. 


\section{Assistance in Applying for Benefits/Services (6 responses). Of}

the six respondents who receive this service, three are assisted by mental health agencies and two by residence operators.

Referral Sources.

When asked how they got in touch with the services they use, respondents reported the following sources:

\section{Number of responses}

Mental hospital

Mental Health Clinics

Residence operators

Vocational Rehabilitation

Psychiatrist

Relative
5

4

2

1

1

1

Six respondents reported using only one source of referral to

services and four mentioned more than one source. One individual commented, "You don't find services until after you have been in the hospital for a while."

\section{Interagency Cooperation.}

When asked for examples of how agencies work together to meet client needs, the following responses were noted:

Vocational programs work with employers to get jobs for clients (1 response).

Mental health helped a person get a medical examination to complete entrance requirements to another program (1 response).

Residence operator calls other agencies for help in solving resident's problems (1 response).

Agencies have holiday party ( 1 response).

Two programs address the same problem through different means

(1 response). 
One service worker calls several other programs and checks on individual's progress (1 response).

Agencies talked together (1 response).

There was one "no response" and two "do not know."

Clients were asked if there is someone who helps them find services; eight interviewees said "yes" and two said "no". of those answering affirmatively, one indicated receiving help from three people, three indicated having help from two people and three indicated having help from one person. Types of helpers mentioned are:

Number of responses

Mental health workers 7

Residence operators 2

Public assistance worker 1

Hospital staff 1

Psychiatrist 1

Relative 1

Assessment of services by respondents. In assessing overall satisfaction with services received, five respondents were satisfied, three were partially satisfied, one person was not satisfied and one person did not respond.

Five of those interviewed made suggestions for improvements in programs and service delivery. Two individuals stated the need for increased financial support; one specifying more personal spending money. Two persons suggested improvements in living conditions; one desired greater privacy and fewer house rules and the other mentioned better physical conditions. One person stated, "They (the government) should cut the military budget and put money into mental health. Not just money, it needs dedicated people." 
Concerning service locality, one individual commented, "Services should be centered in a residential area. It doesn't have to be much -just friendly and understanding; ideally, a warm house where someone cares."

Another respondent stated, "I wish they would do away with shock treatment. The idea of electricity going through my head really scares me. It doesn't help that much because in two or three months, you are back where you started from."

The following is a statement of one individual's view of the service worker role:

Qualities are needed more than skills: Integrity, ability to make sound judgments, dedication. It takes more than money. The first thing a worker should do is live for two months like a chronic. Then services would be much more reality oriented. Experience is the key. A chronic needs a worker who'll spend an afternoon taking him out to the country or the zoo, or will get up at three in the morning if needed, just willingness to be available. . I would stress an important point. After a three-month hospitalization, it's very frightening. Worker's need to accompany discharged patients to resources they're going to use. I could stress the liaison role, and this includes accompanying clients in public, having coffee with them in a restaurant, and visiting them at home. - Workers don't see the patient very much. They don't ask the patient what he really wants; they don't inquire about your real interests.

Respondents identified the need for these additional kinds of services:

\section{Number of responses}

Program that is open on weekends

More one to one contact on a regular basis

Someone to talk to directly about suicidal feelings after business hours

More sports activities
1

1

1

1

Four stated no additional services are needed and two did not respond. 
A last word.

A final comment from an interviewee: "I'm stronger than before. I have insight into my weaknesses. People forget that mental illness can be a strengthening experience. It was a growth-producing experience." 


\section{CHAPTER VII}

SUMMARY OF THE REPORT OF FINDINGS IN MULTNOMAH COUNTY

\section{Introduction}

In the Fall of 1978, a group of graduate students from the School of Social Work at Portland State University interviewed service providers in Multnomah County in an attempt to assess the county's community support system for the chronically mentally ill. The students worked under the guidance of three faculty members with technical assistance from the Community Support Program. The following is a summary of the results of the 77 provider interviews and ten client interviews.

Strengths of The System

The responses to the interviews suggest that service providers in Multnomah County are interested in and concerned about the chronically mentally ill and are seeking new ways to provide services.

The study indicates that a large variety of services are available to this population and eight of the ten clients interviewed stated that they are satisfied or partially satisfied with the services they are receiving.

Service providers also indicated that professionals working with this population seem to have true personal concern for their clients.

It does seem that agencies are attempting to meet the challenge that deinstitutionalization has created for this community. 
Client in the Community

Problem Areas.

The following were identified by providers as significant problems for the client living in the community.

Need for Increased Range of Residential Situations. Forty-seven interviews mentioned this problem. Transitional living situations and residential situations with built-in support systems were two mentioned needs. Other problems include a shortage of structured living situations and group homes.

Need for Improved Case Management/Service Coordination. Case management services were frequently mentioned by 45 out of the 77 interviewed as a problem area. Within the area of case management, the need for follow-up was the most often recorded comment, followed by a need for advocacy. Other problem areas include lack of coordination of services and lack of monitoring clients. For those clients returning to the community from an inpatient facility, availability and coordination of services were seen as problems.

Insufficient Financial Resources. Thirty-seven of the respondents considered lack of financial resources for providing services as a problem for this population. Comments pertaining to this problem area include a need for funds for food, clothing, shelter, personal expenses, medical expenses and specialized treatment.

Inadequate Employment Opportunities. Twenty-seven of those interviewed reported that lack of employment is a problem for this population. Vocational training and a need for supportive, sheltered or protected work opportunities were problems mentioned. 
Isolation/Loneliness/Need for Social or Emotlonal Support. Twenty of the respondents felt that a lack of support systems is a problem for clients in addition to loneliness and isolation.

Insufficient Qutpatient Resources/Services. Twenty of those interviewed mentioned insufficient outpatient resources or services as a problem for the chronically mentally ill. The shortage of suitable and proper resources was frequently mentioned.

The problems most frequently identified by clients were lack of employment opportunities, limited financial resources and inadequate transportation. Several clients also mentioned the need for adequate residential situations.

\section{Problems of Minority Groups.}

Thirty-nine providers identified special problems for minority groups. The comments include the following: discrimination, racism, anit-semitism, irrelevance of existing services, insensitivity of service providers, lack of resources, minority status contributing to mental illness, language barriers, inability to compete for jobs, cumulative prejudices, cultural differences, alcoholism among Native Americans and class differences between clients and service providers. Most respondents defined minority status by ethnic or racial characteristics, although there were many who included income, sex, age, mental capacity and sexual prefercise.

The Client's Day.

A majority of the respondents commented that this population is involved with passive and solitary activities. The following are some of the most frequently mentioned activities of clients as identified by service providers: watching television, participating in family activities, 
sitting or wandering around and drinking coffee in coffee shops. The programs and agencies mentioned as being utilized by some members of this population include mental health clinics, day treatment and various drop-in centers. According to providers, a few clients make use of these community activities.

Most of the clients mentioned that they spend their time participating in program and agency activities or visiting with friends and relatives. Several stated that they watch television or do housework.

Where the Chronically Mentally I1l Cluster.

Fifty-four of the service providers reported that this population does tend to cluster in certain areas. Most frequently mentioned were the northwest, southeast, northeast and downtown sections of Portland; a few respondents mentioned specific eating or drinking establishments, hotels and streets.

Attitude of the Community.

Twenty-seven service providers felt that the community rejected this population. Fifteen interviewees reported accepting attitudes and 23 respondents reported a neutral attitude. The remainder indicated a combination of attitudes. Difficulty in building residential care facilities, finding jobs for the population and a lack of funding were all reported as problems related to rejection.

Four out of the ten clients interviewed indicated they felt that the community was accepting; two reported neutral attitudes; one felt rejection; and three reported a mixture of attitudes.

Service Delivery

Interagency Cooperation.

There was a difference of opinion among providers concerning the 
existence of interagency cooperation. Cooperation is described as moderate to good by 35 respondents. Thirty respondents indicated that cooperation is nonexistent or poor. Also, there were differing responses concerning how agencies cooperate, with 37 respondents stating that cooperation is generally informal. In contrast, fifteen respondents stated that cooperation occurs because of formal agreements between agencies. The most frequently stated reasons for the lack of cooperation are unsufficient funding and staff, "red tape" and the absence of a suitable coordinating system. It was often mentioned that the quality and frequency of interagency cooperation depends upon the abilities of individual workers.

\section{Case Management Issues.}

Providers had varying opinions concerning the existence of case management in Multnomah County. Thirty-two respondents stated that case management is being provided and thirty-nine stated that case management is nonexistent. Twenty-eight respondents said that case management services are inadequate. Thirty-one respondents mentioned that interagency case management is conducted on an informal basis. A general opinion of the respondents was that it is difficult to provide case management because of the lack of resources.

Eight of the ten clients interviewed stated that there is someone in the community who assists them in finding services.

The majority of the service providers state that case management should be the responsibility of one agency. Fifteen felt that it should not be the responsibility of one agency. The most frequently mentioned agency is the Mental Health Division, although it is unclear from the data whether the County or State Mental Health Division is being referred to by the respondents. 
Most of the service providers stated that there would be problems with the development of case management services. The problems identified most often are non-cooperation on the part of agencies and the lack of funding and other resources.

\section{Suggestions for Improvement of the Service Delivery System.}

Some improvements in the current system were suggested by the respondents. The areas needing improvement most of ten mentioned by service providers fall into three categories:

Improved or Expanded Community Services. especiazly group homes and day care facilities.

Case Management. especially the need for follow-up.

"In-House Changes". including improvements in training.

Some of the other areas mentioned include better interagency cooperation, advocacy and changes in community attitudes.

Improvements suggested most frequently by clients include increased financial support and better living conditions.

\section{Barriers}

From the comments made by service providers and clients, it is possible to identify several barriers which may interfere with service delivery in Multnomah County:

\section{Resources.}

This barrier includes insufficient funding for programs and staff, and need for increased community resources such as outpatient services and residential situations. It also includes need for financial resources available to clients.

Training.

The respondents indicated that there is a need for training in a 
wide variety of areas relating to various kinds of skills and knowledge.

\section{Attitudes.}

Reported community attitudes toward the chronically mentally 111 varied from accepting to neutral of rejecting in nature. The lack of strong support on the part or the community may suggest the need for education and information concerning this population before the community will actively support efforts to improve services.

\section{Case Management.}

A comprehensive or systematic way to provide case management services does not currently exist. Also, lack of cooperation is viewed by the respondents as a potential barrier to the development of a case management system.

Training

Twenty-three of the respondents indicated that their agency requires pre-service training; 35 persons stated that they have in-service training. Nineteen of the service providers stated that their agencies include training about mental illness in orientation training. Seventeen interviewees said that they have some connection with academic training. Service providers stated a need for knowledge of mental illness and behavior science, for knowledge of community resources, for specific professional skills, as well as a need for certain personal traits.

The service providers indicated that there is a wide variety of training needs and concerns in the community. Forty-six respondents mentioned at least one deficit in the training of professionals working with the chronically mentally ill. Issues mentioned most of ten are general lack of training, lack of resources (funding, staff and time) for training and lack of knowledge about resources available. 
EPILOGUE

This section discusses some of the researchers' general impressions of various aspects of the study. If also contains some recommendations for future research.

Many researchers commented upon the dedication and enthusiasm of their interviewees despite the numerous problems facing these service providers. Numerous interviewers described respondents' responses as "insightful" and "thoughtful". In addition, many service providers expressed a desire to see the completed study and to increase their knowledge about the target population and services offered to them.

Researchers agreed that a positive aspect of the study was the diverse scope of the types of service providers interviewed, particularly the inclusion of natural helpers and self-help groups. Thus, a broad perspective of the target population was gained and a diverse view of their problems and prospective solutions identified.

Researchers discovered that the study's results generally support the findings reviewed in the literature. However, in the area of the community attitudes toward the chronically mentally ill, findings in this study show some discrepancy with the literature. These discrepancies may be due to the fact that while community residents may verbalize acceptance in principle, they may be less than accepting in their actual contacts with target population, especially in employment and housing. Service providers may be responding to the community behaviors they encounter in working with their clients.

Many researchers commented on the difficulty of reaching service 
providers by telephone when calling to arrange for the interview. Their phone lines were frequently busy. This suggested to the students that interviewees were somewhat inaccessible and that clients might encounter similar problems when attempting to reach providers.

A few researchers and interviewees had some concerns about the interview questions. They stated that they felt the interview questions tended to solicit negative rather than positive information concerning service delivery for the chronically mentally ill. Also, some expressed the opinion that the emphasis on case management narrowed the interviewees' options for suggesting other solutions to the problems of this population.

Several of the researchers raised some concerns about the nature of the responses to a few of the questions. They felt that some of the service providers had a limited perspective of the problems of the chronically mentally ill and that this perspective was determined by the functions of the providers' agencies. It was suggested by some members of the research group that this perspective might have been the result of fragmentation of services and not the fault of the individual provider. Another concern was that some providers did not have much concrete knowledge of how members of the population under study spent their free time and that this occassionally resulted in a negative assessment.

The research group expressed two opinions concerning the impact the study might have had on service providers. One opinion was that the study focused attention on the chronically mentally ill and thereby increased awareness of this population on the part of the service providers. Another opinion was that the study may have contributed to negative labeling by identifying a certain group of people as "chronic." 
The researchers expressed a belief in the importance of consumers' opinions in assessing service delivery and needs. Thus, the imput of both clients and their families was considered valuable. Interviewers were aware that the small and unrepresentative sample of clients and the singular family member interviewed lessened the impact of this portion of the report and provided only a limited perspective.

Concern about the future use of this study was expressed by the researchers and the service providers interviewed. . Both indicated some skepticism about whether the results would be utilized in decision making and future fund allocations for services for the target population. A related question was which agencies and/or individuals would use the study's findings and to what extent this would affect their future planning for service delivery. One objective of the research group was to make this study useful to and available to county service providers interviewed. It is hoped that the study will provide additional information about the community support system, which agencies serve the target population, and what specific services they provide.

One issue which the researchers generally felt was of major importance was the lack of resources identified by both service providers and clients. Inadequate resources were mentioned in conjunction with most variables including staff training, referrals, housing, employment, client recreation, and coordination of services.

A final consideration is future research directions suggested by this study. The following gaps in available research and areas needing investigation have been identified by the research group:

1. Further study of the opinions and perceptions of the chronically mentally ill and their families. Possible areas for exploration 
include unmet needs, availability and accessibility of formal and informal services, preferences and gaps in service delivery, social support systems, and community attitudes and practices.

2. Study of the "typical day" of the target population members. This is strongly recommended due to the paucity of this research in the literature and the conjecture of these researchers that service providers may have limited information in this area.

3. Further investigation of the role of the natural community helpers in meeting this population's needs. This could potentially include boarding home operators, restaurant personnel, pharmacists, and neighbors who provide informal social support, material aid, help in solving problems, and referrals.

4. Further assessment of the barriers to effective service delivery. Additional information is needed on the effect of and solutions to these problems: clients' limited financial resources, lack of cooperation between agencies, lack of agency and community resources to meet clients' total needs, inadequate training, and lack of employment opportunities.

5. A study of the social service network in Multnomah County. This would examine interagency referral of clients and the exchange of resources. Agencies which work with the chronically mentally ill would be identified and surveyed to gather information concerning their funding sources, functions, contracts with other agencies, rates of client referral and specific agencies to which referrals are made. This study would indicate which agencies were most heavily involved in interdependent relationships. A comparison of the rate of interdependence with type of agency, funding source, agency 
functions, and other characteristics might provide some information on how to improve interagency cooperation and coordination of resources. 


\section{B I B L I O G R A P H Y}

Aiken, Michael, Dewar, Robert, Di Tomaso, Nancy, Hage, Jerald, Zeitz, Gerald. Coordinating Human Services, San Francisco: Josey-Bass Publishers, 1975.

Allen, P.L. "A Consumer's View of California's Mental Health Care System." Psychiatry Quarterly, Vol. 48 (1974), p. 1-13.

Altshuler, Steven C. and Forward, John. "The Inverted Hierarchy: A Case Manager Approach to Mental Health Services." Administration in Mental Health (Fall, 1978), p. 57-67.

The American Heritage Dictionary of the English Language, New York: American Heritage Publishing Co., 1975.

Aring, C.D. "The Ghee1 Experience: Eternal Spirit of the Chainless Mind." Journal of the American Medical Association. Vol. 230 (1974), p. 998-1001.

Astrachan, Boris and Levinson, Daniel. "Organizational Boundaries: Entry into the Mental Health System." Administration in Mental Health. (Summer, 1974), p. 3-12.

Bachrach, Leona L. "A Conceptual Approach to Deinstitutionalization." Hospital and Community Psychiatry. Vol. 29 (9), (September, 1978), p. 573-578.

Bachrach, Leona L. Deinstitutionalization: A Conceptual Framework. Seminar Presentation, Second Annual Statewide Outreach Conference, Terrel1 State Hospita1, Terre11, Texas, August, 1976.

Bachrach, Leona L. "Deinstitutionalization of Mental Health Services in Rural Areas." Hospital and Community Psychiatry. Vol. 28 (9), (September, 1977), p. 669-672.

Bachrach, Leona L. Deinstitutionalization: An Analytic Review and Sociological Perspective. DHEW Publication (76-351), 1976, U.S. Government Printing office, Washington, D.C., Superintendent of Documents.

Bachrach, Leona L. "A Note on Some Recent Studies of Released Mental Hospital Patients in the Community," American Journal Psychiatry. Vol. 133 (1), (January, 1976), p. 73-75. 
Baker, Frank and Schulberg, Herbert. "The Caregiving System in Community Mental Health Programs: An Application of Open Systems Theory." Mental Health Digest. Vol. 3(4), (Apri1, 1971), p. 13-16.

Bassuk, Ellen and Gerson, Samuel. "Deinstitutionalization and Mental Health Services." Scientific American. Vol. 238(2), (February, 1978), p. 46-53.

Beard, John H. "Psychiatric Rehabilitation at Fountain House," in Rehabilitation Medicine and Psychiatry, Jack Meislin, ed., Springfield, Illinois: Charles C. Thomas Publishing Company, 1976. p. 393-413.

Bigelow, Douglas A. and Beiser, Morton. "Rehabilitation for the Chronically Mentally I11: A Community Program." Greater Vancouver Mental Health Service, Vancouver, B.C., March, 1977. Unpublished paper.

Blank, H. Robert. "Community Psychiatry and the Psychiatrist in Private Practice," in Bellak, Leopold, ed. Handbook of Community Psychiatry and Community Mental Health. New York: Guren \& Stratton, 1964, p. $300-318$.

B1oom, Bernard L. Community Mental Health: A General Introduction. Monterey, California: Brooks-Cole Publishing Co., 1977.

Bous, Jonathan F. "Issues Critical to the Survival of Community Mental Health," The American Journal of Psychiatry, Vol. 135: (9), September, 1978, 1029-1035.

Bowen, W.T. and Fry, T.J. "Group Living in the Community for Chronic Patients." Hospital and Community Psychiatry. Vol. 22 (1971), p. 205-206

Brandon, Muriel. A Post-Hospital Resocialization Program. Osawatomie State Hospital, Osawatomie, Kansas, 1961.

Brattler, Thomas Edward. "The Psychotherapist as Advocate: Extending the Therapeut1c Alliance with Adolescents." Journal of Contemporary Psychotherapy. Vol 8, (Winter/Spring, 1977), p. 119-127.

Brooke, Bryan D., Cortes, Marguerite, Narch, Robert, and SundbergStirling, Mary. "Community Families: An Alternative to Psychiatric Hospital Intensive Care." Hospital and Community Psychiatry, Vo1. 27 (3), (March, 1976), p. 195-197.

Brown, Bertram S., M.D. "Responsible Community Care of Former Mental Hospital Patients," New Dimensions in Mental Health. March, 1977, U.S. Department of Health, Education \& Welfare. Washington, D.C.: Superintendent of Documents. 
Chamberlin, Judi. "Inside the Mental Patients' Association," State and Mind, Vol. 6 (4), (Summer, 1978), p. 21-30, Vol. 7 (1), (Fal1, 1978), p. 69.

Chouinard, E. "Family Homes for Adults." Social \& Rehabilitation Record. Vol. 2, (1975), p. 10-18.

The Community Mental Health Centers Act, 1963 (Public Law 88-164, Title II), p. 290-294.

Crown, Sidney. "On Being Sane in Insane Places: A Comment From England." Journal of Abnormal Psychology, Vol. 84 (5), (1975), p. 453-455.

Cutler, David and Beigel, Allan. "The C.O.P.E. Program: A Social Network for Chronically Mentally I1l Persons Living in the Community." August, 1978. Unpublished paper.

Datel, William E. and Murphy, Jane G. "A Service-Integrating Model for Deinstitutionalization." Administration in Mental Health, (Spring, 1975), p. 35-45.

Dohrenwend, Bruce P. and Chin-Shong, Edwin. "Social Status and Attitude Toward Psychological Disorder: The Problem of Tolerance of Deviance." American Sociological Review, Vol. 32 (1), (February, 1967), p. 417433.

Dunn, June. "Six Models of Case Management." Presented at a Workshop entitled "continuity of Care/Case Management of the Chronically Mentally I11." Salem, Oregon: State Mental Health Division, December 7, 1978.

Fairweather, George, Sanders, David, Maynard, Hugo, Cressler, David and Black, Dorothy. Community Life for the Mentally I11: An Alternative in Institutional Care. Chicago: Aldine Publishing Co., 1969.

Farina, Amerigo, Felner, Robert D. and Boudreau, Louis A. "Reactions of Workers to Male \& Female Mental Patient Job Applicants." Consulting and Clinical Psychology, Vol. 41 (3), p. 363-372.

Fellowship House. The Psycho-Social Rehabilitation Center of Dade Cuunty, Inc. Program Description. South Miami, Florida: 1978.

Feldman, Saul. "Problems \& Prospects: Administration in Mental Health." Administration in Mental Health. (Winter, 1972), p. 4-11.

Field, Gary. "People System of Case Management." Presented at a Workshop entitled "Continuity of Care/Case Management for the Chronically Mentally Ill." Salem, Oregon: State Mental Health Division, December 7, 1978. 
Gage, Robert W. "Integration of Human Services Delivery Systems." Public Welfare. Vol. 34 (Winter, 1976), p. 27-33.

General Accounting Office. "Returning the Mentally Disabled to the Community: Government Needs to Do More." (HRP-76-152) Washington, D.C.: The Government Printing Office, 1977.

Glasscote, Raymond M., Kraft, Alan, Glassman, Sidney and Jepson, William. Partial Hospitalization for the Mentally Ill. Washington, D.C.: The Joint Information Service, 1969.

Gove, Walter R. "Societal Reaction as an Explanation of Mental Illness: An Evaluation." American Sociological Review, Vol. 35 (October, 1970), p. 873-84.

Gove, Walter R. and Fair, Jerry. "The Stigma of Mental Hospitalization." Archives of General Psychiatry, Vol. 38 (April, 1973), p. 494-500.

Greenblatt, Levison, Klernan, Enalt. Mental Patients in Transition. Springfield, Illinois, Charles C. Thomas, 1961.

Grenny, G.W. and Crandell, A. "A Mental Patient from State Hospital to Community: A Follow-up Study of Patients Moving from a State Hospital." Fairfield, California: Solano County Mental Health Services, 1973.

Grocetti, Guido, Spiro, Herzl R., and Siassi, Iradj. "Are the Ranks Closed? Attitudinal Social Distance and Mental Illness." The American Journal of Psychiatry, Vol. 127, (March, 1971), p. 1121-27.

Gumrukcu, Patricia. "The Efficacy of a Psychiatric Halfway House: A Three Year Study of a Therapeutic Residence." The Sociological Quarterly Journal of the Midwest Sociological Society, Vol. 9 , (Summer, 1968), p. 374-86.

Herbert, W. "NIMH Eyes New Support Systems: Seeking the Missing Rings in the Service Ladder." APA Monitor, Vol. 8 (7), (1977), p. 1-11.

Jacobson, Doris Seder. "From Protective Custody to Treatment in a Hurry." Social Work, Vol. 18, (1973), p. 55-64.

Jones, Maxwe11. "Community Care for the Chronic Mental Patients: The Need for a Reassessment." Hospital and Community Psychiatry, Vol. 26 (2), February, 1975, p. 94-98.

Joint Commission on Accreditation of Hospitals. "Principals for Accreditation of Community Mental Health Service Programs" 1975. Unpublished paper.

Joint Commission on Mental Illness and Health. Action for Mental Health: Final Report of the Joint Commission on Mental Illness and Health, New York, N.Y.: John Wiley and Sons, Inc., 1961. 
Kantor, Lyle E., Kausch, Donald F. and Smith, Linda L. "Development of an Aftercare Program in a Nonmetropolitan Area." Community Mental Health Journal, Vo1. 14, (Spring, 1978), p. 46-53.

Katkin, Steven, Zimmerman, Virginia, Rosenthal, Jonathan, Ginsburg, Marshall. "Using Volunteer Therapists to Reduce Hospital Readmissions." Hospital and Community Psychiatry, Vol. 26 (3), (March, 1975), p. 151-153.

Keith, Samuel J. "Community Support Systems: Multifaceted Approaches to a Complex Problem." Schizophrenia Bulletin, Vol. 4 (3), (1978), p. $316-318$.

Kennedy, J.F. Message from the President of the United States Relative to Mental Illness and Mental Retardation, 88 th Congress, First Session, U.S. House of Representatives Document No. 58, Washington, D.C.: U.S. Government Printing Office, 1963.

Keskiner, A. and Zalcman, M. "Returning to Community Life: The Foster Community Model." Diseases of the Nervous System. Vo1. 35 (1974), p. 419-426.

Kittrie, Nicholas N. The Right to Be Different: Deviance and Enforced Therapy. The John Hopkins Press, 1971.

Knight, James \& Davis, Winborn. Manual for Comprehensive Community Mental Health Clinic. Springfield, Illinois: Charles C. Thomas, 1964.

Koenig, Peter. "The Problem That Can't Be Tranquilized." The New York Times Magazine. May 21, 1978, p. 3-6.

Kraus, Ernest A. Pathways Back to the Community. San Francisco: Spring Publishing Co., 1970 .

Lamb, H. Richard. Community Survival for Long-Term Patients. San Francisco: Jossey-Bass Publishers, 1974.

Lamb, H. Richard. "An Educational Model for Teaching Living Skills to Long-Term Patients," Hospital and Communtty Psychiatry. Vol. 27 (12), (December, 1976), p. 875-877.

Landy, David and Greenblatt, Milton. Halfway House (U.S. Dept. of Health, Education \& Welfare), 1965, Washington, D.C.

Long, Nicholas, "A Model for Coordinating Human Services." Administration for Mental Hea1th. (Summer, 1974), p. 21-27.

Lynton, Rolf P. "Linking an Innovative Subsystem into the System." Administrative Science Quarterly. Vol. 14, (1969), p. 388-415. 
Magaziner, Ellen, McCarthy, Kathleen and Staffel, Reyn. "Strategies for Reducing Recidivism of Mental Patients in Region I," MSW practicum, Portland State University, 1976.

Marshal1, Helen. Dorothea Dix: Forgotten Samaritan, University of North Carolina Press, 1937.

Mechanic, David. Mental Health \& Social Policy. Englewood, New Jersey: Prentice-Hal1, Inc., 1969.

Mental Health Association of Oregon. Final Report of the Task Force on Services for the Chronically Mentally I1l. (October, 1978): p. 1-8. Unpublished report.

Mental Health Study Act of 1955 (Public Law 84-182), p. 381-383.

Moore, Pam. "GAO Urges Greater Effort on Community Care." APA Monitor, Vol. 8 (2), (1977), p. 1-16.

NatIonal Institute of Mental Health, Division of Biometry. Re-admissions to Inpatient Services of State and County Mental Hospitals. 1972. Statistical Note 110, Rockville, Maryland: U.S. Department of Health, Education and Welfare, 1974.

National Mental Health Act, 1946 (Public Law 79-487), p. 91-96.

Ochberg, Frank M. "Community Mental Health Center Legislation: F1ight of the Phoenix." American Journal of Psychiatry. Vol. 133 (1), (January, 1976), p. 56-61.

Ozarin, Lucy D. "Community Alternatives to Institutional Care." American Journal of Psychiatry, Vo1. 133 (1), (January, 1976), p. $69-72$.

Pasamanick, Benjamin, Scarpitti, Frank R. and Dinitz, Simon. Schizophrenics in the Community: An Experimental Study in the Prevention of Hospitalization. New York: Appleton-Century-Crofts, 1967.

Peterson, Ronald. What Are the Needs of Chronic Mental Patients? Presented at the APA Conference on the Chronic Mental Patient. Washington, D.C.: January 11-14, 1978.

Place, D.M. and Weiner, S. Reentering the Community: A Pilot Study of Mentally Ill Patients Discharged from NAPA State Hospital. Menlo Park, California: Stanford Research Institute, June, 1974.

"The Plight of the Delnstitutionalized Mental Patient." Science, Vo1. 200, (June 23, 1975), p. 1366.

Polak, Paul and Jones, Maxwe11. "The Psychiatric Nonhospital: A Model for Change," Community Mental Health Journal. Vol. 9 (2), (1973), p. $123-132$. 
President's Commission on Mental Health, Preliminary Report, Washington D.C., 1977.

Purvis, S.A. and Miskimins, R.W. "Effects of Community Follow-up on Post-Hospital Adjustment of Psychiatric Patients." Community Mental Health Journal, Vol. 6 (5), (1970), p. 374-382.

Rabkin, Judith. "Public Attitudes Toward Mental Illness. A Review of the Literature." Schizophrenia Bulletin, Vol. 10 (4), p. 9-33.

Rapoport, Rhona and Rapoport, Robert N. "Pattent's Families: Assets and Liabilities," in Greenblatt, Milton, et.al. Mental Patients in Transition. Springfield, Illinois: Charles C. Thomas Publisher, 1961.

Raush, H.L. and Raush, C.L. The Halfway House Movement: A Search for Sanity. New York: Appleton, 1968.

Reich, R. and Siega1, L. "The Chronically Mentally IIl Shuffle to Oblivion." Psychiatric Annals. Vo1. 3, November, 1973.

Richmond, C. "Expanding the Concepts of the Halfway House: A Satellite Housing Program." International Journal of Social Psychiatry, Vol. 16, $(1969-70), \frac{96-102 .}{9}$

Rosenhan, D.L. "On Being Sane in Insane Places." Science. Vol. 179, (January, 1973), p. 250-258.

Sanda11, Hilary, Hawley, Timothy, and Gordon, Gloria. "The St. Louis Community Homes Program: Graduated Support for Long-Term Care." The American Journal of Psychiatry. "Vo1. 132, (June, 1975), p. 617-22.

Sanders, David H. "Innovative Environments in the Community: A Life for the Chronic Patient," Schizophrenia Bulletin. Vol. 1 (6), (Fall, 1972), p. 49-58.

Sarbin, Theodore R. and Mancuso, James C. "Failure of a Moral Enterprise: Attitudes of the Public Toward Mental Illness." Journal of Consulting and Clinical Psychology. Vol. 35 (2), $(1978)$, P. 159-173.

Schwartz, Carol C., Myers, Jerome K., and Astrachan, Boris M. "Psychiatric Labeling and the Rehabilitation of the Mental Patient." Archives of General Psychiatry. Vol. 31 (September, 1974), p. 329-34.

Sculthorpe, W.B. "Multiple Placements of Psychotic Patients in Foster Homes." Social Casework. Vol. 41, (1960), p. 517-523.

Segal, Stephen P. "Attitudes Toward the Mentally I11: A Review." Social Work. Vol. 23, (May, 1978), p. 211-17. 
Shean, G. "An Effective \& Self-Supporting Program of Community Living for Chranic Patients." Hospital and Community Psychiatry. Vol. 24, (1973), P. 97-99.

Sieder, V.M. and Califf, C.J. "Homemaker-mome Health Aid Service to the Mentally II1 \& Emotionally Disturbed." National Council For Homemaker Aids, 1972.

Silverstein, Max. Psychiatric Aftercare Planning for a Community Mental Health Service. Philadelphia, Pennsylvania: University of Pennsylvania Press, 1968.

Smith, W.G., and Hart, Donald W. "Community Mental Health: A Noble Failure?" Hospital and Community Psychiatry. Vol. 26 (9), (September, 1975), p. 581-603.

Sorenson, David A., Tannenbaum, Robert, and Tannenbaum, Deena. Harlem Valley Psychiatric Centers Model for Deinstitutionalization and Development of Community Linkages and Support Systems. Harlem Valley Psychiatric Center, August, 1977, Program Description.

Stein, Leonard and Test, Mary Ann. "Special Living Arrangements: A Model for Decision-Making," Hospital and Community Psychiatry. Vol. 28, (August, 1977), p. 608-610.

Stein, Leonard, Test, Mary Ann, and Marx, Arnold. "Alternative to the Hospital: A Controlled Study," American Journal of Psychiatry. Vo1. 132, (May, 1975), p. 517-521.

Szasz, Thomas. "The Myth of Mental Illness," in Exploring Madness: Experience, Theory and Research. James Fademan and Donald Keuman, eds., Belmont, California: Wadsworth Publishing Co., Inc., 1973.

Test, Mary Ann and Stein, Leonard I. "A Community Approach to the Chronically Disabled Patient." Social Policy. Vol. 8 (1), (May-June, 1977), p. 8-16.

Test, Mary Ann and Stein, Leonard. "Community Treatment of the Chronic Patient." Schizophrenia Bulletin. Vol 4 (3), (1978), p. 350-351.

Townsend, Ernest J. "Case Managers: Can They Pull the CSS Together?" Community Support Service Journal. Vol. 1, (September - October, 1978), P. 2-4.

Thresholds, 2700 North Lakeview Avenue, Chicago, Illinois, Program Description, 1978.

Turner, Judith Clark and TenHoor, William J. "The NIMH Community Support Program: Pilot Approach to a Needed Reform." Schizophrenia Bulletin. Vol. 4 (3), (1978), p. 319-344. 
Uri, Averam, Segal, Steven P. "Exclusion of the Mentally I11, Reflection of an 01d Problem In a New Context." Archives of General Psychiatry. Vol. 29, (July, 1973), p. 126-131.

Wechsler, H. "Transitional Dependence for Former Mental Patients: A Survey of Half-way Houses and Related Rehabilitative Facilities." Mental Hygiene. Vol. 45, (1961), p. 65-67.

Weiner, Bernard. "On Being Sane in Insane Places: A Process (Attributional Analysis) \& Critique." Journal of Abnormal Psychology, Vol. 84: 55, (1975), p. 433-41).

Zaitz, Leslie. "Family Blames Agencies for Mentally Ill Woman's Suicide," Portland, Oregon, The Oregonian, October 17, 1978, p. B3. 
APPENDIX A

INTERVIEW INSTRUMENTS AND CHECKLISTS 


\section{Department of Human Resources}

\section{OFFICE OF THE DIRECTOR}

318 PUBLIC SERVICE BUILDING, SALEM, OREGON 97310 PHONE 378-3033

The State Mental Health Division in cooperation with the Department of Human Resources has been the recipient of a federal contract to assist in the development of community support systems for chronically mentally ill adults. The Community Support Program (CSP) will focus on client needs in formal and natural support networks as well as issues of interagency coordination.

One part of the project research includes interviews that are being conducted in four counties. The interviews are designed to assess the components of support systems already in place in Oregon, as well as gaps and needs in the system. A report based on such interviews in Umatilla County has been completed. The end result will be a model or several models of a community support system based on information from various communities. This input will be combined with an examination of existing systems and modified to better meet Oregon's needs in this area. A three year plan will be developed in Spring 1979, based on this input, and as a final result, more federal dollars may be available for additional community programs for the chronically mentally ill.

The School of Social Work at Portland State University is collaborating with the Multnomah County Mental Health Division and the State Mental Health Division Community Support Project to accomplish the Multnomah County study. A group of graduate social work students from the School of Social Work is conducting the interviews and preparing the report for Multnomah County. This work, which contributes to the fulfillment of the Master's program research requirements for these students, is under the supervision of professors June Dunn, Barbara Friesen and Nancy Koroloff of the Portland State University faculty. 
The graduate students will be conducting interviews in Multnomah County during the months of November and December. In order to make the study as comprehensive as possible, they will be talking with staff from the following agencies: Community Mental Health.Programs; Adult and Family Services Division; Vocation Rehabilitation Division; Social Security Administration; and the Employment Division. These agencies were selected because 1) they are the main state and federal agencies responsible, in part, for the chronically mentally ill, and; 2) these agencies are most likely to be involved in a community support system. In addition, other public and private agencies serving this population and unique to Multnomah County will be included.

Members of the graduate student research group would like to include information from you in the study. will be contacting you within the next few days to schedule an interview time.

In order to provide you with some orientation to the Community Support Project, we have enclosed a copy of the CSP goals and philosophy statement.

A copy of the questions that will be asked during the interview is enclosed for your review. Base your responses to the questions on your own definition of chronically mentally ill.

Also enclosed is a Service Components Checklist. This checklist shows service components that might make up a total community support system and which may exist in your community. Please complete this checklist before your meeting.

If you have any questions, please call June Dunn at the Portland State University School of Social Work at 229-4897.

Sincerely,

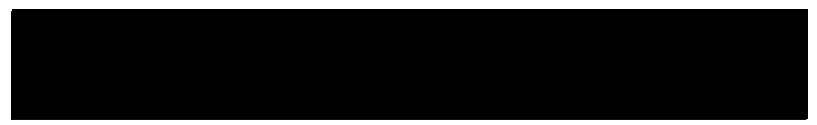

William Duke Morton

Deputy Director

Department of Human Resources
Ronald Milstein

Director

Multnomah County Mental

Health Program
Carol Cordes

Project Director

Community Support Program

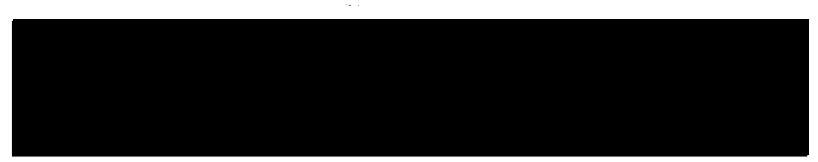




\section{COMMUNITY SUPPORT SYSTEM PROJECT \\ Department of Human Resources \\ Mental Health Division \\ 2575 Bittern Street NE. \\ Salem, Oregon 97310 \\ (503) $378-2178$}

Carol Cordes, Project Director

David J. Langenes, Ph.D., Project Researcher

\section{GOALS AND ASSUMPTIONS OF THE COMMUNITY SUPPORT PROGRAM}

The National Institute of Mental Health (NIMH) has recently funded sixteen Community Support Programs (CSPs) throughout the United States. Seven of the programs (of which Oregon has one) are operating at the state level, while the remaining nine involve local areas within certain states. The programs were funded initially for one year, with the possibility of funding for an additional two years.

The goals of these programs is to help devise a network of people in the community committed to assisting the chronic mentally and emotionally disabled adult to meet his/her needs and develop his/her potential without being unnecessarily isolated or excluded from the community (NIMH, 1977). In order to achieve this goal, various sub-goals must be achieved. They include:

1. Definition of the target population.

2. Identification of needs and potential of target population.

3. Assessment of services currently available for target population.

4. Identification of undeveloped community resources.

5. Legislative, financial, and administrative cooperation.

Underlying these goals are a number of working assumptions that are shared by the CSP staff. They include:

1. Traditional institutional care (e.g., hospitalization) of the target population is beset with problems that include cost, human and civil rights, and the side effects of extended hospitalization. Therefore, it is desirable to investigate and develop alternatives to hospitalization (NIMH, 1977).

2. Simply returning individuals to their communities probably will not meet their needs (Bassuk and Gerson, 1978; Erickson, 1975; NIMH, 1977). 
3. Community support and follow-up care can prevent and/or reduce hospitalization (Bassuk and Gerson, 1978; Erickson, 1975).

4. Such support and care needs to be addressed to a1l aspects of the individual's functioning (transportation, employment, social skills, leisure activities, residential facilities, etc.). (Erickson, 1975, Turner, 1978, attached).

5. Mental Health systems cannot assume total responsibility for the target population (Bassuk and Gerson, 1978), but it is appropriate that they assume leadership for developing community support systems (NIMH, 1977).

6. Members of the target population have needs, strengths, and potential which should not be ignored or wasted (NIMH, 1977; Peterson, 1978). To develop these strengths and potential, they should be as self-sufficient and maintain as much control over their lives as possible.

7. Significant (but often unnecessary) organizational, financial, social, and psychological barriers interfere with the delivery of services to and need reduction and personal development of the target population (Bassuk and Gerson, 1978, NIMH, 1977).

8. Untapped resources (social, financial, etc.) do exist in the community and can have a significant impact on the lives of the target population.

9. An effective and efficient method to deliver services to and help meet the needs of the target population is to have a "core service agency" that is committed to these goals (Turner, 1978). (Such an agency need not provide services to meet all of those needs.)

10. Equally important as (9.) is the existence of a case manager responsible for maintaining contact with the client on a continuing basis and serving as an advocate and liaison between service agencles, groups, and individuals who can help the client meet his/her needs and assist in developing his/her potential (Turner, 1978).

As Information is collected over the year, the CSP staff will be better able to test these assumptions and their relevance to Oregon and its various regions. 


\section{REFERENCES}

Bassuk, E.L., \& Gerson, S. Desinstitutionalization and Mental Health Services. Scientific American, 1978, 238, 46-53.

Erickson, R.C. Outcome Studies in Mental Hospitals: A review. Pscyhological Bulletin, 1975, 82, 519-540.

NIMH. Program Description: The NIMH Community Support Program (CSP). Washington: National Institute of Mental Health, 1977.

Peterson, R. What are the needs of the Chronic Mental Patient. Paper presented at the January, 1978 meeting of American Psychiatric Association, Washington, D.C.

Turner, J.E. Defining a Community Support System. Hospital \& Community Psychiatry, 1978, 29, 31-32. 


\section{INSTRUCTIONS}

is is a list of service mponents that might make a total corsunity support scei for chrontc mentally d emorlonally disabled ules.

are trying to determine lch of these cooponents I avallable for this popat on in your comunity. sase check the ones that : provided directly by II agency, as well as those it are available elsewhere your comounity.

the service 1 s not provided if you don't knov if it is ivided, please leave the ce blank. Feel free to any other service compon3 you think need to be luded.

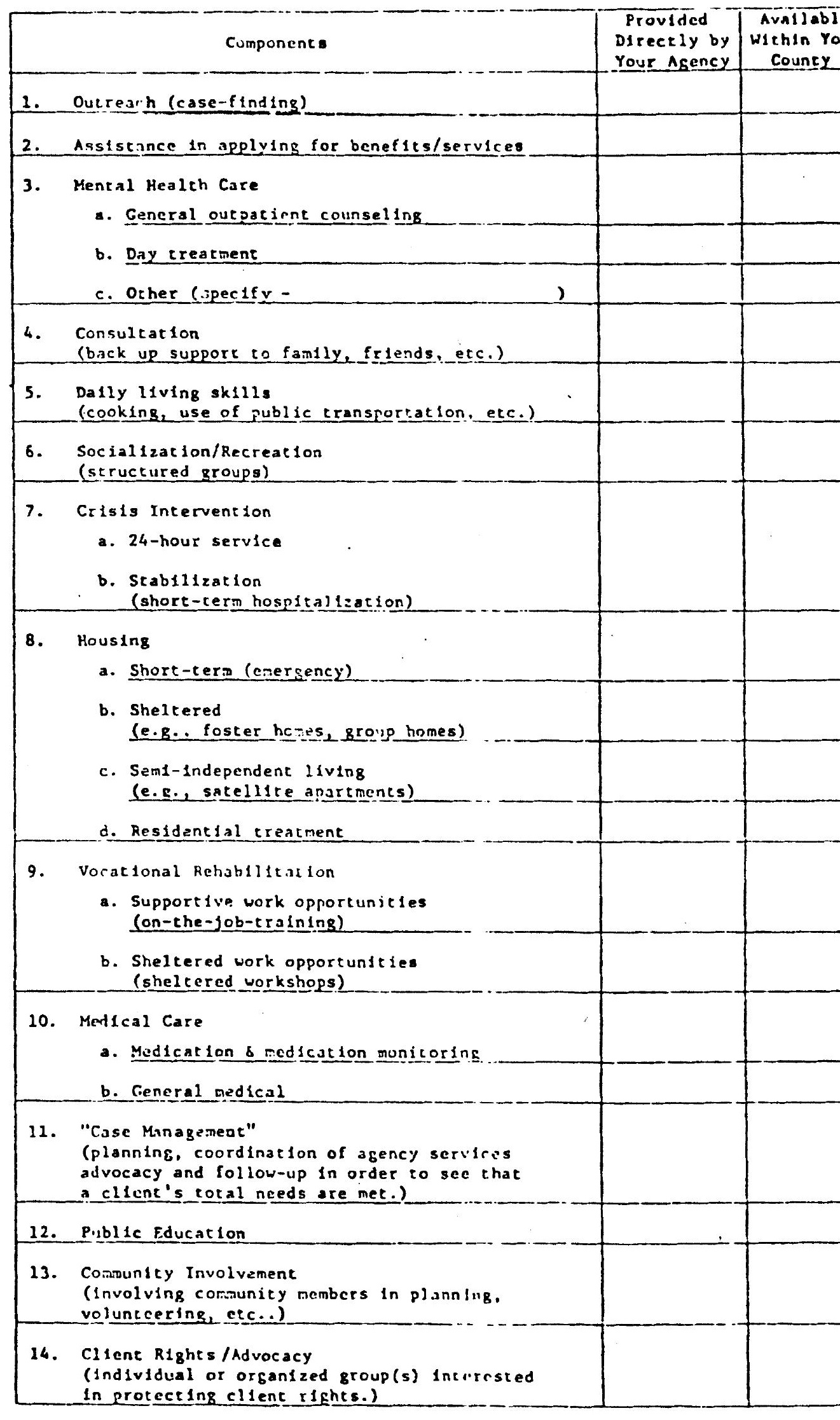


1. What are the most significant problems of the chronic mentally 111 in your community?

2. How do individuals in this group spend their free time (in your community)?

3. Do people in this group tend to cluster (e.g. live, recreate) in any specific geographic area(s) in the community?

4. Which services provided by your agency are most heavily used by the chronic mentally ill?

5. How do agencies in this county work together to meet the needs of a shared client?

6. What would you do in order to improve existing services in order to more adequately meet the needs of this population? What would you change both in your agency and in other agencies?

7. Is case management* occurring for this group either formally or Informally? For instance: What happens when someone is discharged from a hospita1? Is anyone responsible for seeing that they have a service plan and that it is carried out?

*Definition of Case Management: Planning, coordination of agency services, advocacy, and follow-up in order to see that a client's total needs are met. It involves coordin- ation within and between agencies.

8. If funds and staff were provided to do interagency case management, what do you think would be the best way to do it?

9. Are there any community organizations providing services or showing an interest in this population, such as service clubs, church groups, etc.?

10. Are there any citizens of the community who are advocates for this group or could become advocates? (Such as agency personnel, business leaders, government officials)

11. How accepting is the community of the chronic mentally ill who are living in the community?

12. What spectal skills do you feel are needed by your agency staff in order to serve this population?

13. What kinds of training does your staff receive in regard to this population? 

DATE

AGENCY INTERV IENER

BEFORE THE INTERVIEW

I-INTRODUCE YOURSELF

2-THANK THE RESPONDENT FOR TAKING THE TIME TO BE INTERVIEWED

3-EXPLAIN THAT:

A-WE ARE COLLECTING DATA TO ASSESS EXISTING SERVICES FOR THE CHRONICALLY MENTALLY ILL IN MULTNOMAH COUNTY. WE WANT TO IDENTIFY SOME OF THE STRENGTHS AND WEAKNESSES IN THE EXISTING SERVICE DELIVERY SYSTEM AND WOULD LIKE TO HEAR THEIR IDEAS FOR IMPROVING WHAT PRESENTLY EXISTS. THIS INFORMATION WILL BE USED IN DEVELOPING A THREE-YEAR PLAN FOR FURTHER DEVELOPMENT OF COMMUNITY SUPPORT SYSTEMS IN OREGON.

B-WE (A GROUP OF PSU, SSW STUDENTS) ARE WORKING IN COLLABORATION WITH THE COMMUNITY SUPPORT PROJECT AND MULTNOMAH COUNTY MENTAL HEALTH TO COLLECT THE DATA.

(NOTE: YOU WILL NEED TO DECIDE HOW MUCH DETAIL ABOUT A AND B THE RESPONDENT NEEDS, BASED ON HOW THEY RECEIVE YOU, WHETHER OR NOT THEY REMEMBER THE LETTER, ETC.)

4-MAKE IT CLEAR THAT ALL QUESTIONS PERTAIN TO THE CHRONIC MENTALLY ILL POPULATION. AT THIS POINT, ASK THE INTERVIEWEE WHAT HIS DEFINITION OF CHRONIC IS, OR WHAT IT MEANS TO HIM. (IF THIS IS DIFFERENT FROM WHAT WE MEAN BY CHRONIC, WE HAD BETTER CLARIFY WITH A BRIEF SYNOPSIS OF THE CSP DEFINITION)

DEFINITION OF CHRONIC:

5-THE CSS CHECKLIST (WHICH WAS SENT IN ADVANCE) SHOULD BE COLLECTED NEXT. IT SHOULD BE MADE CLEAR THAT CSP'S PLAN IS TO DEVELOP A MODEL PROGRAM BASED UPON AN IDEA LIKE THIS, BUT PROBABLY WILL NOT DUPLICATE IT. IF THE INDIVIDUAL DID NOT RECEIVE THE. CHECKLIST, OR DID NOT COMPLETE IT, ASK HIM/HER TO COMPLETE IT NOW. THEY ARE TO INDICATE WHAT SERVICES THEIR AGENCY PROVIDES AND WHICH ARE PROVIDED BY OTHERS BY CHECKING THE PROPER COLUMN. IF THEY DO NOT KNOW ABOUT A PARTICULAR SERVICE, HAVE THEM LEAVE THE LINE BLANK. 
6-OPTIONAL QUESTION WHEN APPROPRIATE, YOU MIGHT BEGIN THE INTERVIEW BY ASKING ABOUT THEIR MOST SUCCESSFUL AND LEAST SUCCESSFUL CASES. THIS MAY BE MOST APPLICABLE FOR COMMUNITY MENTAL HEALTH PROGRAMS, THOUGH IT MAY HELP BREAK THE ICE TO GO IN THIS DIRECTION IN OTHER AGENCIES.

\section{THE INTERVIEW}

IA-WHAT ARE THE MOST SIGNIFICANT PROBLEMS OF THE CHRONIC MENTALLY ILL IN YOUR COMMUNITY? (CHECK AS MANY AS APPLY, AND RECORD SPECIFIC COMMENTS)

LACK OF EMPLOYMENT

LACK OF RESIDENTIAL SITUATIONS

LACK OF CASE MANAGEMENT/SERVICE COORDINATION

LACK OF TRANSPORTATION

LIMITED FINANCIAL RESOURCES OF CLIENT

OTHER (SPECIFY)

IB-ARE THERE SPECIAL PROBLEMS FOR ANY MINORITY GROUPS WITHIN THAT POPULATION? 
2-HOW DOES A CHRONIC MENTALLY ILL PERSON SPEND HIS/HER TIME IN THE COMMUNITY? (RECORD ALL ACTIVITIES MENTIONED)

3A-DO PEOPLE IN THIS GROUP TEND TO CLUSTER (E.G., LIVE, RECREATE) IN ANY SPECIFIC GEOGRAPHIC AREAS IN THE COMMUNITY? (LIST SPECIFIC AREA)

IF YES:

3B-DO YOU KNOW WHAT IT IS ABOUT THIS AREA THAT ATTRACTS THIS GROUP?

(CHECK AS MANY AS APPLY, AND RECORD SPECIFIC COMMENTS)

RESIDENT IAL

EATING

SOCIAL/RECREAT IONAL

OTHER (SPECIFY)

3C-DOES THIS AGENCY PLACE ANY SPECIAL EMPHASIS ON WORKING WITH PEOPLE IN THOSE AREAS?

YES NO

IF YES, IN WHAT WAYS? 
4A-WHAT SERVICES PROVIDED BY YOUR AGENCY ARE MOST HEAVILY USED BY THE CHRONIC MENTALLY ILL? (CHECK AS MANY AS APPLY AND RECORD SPECIFIC COMMENTS)

VOCATIONAL TRAINING/PLACEMENT

FINANCIAL AID

THERAPY/COUNSELING

RESIDENTIAL PLACEMENT

TRANSPORTATION

DAILY LIVING STILLS TRAINING

SOCIALIZATION/RECREATION

MEDICAL CARE/MEDICATION

EDUCATION

LEGAL SERVTICE

ASSISTANCE IN APPLYING FOR BENEFITS/SERVICES OTHER (SPECIFY)

4B-HOW DO CLIENTS GET INTO THOSE SERVICES (REFERRAL SOURCES).

(LIST SPECIFIC REFERRAL SOURCES)

INTER-AGENCY REFERRAL

INTER-AGENCY REFERRAL

SELF REFERRAL

5-HOW DO AGENCIES IN THIS COUNTY WORK TOGETHER TO MEET THE NEEDS OF SHARED CLIENTS?

(PROBE: WHAT DO YOU DO WHEN YOU GET AN INAPPROPRIATE REFERRAL?)

LIST EXAMPLES: 
6-WHAT WOULD YOU DO TO IMPROVE EXISTING SERVICES IN ORDER TO MORE ADEQUATELY MEET THE NEEDS OF THIS POPULATION? WHAT WOULD YOU CHANGE BOTH IN YOUR AGENCY AND IN OTHER AGENCIES? (PROBE: WHAT DO YOU SEE AS THE STRENGTHS AND WEAKNESSES IN THE EXISTING SYSTEM?) LIST SPECIFIC SUGGESTIONS.

7-IS CASE MANAGEMENT* OCCURING FOR THIS GROUP EITHER FORMALLY OR INFORMALLY? (FOR INSTANCE: WHAT HAPPENS WHEN SOMEONE IS DISCHARGED FROM A HOSPITAL? IS ANYONE RESPONSIBLE FOR SEEING THAT THEY HAVE A SERVICE PLAN AND THAT IT IS CARRIED OUT?)

*CASE MANAGEMENT: PLANNING, COORDINATION OF AGENCY SERVICES, ADVOCACY AND FOLLOW-UP IN ORDER TO SEE THAT A CLIENT'S TOTAL NEEDS ARE MET. IT INVOLVES COORDINATION WITHIN AND BETWEEN AGENCIES.

YES, THERE IS CASE MANAGEMENT

NO, THERE IS NO CASE MANAGEMENT

EXAMPLES : 
8A-IF FUNDS AND STAFF WERE PROVIDED TO DO INTERAGENCY CASE MANAGEMENT, WHAT DO YOU THINK WOULD BE THE BEST WAY TO DO IT? (SPECIFY METHOD)

8B-SHOULD IT BE THE RESPONSIBILITY OF ONE AGENCY?

YES

NO

IF YES, WHICH ONE?

8C-WHAT KINDS OF PROBLEMS WOULD YOU ANTICIPATE IN THE DEVELOPMENT OF GREATER INTERAGENCY CASE MANAGEMENT?

9-ARE THERE ANY COMMUNITY ORGANIZATIONS PROVIDING SERVICES OR SHOWING AN INTEREST IN THIS POPULATION, SUCH AS SERVICE CLUBS, CHURCH GROUPS, ETC.?

(LIST THE ORGANIZATION AND SPECIFY THEIR INVOLVEMENT) 
10-ARE THERE CITIZENS OF THE COMMUNITY WHO ARE ADVOCATES FOR THIS GROUP OR COULD BECOME ADVOCATES?

(SUCH AS AGENCY PERSONNEL, BUSINESS LEADERS, GOVERNMENT OFFICIALS?)

11-HOW ACCEPTING IS THE COMMUNITY OF THE CHRONIC MENTALLY ILL WHO ARE LIVING IN

THE COMMUNITY?

ACCEPTING

NEUTRAL

REJECTING

OTHER (SPECIFY)

ASK FOR EXAMPLES OF ACCEPTANCE OR REJECTION:

12-WHAT SPECIAL SKILLS DO YOU FEEL ARE NEEDED BY YOUR AGENCY STAFF IN ORDER TO SERVE THIS POPULATION? (PROBE: IS SPECIAL TRAINING NEEDED?) 
I3A-WHAT KIND OF TRAINING DOES YOUR STAFF RECEIVE IN REGARD TO THIS POPULATION?

PRE-SERVICE

ORIENTATION

IN-SERVICE

ACADEMIC (E.G., COLLEGE CLASSES)

13B-WHAT ARE THE DEFICITS IN EXISTING TRAINING?

(PROBE: AVAILABILITY OF TRAINING)

14-CAN YOU GIVE US A BREAKDOWN OF THE AMOUNT OF STAFF TIME THAT YOUR AGENCY GIVES TO THE CHRONIC MENTALLY ILL? (PROBE: IS THERE ONE PERSON WHO HAS AN ASSIGNED CASELOAD OF CHRONICS?)

NOTE: WHEN ASKING FOR INFORMATION ABOUT STAFF TIME, ASK IF THERE IS A DOCUMENT AVAILABLE THAT GIVES THIS INFORMATION. ATTACH DOCUMENT TO THIS SCHEDULE. 
15-ARE THERE ANY USER (UTILIZATION) DATA IN PRINTED FORM (E.G., GRANT APPLICATIONS, EVALUATION DATA, CLIENT DESCRIPTIVE DATA) THAT WE COULD HAVE A COPY OF? (THIS IS TO DETERMINE HOW MANY PEOPLE ARE USING THE SERVICES AND THEIR CHARACTERISTICS-ATTACH TO THIS SCHEDULE)

16-ARE THERE ANY OTHER THINGS THAT YOU WOULD LIKE TO SAY THAT WE HAVE NOT ASKED ABOUT? 
HE INTERVIEWER SHOULD NOT FILL IN HIS/HER IMPRESSIONS UNTIL AFTER LEAVING THE NTERVIEW SITUATION. THEY SHOULD BE FILLED IN AS SOON AS POSSIBLE AFTER LEAVING.

-WHAT KIND OF ANSWERS (E.G., SHORT, RAMBLING, INSIGHTFUL, DUBIOUS) WERE GIVEN?

-WHAT INDICATIONS DID THE INTERVIEWEE'S PROVIDE OF HIS/HER DEGREE OF INTEREST IN ITHE CHRONICALLY MENTALLY ILL? (E.G., ASKED YOU A LOT OF QUESTIONS)

-WAS THIS AN EASY OR DIFFICULT INTERVIEW FOR YOU TO CONDUCT? WHY?

4-OTHER COMMENTS ABOUT THE INTERVIEW (E.G., LOCATION, NOISE LEVEL, INTERRUPTIONS). 
DATE

AGENCY

INTERV IEWER

BEFORE THE INTERVIEW

1-INTRODUCE YOURSELF

2-THANK THE RESPONDENT FOR TAKING THE TIME TO BE INTERVIEWED

3- EXPLAIN THAT:

A-WE ARE COLLECTING DATA TO ASSESS EXISTING SERVICES FOR THE

MENTALLY

ILL IN MULTNOMAH COUNTY. WE WANT TO IDENTIFY SOME OF THE STRENGTHS AND WEAKNESSES

IN THE EXISTING SERVICE DELIVERY SYSTEM AND WOULD LIKE TO HEAR THEIR IDEAS FOR

IMPROVING WHAT PRESENTLY EXISTS. THIS INFORMATION WILL BE USED IN DEVELOPING A

THREE-YEAR PLAN FOR FURTHER DEVELOPMENT OF COMMUNITY SUPPORT SYSTEMS IN OREGON.

B-WE (A GROUP OF PSU, SSW STUDENTS) ARE WORKING IN COLLABORATION WITH THE COMMUNITY SUPPORT PROJECT AND MULTNOMAH COUNTY MENTAL HEALTH TO COLLECT THE DATA.

THE INTERVIEW

IA-WHAT ARE THE MOST SIGNIFICANT PROBLEMS OF THE PERSON WHO'S BEEN IN THE HOSPITAL A LOT IN YOUR COMMUNITY? (CHECK AS MANY AS APPLY, AND RECORD SPECIFIC COMMENTS)

LACK OF EMPLOYMENT

LACK OF RESIDENTIAL SITUATIONS

LACK OF CASE MANAGEMENT/SERVICE COORDINATION

LACK OF TRANSPORTATION

LIMITED FINANCIAL RESOURCES OF CLIENT

OTHER (SPECIFY) 
1B-ARE THERE SPECIAL PROBLEMS FOR ANY MINORITY GROUPS WITHIN THAT POPULATION?

2 - HOW DO YOU SPEND YOUR TIME IN THE COMMUNITY?

(WHAT TIME DO YOU USUALLY GET UP?)

(DO YOU WORK?)

(HOW OFTEN DO YOU PARTICIPATE IN SOCIAL ACTIVITIES?)

(ETC.)

3A-ARE THERE ANY PARTICULAR PLACES IN THE COMMUNITY WHERE YOU LIKE TO SPEND TIME?

IF YES:

3B-WHAT IS IT ABOUT THIS AREA THAT ATTRACTS YOU?

(CHECK AS MANY AS APPLY, AND RECORD SPECIFIC COMMENTS)

RESIDENTIAL

EATING

SOCIAL/RECREATIONAL

OTHER (SPECIFY) 
4 -WHAT TYPE OF TRANSPORTATION DO YOU USE TO GET AROUND THE CITY?

IS THAT SATISFACTORY?

5A-DO YOU RECEIVE HELP FROM ANY SOCIAL SERVICE AGENCIES? (CHECK AS MANY AS APPLY AND RECORD SPECIFIC COMMENTS)

WHAT WHERE COMMENTS

VOCATIONAL TRAINING/PLACEMENT

FINANCIAL AID

THERAPY/COUNSELING

RESIDENTIAL PLACEMENT

TRANSPORTATION

DAILY LIVING SKILLS TRAINING

SOCIALIZATION/RECREATION

MEDICAL CARE/MEDICATION

EDUCATION

LEGAL SERVICE

ASSISTANCE IN APPLYING FOR

BENEFITS/SERVICED

OTHER (SPECIFY)

|

5B-ARE YOU SATISFIED WITH THE HELP YOU'RE GETTING?

IF NO:

WHY NOT? WHAT CAN YOU SUGGEST TO MAKE THIS HELP BETTER? 
5C-HOW DID YOU GET IN TOUCH WITH THESE SERVICES?

(DID SOMEONE HELP YOU OR SUGGEST WHERE YOU COULD GO?)

6 -DO YOU KNOW OF WAYS THESE PROGRAMS WORK TOGETHER TO HELP YOU GET WHAT YOU NEED?

LIST EXPAMPLES:

7A-ARE THERE OTHER KINDS OF PROGRAMS OR SERVICES YOU NEED?

7B-IS THERE SOMEONE WHO HELPS YOU FIND THE SERVICES YOU NEED?

8 -IN GENERAL, HOW DO YOU THINK PEOPLE IN THIS COMMUNITY FEEL ABOUT PEOPLE WHO HAVE BEEN IN A MENTAL HOSPITAL?

ACCEPTING

NEUTRAL

REJECTING

OTHER (SPECIFY)

CAN YOU GIVE EXAMPLES? 
9 -ARE THERE ANY OTHER THINGS THAT YOU WOULD LIKE TO SAY THAT WE HAVE NOT ASKED ABOUT? 
HE INTERVIEWER SHOULD NOT FILL IN HIS/HER IMPRESSIONS UNTIL AFTER LEAVING THE NTERVIEW SITUATION. THEY SHOULD BE FILLED IN AS SOON AS POSSIBLE AFTER LEAVING.

-WHAT KIND OF ANSWERS (E.G., SHORT, RAMBLING, INSIGHTFUL, DUBIOUS) WERE GIVEN?

:-WHAT INDICATIONS DID THE INTERVIEWEE'S PROVIDE OF HIS/HER DEGREE OF INTEREST

IN ITHE CHRONICALLY MENTALLY ILL? (E.G., ASKED YOU A LOT OF QUESTIONS)

3-WAS THIS AN EASY OR DIFFICULT INTERVIEW FOR YOU TO CONDUCT? WHY?

4-OTHER COMMENTS ABOUT THE INTERVIEW (E.G., LOCATION, NOISE LEVEL, INTERRUPTIONS). 


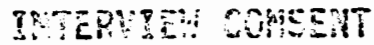

\section{TO THE CLIENS:}

In order to lean wore about the s?artienes of nente? ne? th saryces

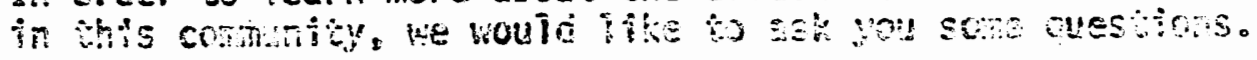

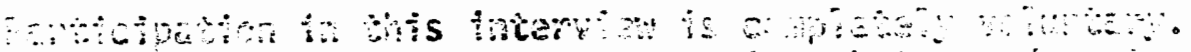

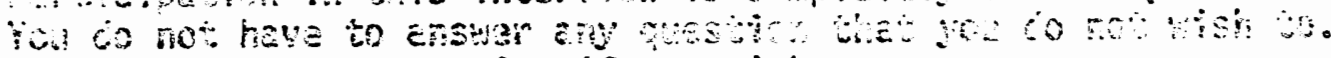

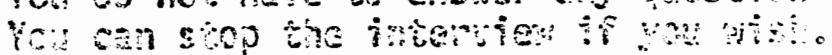

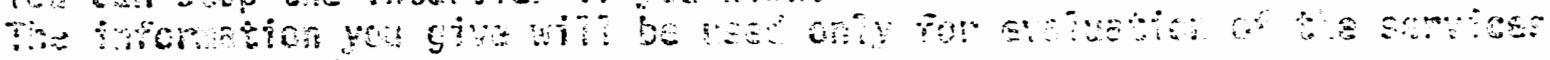
you recetes.

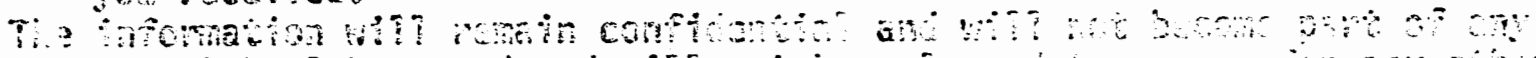

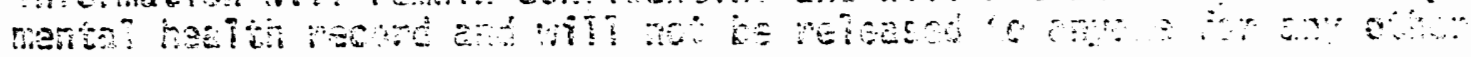

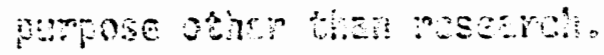

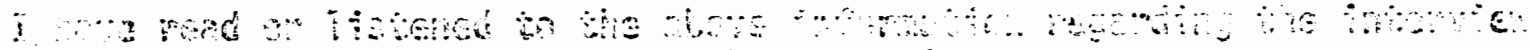

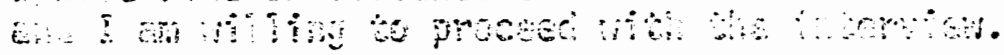

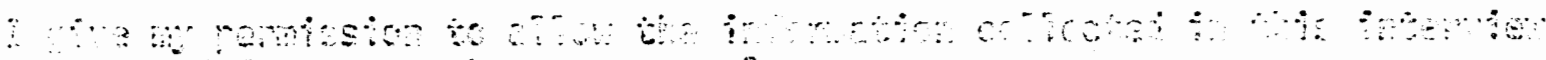
$\therefore \quad \because \because \because \because 9)$

$$
\text { An: }
$$


APPENDIX B

LIST OF PARTICIPANTS AND CHECKLIST RESULTS 


\section{LIST OF PARTICIPANTS}

Community Mental Health Agencies

University of Oregon Medical School - Outpatient Psychiatry Multnomah County Mental Health Involuntary Commitment Program Providence Day Treatment

Delauney Mental Health Center

Morrison Center

Outside - In

Community Mental Health Outpatient Component

S.E. Mental Health Clinic - 2 interviews

Multnomah County Mental Health - West Clinic

Multnomah County Mental Health

Center for Community Mental Health Day Treatment

Mental Health Deaf Project

Multnomah County Mental Health Administration

Group Care Facilities

Open Heart

Care Vista

Glendover Nursing Home and Retirement Villa

Lambert House

House of Care, Inc.

Rita Owen Group Home

Parry Center for Children

Agencies Providing Psychiatric In-Patient Services

Providence In-Patient Mental Hospital

V.A. Hospital

Portland Adventist Hospital

Woodland Park Mental Hospital

Cedar Hills Psychiatric

University of Oregon Health Science Center - Crisis Unit

University of Oregon Health Science Center - Ward SA (5f)

Dammasch State Hospital

Federal/State/Local Government Agencies

Portland Park Bureau

Social Security Administration - 2 branch offices

Pact Neighborhood Center

Adult and Family Services - S.E. Branch

Multnomah County Public Guardian and Conservator

Multnomah County Community Health Nurses

Adult and Family Services - Gresham

Licensing Bureau - Portland 


\section{Corrections}

Multnomah County Adult Corrections

Public Defender

Gresham Police

Portland Adult Corrections - Department of Vocational Rehabilitation

Multnomah County Sheriff Department

Multnomah County Corrections - Health Care

Nultnomah County Circuit Court - Probate

Agencies Dealing with Substance Abuse Problems

Hooper Memorial Center

Native American Rehabilitation Association (NARA)

Private Agencies

St. Vincent de Paul

Salvation Army Social Services

Indo-Chinese Service Center

Visiting Nurse's Association

Kaiser Mental Health

Portland Rehabilitation

American Red Cross - Military Family Service

Metropolitan Family Service

YWCA - Women's Resource Center

Loaves \& Fishes - Meals on Wheels

Goodwill

Tri-Community Council

NW Pilot Project on Aging

Volunteers of America - Adult Daycare

Recovery, Inc.

Mental Health Association

David's Harp

Northwest Counseling Associates

TMED

West Hills Counseling

Natural Helpers

Fryers Quality Pie

Governor Hotel

Westport Villa Hotel

Wheel of Fortune Restaurant

Others

Northwest District Association

Portland Rescue Mission

Private Social Worker

Friendly House

Ten clients, involved in community support systems, were also interviewed. 


\section{CHECKLIST RESULTS}

In order to assess the components of a community support system that exists in Multnomah County, a checklist of service components was developed. National Institute of Mental Health (NIMH) community support system components were used as a guide and then revised to better reflect Oregon's resource. The Umatilla County checklist served as a model. The resulting checklist (see appendix a) was mailed to service providers before the interview. Each person was requested to check which services are provided by his/her agency, and which are generally available in the county.

Seventy six checklists were returned at the time of the interview. This information was used to assess a composite knowledge of the community support system in Multnomah County. The following section will look at the NIMH components of a community support system and their relationship to what actually exists in the Oregon system, and in particular Multnomah County.

The components of a community support system defined by NIMH are as follows:

1) Identify the population at risk.

2) Help disabled persons apply for income, medical and other benefits.

3) Provide 24-hr., quick response crists assistance.

4) Provide psychosocial rehabilitation services.

5) Provide supportive services of indefinite duration.

6) Provide adequate medical and mental health care.

7) Offer backup support, assistance and consultation. 
8) Involve concerned community members.

9) Establish grievance procedures and mechanisms to protect client rights.

10) Facilitate the movement of clients through the system by case management.

Each of these will be discussed in terms of responses to the revised checklist.

Summary of Checklist Results.

1) Identify the population at risk.

a) Outreach. Twenty-one agencies of the $76(28 \%)$ reported that they did outreach.

2) Help disabled persons apply for income, medical and other benefits.

a) Assistance in applying for benefits/services. Forty-three agencies $(57 \%)$ indicated that they helped clients apply for benefits.

3) Provide 24 hour quick response crisis intervention.

a) Twenty-four hour crisis intervention. Twenty-two agencies (28\%) reported providing this service.

b) Crisis Intervention, Short Term Hospitalization. Eighteen agencies $(24 \%)$ reported providing this service.

4) Provide psychosocial rehabilitation services.

a) Daily Living Skills. Twenty-eight respondents (37\%) reported providing this service.

b) Socialization and Recreation. Thirty agencies (40\%) reported providing this service.

c) Vocational Rehabilitation.

1. On the job training. Twelve agencies reported that they provided this service.

2. Sheltered Workshop. Six agencies reported that they provided this service.

5) Provide supportive services of indefinite duration.

a) Housing, Emergency. Thirteen agencies reported providing this service. 
b) Housing, Sheltered. Nine agencies reported that they provide this service.

c) Housing, Semi-Independent. Three agencies reported

d) Housing, Residential Treatment. Eleven agencies reported that they provided this service.

6) Provide adequate medical and mental health care.
a) Mental Health Out-patient care. Twenty eight agencies (37\%) reported that they provide this service.
b) Mental Health Day Treatment. Fifteen agencies (20\%) reported that they provided day treatment services.
c) Mental Health, Other. Nineteen agencies reported providing other mental health services in addition to out-patient and day treatment services.
d) Medical Care, Medication Monitoring. Thirty-one agencies $(41 \%)$ reported that they provide this service.
e) Medical Care, General. Twenty-one agencies reported providing this service.

7) Offer backup support, assistance and consultation.
a) Consultation. Fifty-six (74\%) reported that they provided consultation services
b) Public Education. Twenty agencies (26\%) reported that they provided community education services.

8) Involve concerned community members.
a) Community Involvement. Thirty-four agencies (45\%) reported citizen involvement in their programs.

9) Establish grievance procedures and mechanisms to protect client rights.

10) Facilitate the movement of clients through the system by case management.
a) Case Management. Thirty agencies (39\%) reported providing case management services. 
How to Read the Tables

Seventy-six checklists were compiled out of a total of seventy-seven interviews, The service provider agencies were grouped into service categories, i.e. Corrections, Psychiatric Inpatient, etc.

Table $A b$ is the tabulation by each service category of service components provided by the agency. Table Ac is the tabulation by each service category of perceived service components available in the community. $\mathrm{N}$ equals the total number of respondents (76 agencies); $\mathrm{n}$ equals the total number of respondents in each service category (this number will vary).

Tables A1 - A9 contain the tabulations of service components provided by each agency in the service categories. Tables A10 - A18 contain the tabulations of service components avallable in the community, as perceived by each agency in the service categories. 


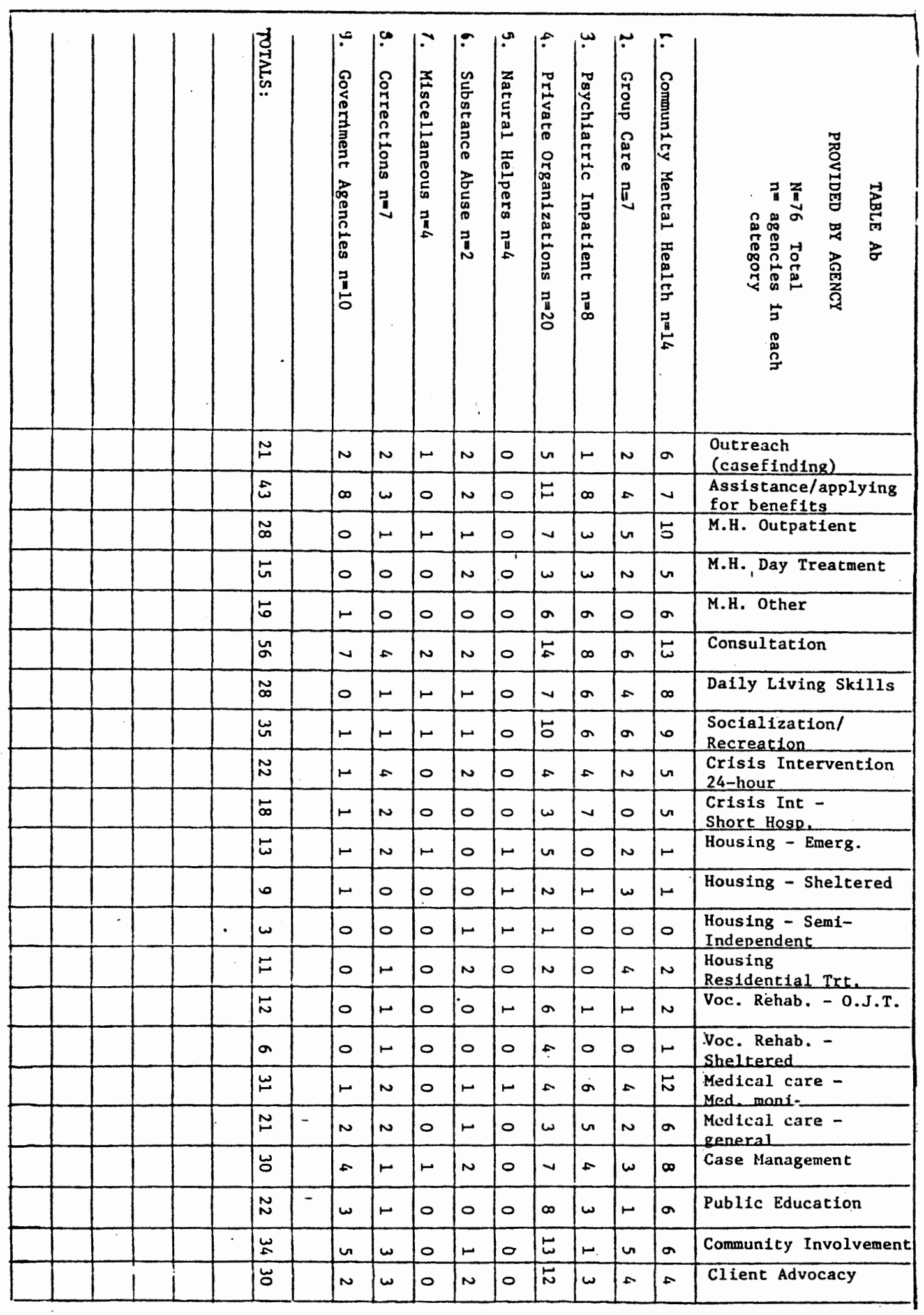




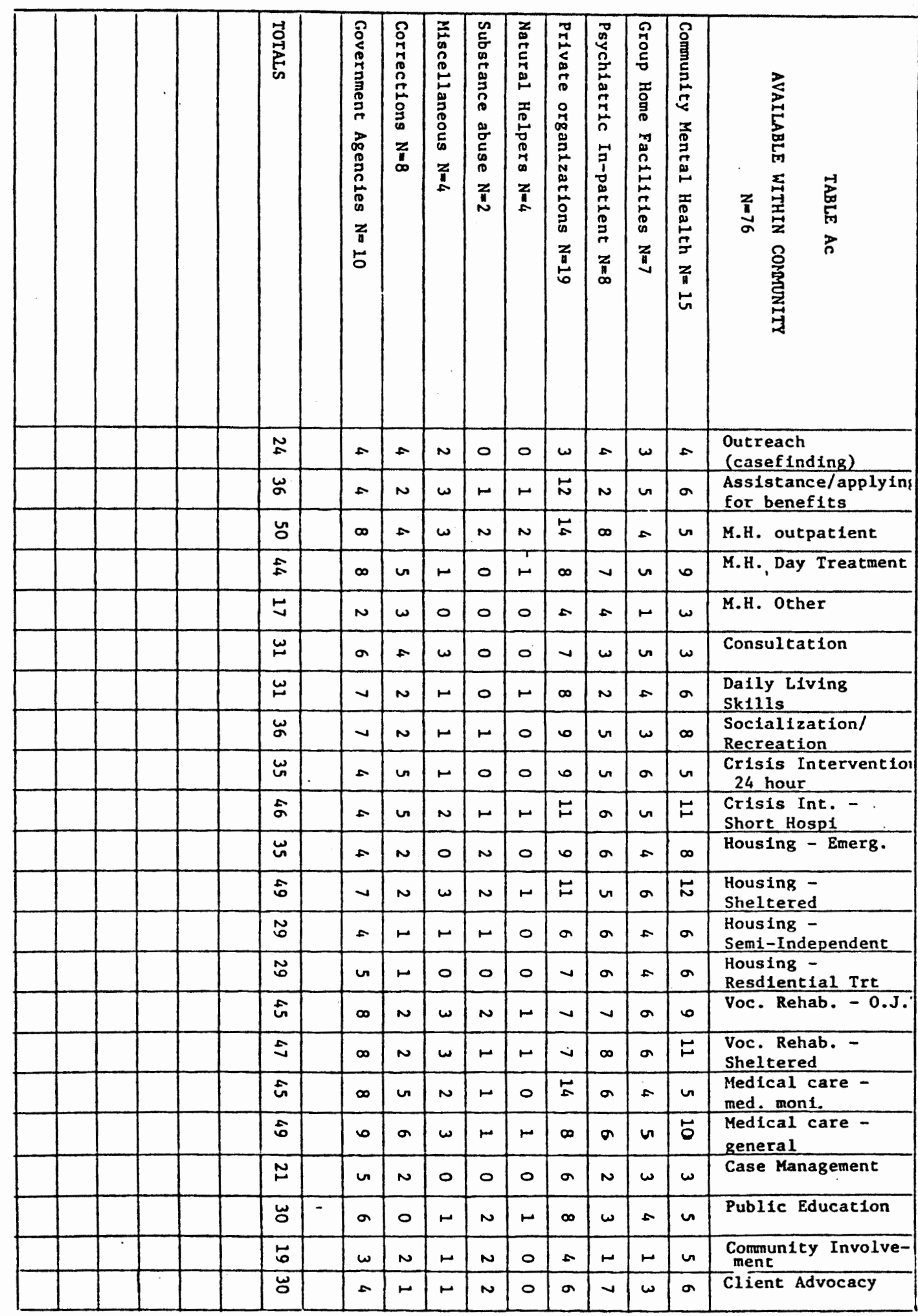




\begin{tabular}{|c|c|c|c|c|c|c|c|c|c|c|c|c|c|c|c|}
\hline 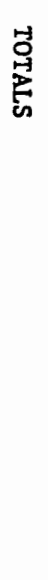 & $\begin{array}{l}3 \\
5 \\
? \\
0 \\
0 \\
3 \\
3 \\
3 \\
0 \\
0 \\
0\end{array}$ & 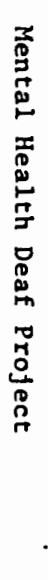 & 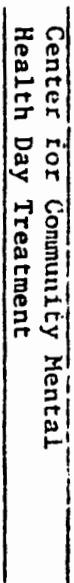 & 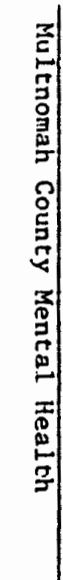 & 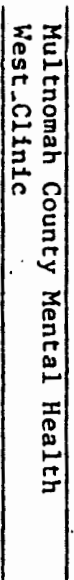 & 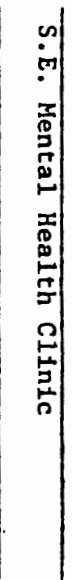 & 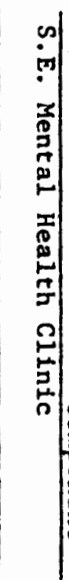 & 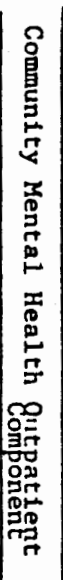 & 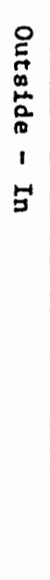 & $\begin{array}{l}7 \\
0 \\
0 \\
0 \\
0 \\
0 \\
0 \\
0 \\
0 \\
0 \\
0 \\
0 \\
0 \\
0 \\
0\end{array}$ & 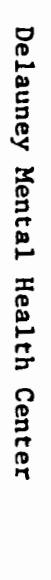 & 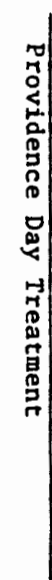 & 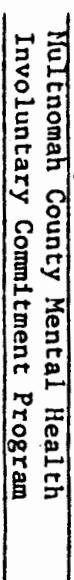 & 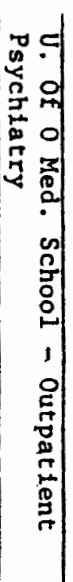 & 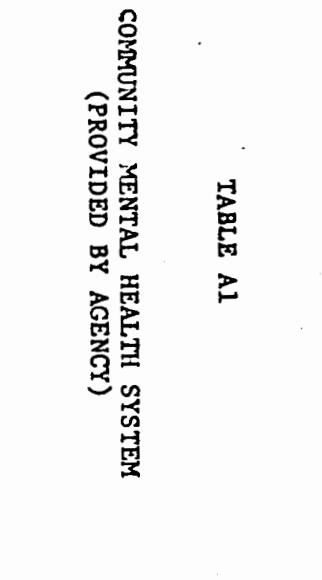 \\
\hline$a$ & $x$ & $x$ & & & $x$ & & $x$ & & & $x$ & & $x$ & & & $\begin{array}{l}\text { Oucreach } \\
\text { (casefinding) }\end{array}$ \\
\hline$v$ & $x$ & $x$ & & & $x$ & & $x$ & $x$ & & $x$ & & $x$ & & & $\begin{array}{l}\text { Assistance/applying } \\
\text { for benefits }\end{array}$ \\
\hline 5 & $x$ & $x$ & & $x$ & $x$ & $x$ & $x$ & $x$ & & $x$ & $x$ & & & $x$ & M.H. outparlent \\
\hline u & $x$ & $x$ & $x$ & & & & & $x$ & & 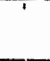 & & $x$ & & & M.H. ,Day Treatment \\
\hline$a$ & $x$ & & & & $x$ & & $x$ & $x$ & $x$ & & & & $x$ & & M.H. Other \\
\hline ๘ & $x$ & & $x$ & $x$ & $x$ & $x$ & $x$ & $x$ & $x$ & $\ddot{2}$ & $x$ & $x$ & $x$ & $x$ & Consultation \\
\hline$\infty$ & $x$ & $x$ & $x$ & & & $x$ & $x$ & $x$ & & $x$ & & $x$ & & & Daily Living Skills \\
\hline 0 & $x$ & & $x$ & & $x$ & $x$ & $x$ & $x$ & & & $x$ & $x$ & $x$ & & $\begin{array}{l}\text { Socialization/ } \\
\text { Recreation }\end{array}$ \\
\hline$u$ & $x$ & $x$ & & & & & & & $x$ & & $x$ & $x$ & & & $\begin{array}{l}\text { Crisis } \\
\text { Intervention }\end{array}$ \\
\hline$n$ & $x$ & $x$ & & & & & & & & & & $x$ & $x$ & $\underline{x}$ & $\begin{array}{l}\text { Crisis Int. - } \\
\text { Short Hosp. }\end{array}$ \\
\hline$\sim$ & & $x$ & & & & & & & & & & & & & $\begin{array}{l}\text { Housing - } \\
\text { Emergency }\end{array}$ \\
\hline$\leftarrow$ & & $x$ & & & & & & & & & & & & & $\begin{array}{l}\text { Housing - } \\
\text { Sheltered }\end{array}$ \\
\hline 0 & & & & & & & & & & & & & & & $\begin{array}{l}\text { Housing - } \\
\text { Semi-Independent }\end{array}$ \\
\hline$N$ & $x$ & $x$ & 1. & & & & & & & & & & & & $\begin{array}{l}\text { Housing - } \\
\text { Residential }\end{array}$ \\
\hline$N$ & & 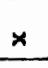 & & & & & & & & & & $\underline{x}$ & & & $\begin{array}{l}\text { Voc. Rehab. - } \\
\text { O.J.T. }\end{array}$ \\
\hline$r$ & & $x$ & & & & & & & & & & & & & $\begin{array}{l}\text { Voc. Rehab. - } \\
\text { Sheitered }\end{array}$ \\
\hline 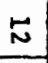 & $x$ & & $x$ & 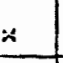 & $x$ & $x$ & $x$ & $x$ & & $x$ & $x$ & $x$ & $x$ & $x$ & $\begin{array}{l}\text { Medical care - } \\
\text { Med. moni: }\end{array}$ \\
\hline a & $x$ & $x$ & & & $x$ & & & & $x$ & & & $x$ & & $x$ & $\begin{array}{l}\text { Medical care - } \\
\text { general }\end{array}$ \\
\hline$\infty$ & & $x$ & $x$ & & & & $x$ & & & $\ddot{4}$ & $x$ & $x$ & $x$ & $x$ & Case Management \\
\hline$a$ & $x$ & $x$ & & & - & $x$ & $x$ & & & $x$ & & & $x$ & & Public Education \\
\hline$a$ & $x$ & & $x$ & & & & $x$ & & & $x$ & & $\underline{x}$ & $x$ & & $\begin{array}{l}\text { Community } \\
\text { Involvement }\end{array}$ \\
\hline- & $x$ & $x$ & $x$ & & & & & & & $x$ & & & & & Clfent Advocacy \\
\hline
\end{tabular}




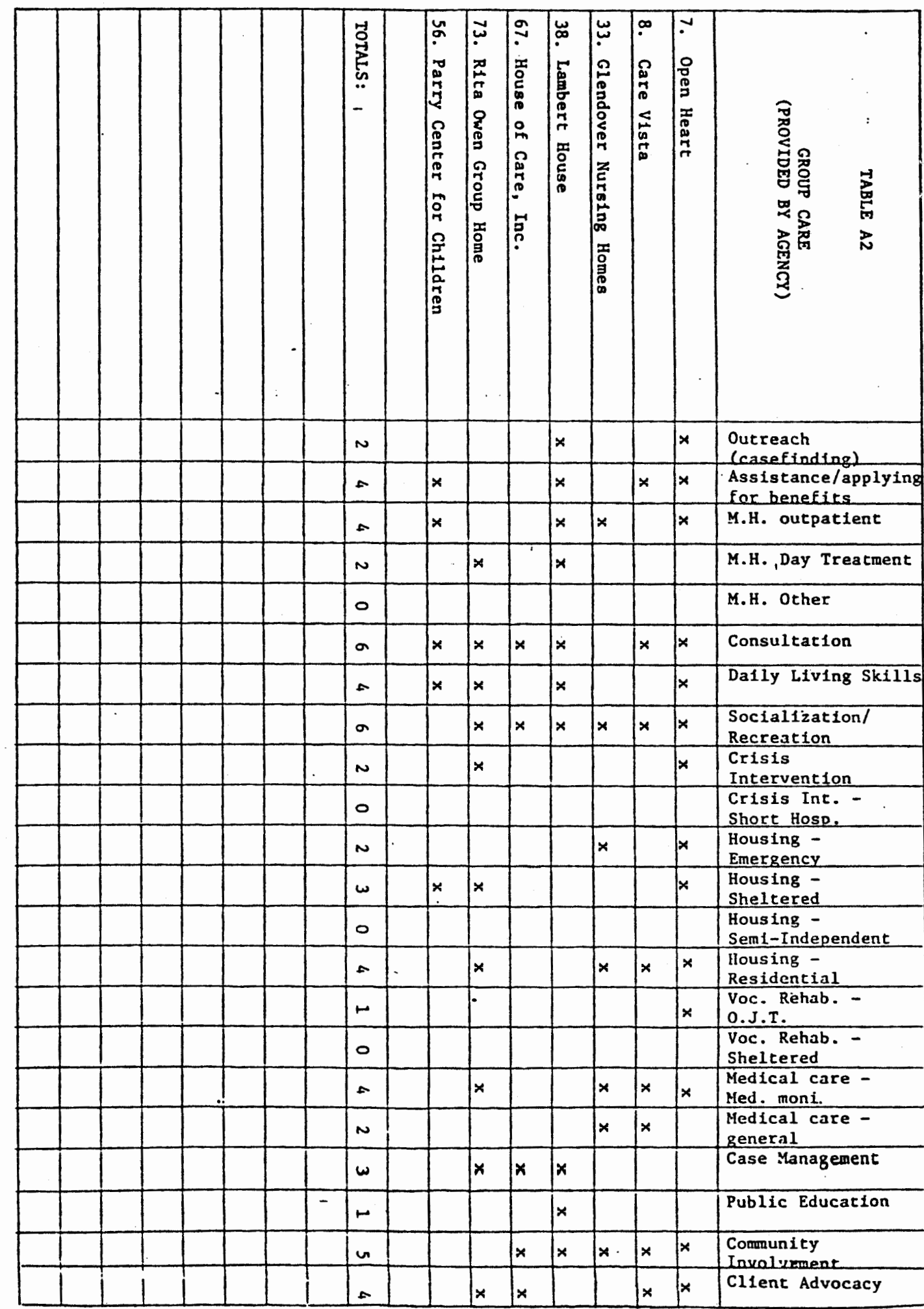




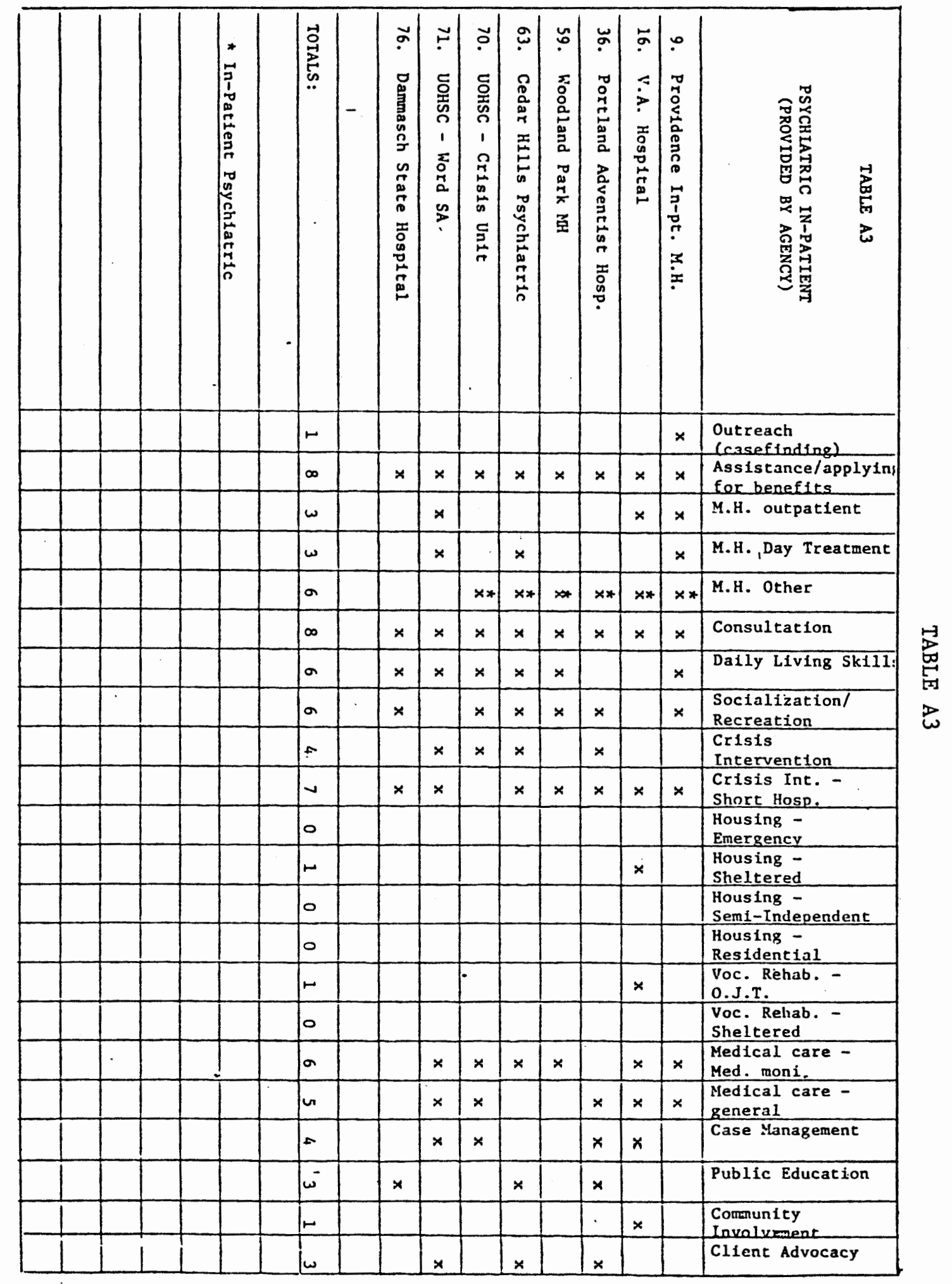




\begin{tabular}{|c|c|c|c|c|c|c|c|c|c|c|c|c|c|c|c|c|c|}
\hline 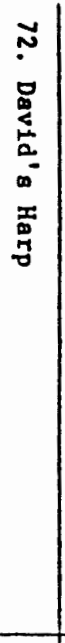 & 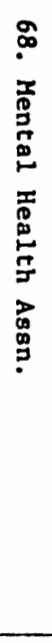 & 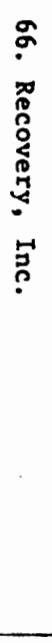 & 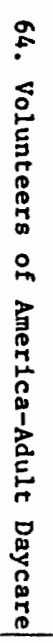 & 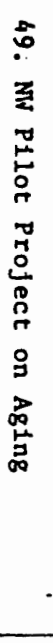 & 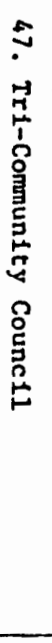 & 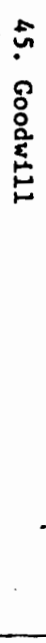 & 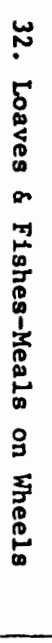 & 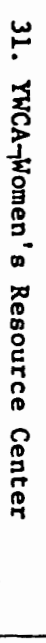 & 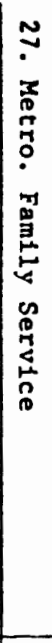 & 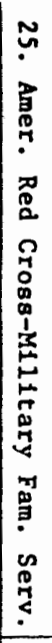 & 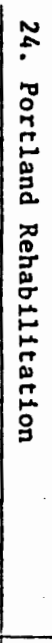 & 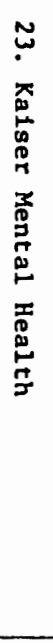 & 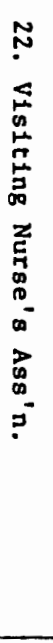 & 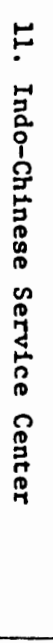 & 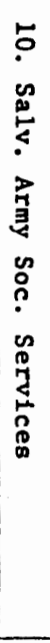 & 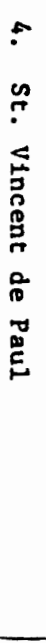 & 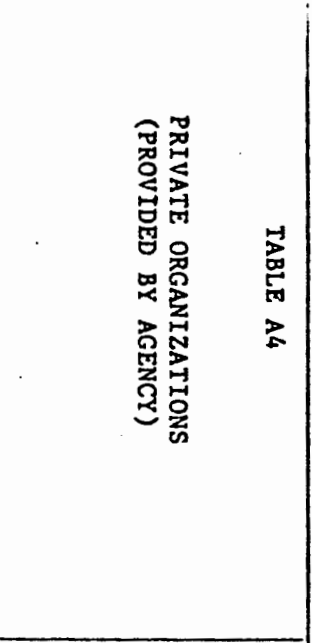 \\
\hline & $\star$ & & $x$ & $x$ & & & 忩 & & & $x$ & & & & $x$ & & & $\begin{array}{l}\text { Outreach } \\
\text { (casefind } 1 \text { ng) }\end{array}$ \\
\hline & $x$ & & $\star$ & $x$ & * & * & 管 & $x$ & $x$ & $x$ & $x$ & $x$ & & & $x$ & & $\begin{array}{l}\text { Assistance/applyin/ } \\
\text { for benefits }\end{array}$ \\
\hline & 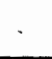 & & & * & & $\star$ & 忽 & $x$ & & & & $x$ & & $x$ & $x$ & & M.H. outpatient \\
\hline & & & $x$ & & & $x$ & 学 & & & & & & & & & & M.H., Day Treatment \\
\hline & & $\times$ & $\times$ & & & & to & & $x$ & $x$ & $x$ & & & $x$ & & & M.H. Other \\
\hline$x$ & $\times$ & & $\times$ & $x$ & & $\times$ & 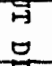 & $\times$ & $x$ & $x$ & $x$ & $x$ & & $x$ & $x$ & & Consultation \\
\hline$x$ & & & & $x$ & & $x$ & $\begin{array}{l}y \\
z\end{array}$ & & $x$ & & & & & $x$ & & $x$ & Dally Living Skill: \\
\hline$x$ & $x$ & & $x$ & * & & $x$. & 8 & $x$ & & & & $x$ & & $x$ & & $\star$ & $\begin{array}{l}\text { Soclalization/ } \\
\text { Recreation }\end{array}$ \\
\hline & & & $x$ & & & $x$ & 量 & & & $x$ & & $x$ & & & & & $\begin{array}{l}\text { Crisis } \\
\text { Intervention }\end{array}$ \\
\hline & & & $x$ & $x$ & & & 藏 & & & & & $x$ & & & & & $\begin{array}{l}\text { Crisis Int. - } \\
\text { Short Hosp. }\end{array}$ \\
\hline & & & $x$ & $x$ & & $x$ & 畄 & $x$ & & & & & & & $x$ & & $\begin{array}{l}\text { Housing - } \\
\text { Emergency }\end{array}$ \\
\hline & & & 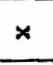 & & & $x$ & 点 & & & & & & & & & & $\begin{array}{l}\text { Housing - } \\
\text { Sheltered }\end{array}$ \\
\hline & & & & $x$ & & & & & & & & & & & & & $\begin{array}{l}\text { Housing- } \\
\text { Semi-Independent }\end{array}$ \\
\hline & & & $\star$ & & & & & & & & & & & & & $x$ & $\begin{array}{l}\text { Housing - } \\
\text { Residential }\end{array}$ \\
\hline & & & $x$ & $x$ & & $x$ & & & $x$ & & $x$ & & & & & $x$ & $\begin{array}{l}\text { Voc. Rehab. - } \\
\text { O.J.T. }\end{array}$ \\
\hline & & & $x$ & & & $x$ & & & & & $x$ & & & & & $x$ & $\begin{array}{l}\text { Voc. Reliab. - } \\
\text { Sheitered }\end{array}$ \\
\hline & & & $x$ & $\times$. & & $\star$ & & & & & & $x$ & & & & & $\begin{array}{l}\text { Medical care - } \\
\text { Med. mon1: }\end{array}$ \\
\hline & & & $x$ & & & & & & & & & $x$ & $x$ & & & & $\begin{array}{l}\text { Medical care - } \\
\text { gencral }\end{array}$ \\
\hline & & & $x$ & $x$ & & $x$ & & & $x$ & & $x$ & & & $x$ & & & Case Vlanagement \\
\hline$x$ & $x$ & $x$ & & $x$ & $x$ & $*$ & - & & & & & & & & & & Public Education \\
\hline$x$ & $x$ & & $x$ & $*$ & $x$ & $x$ & & $x$ & $x$ & & $x$ & & & $x$ & & $x$ & $\begin{array}{l}\text { Community } \\
\text { Involvenent }\end{array}$ \\
\hline$x$ & $x$ & & $\times$ & $x$ & & $x$ & & $x$ & $x$ & $x$ & $x$ & & & $x$ & x & & Cllent Advocacy \\
\hline
\end{tabular}




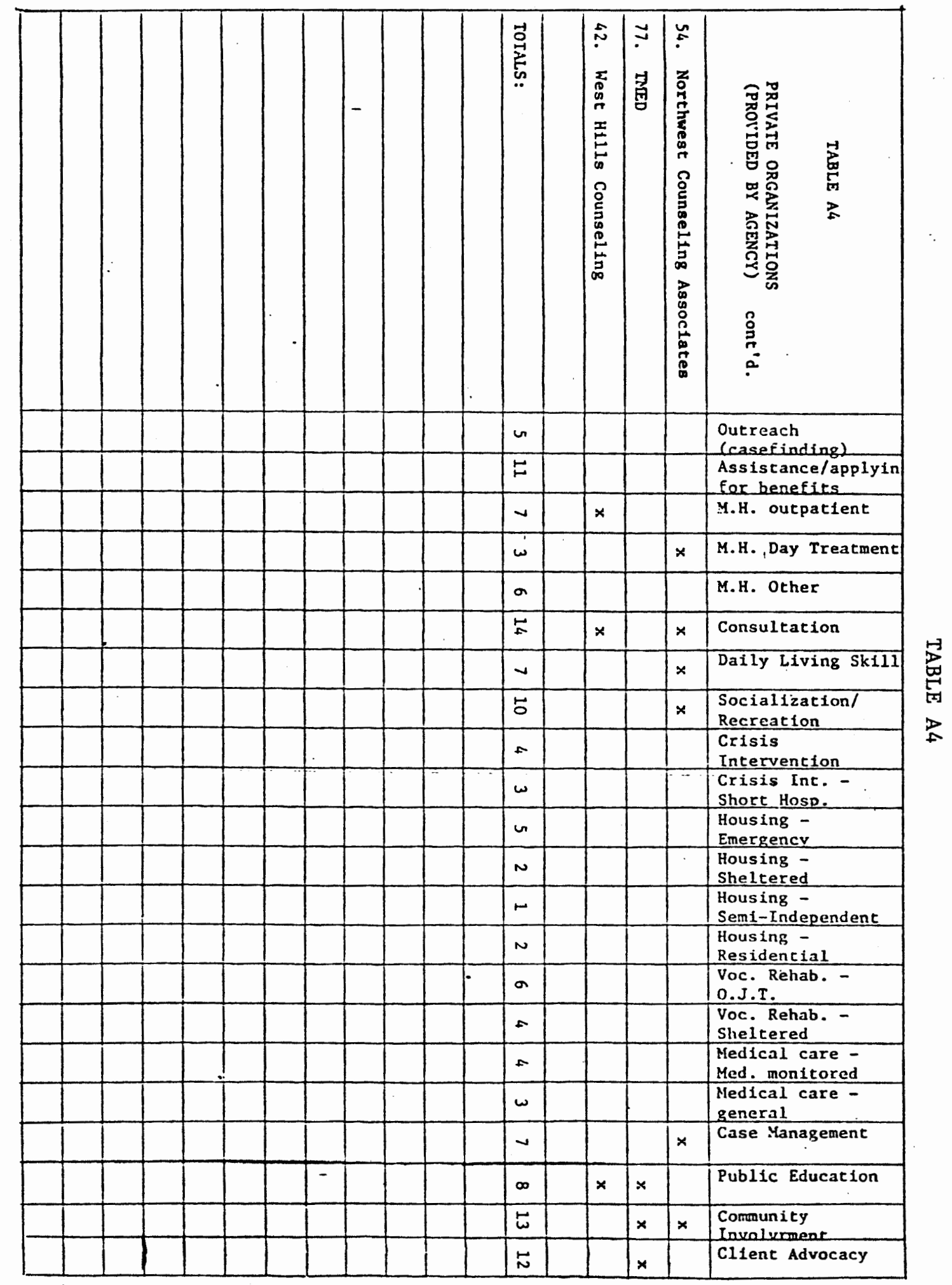




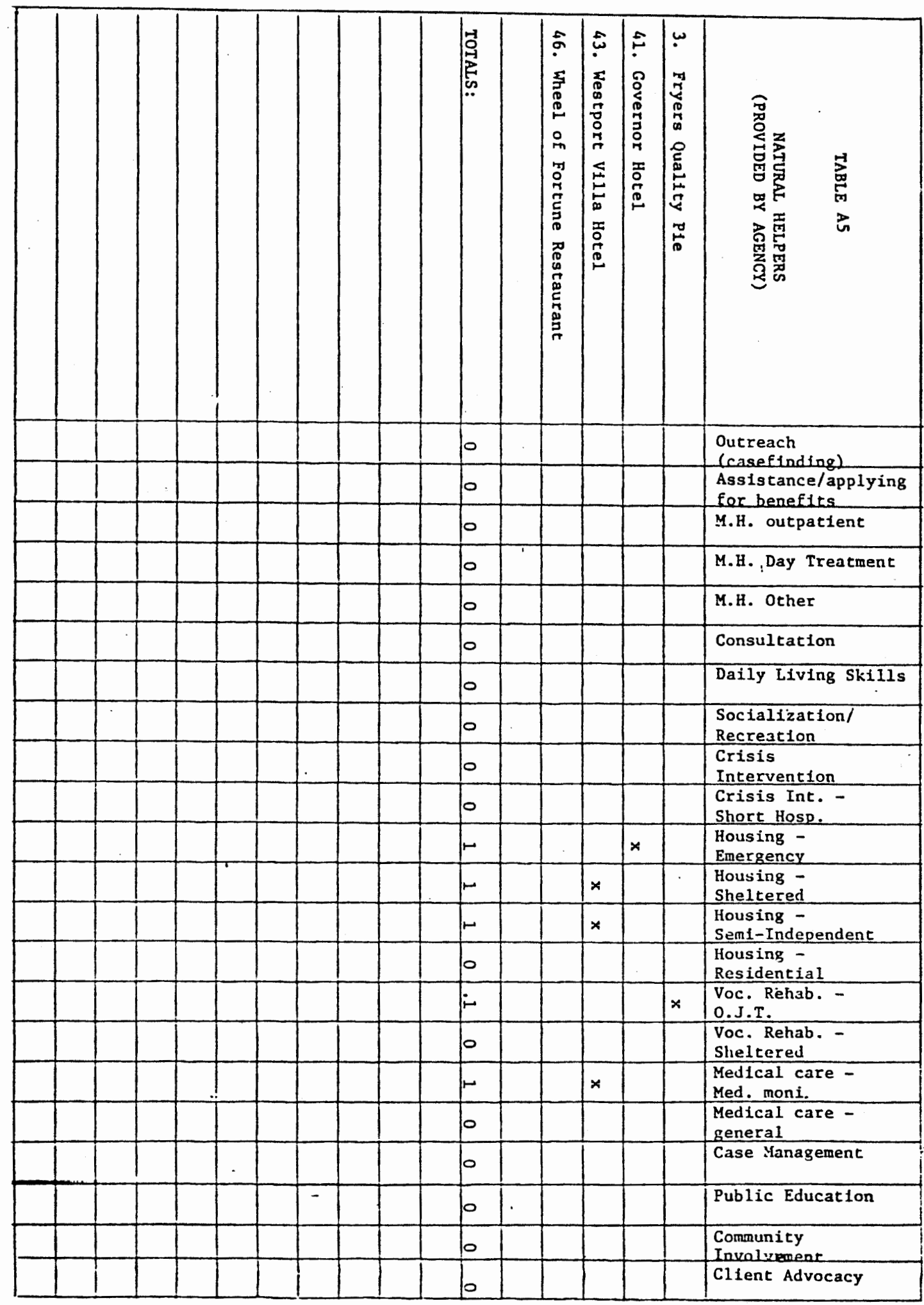




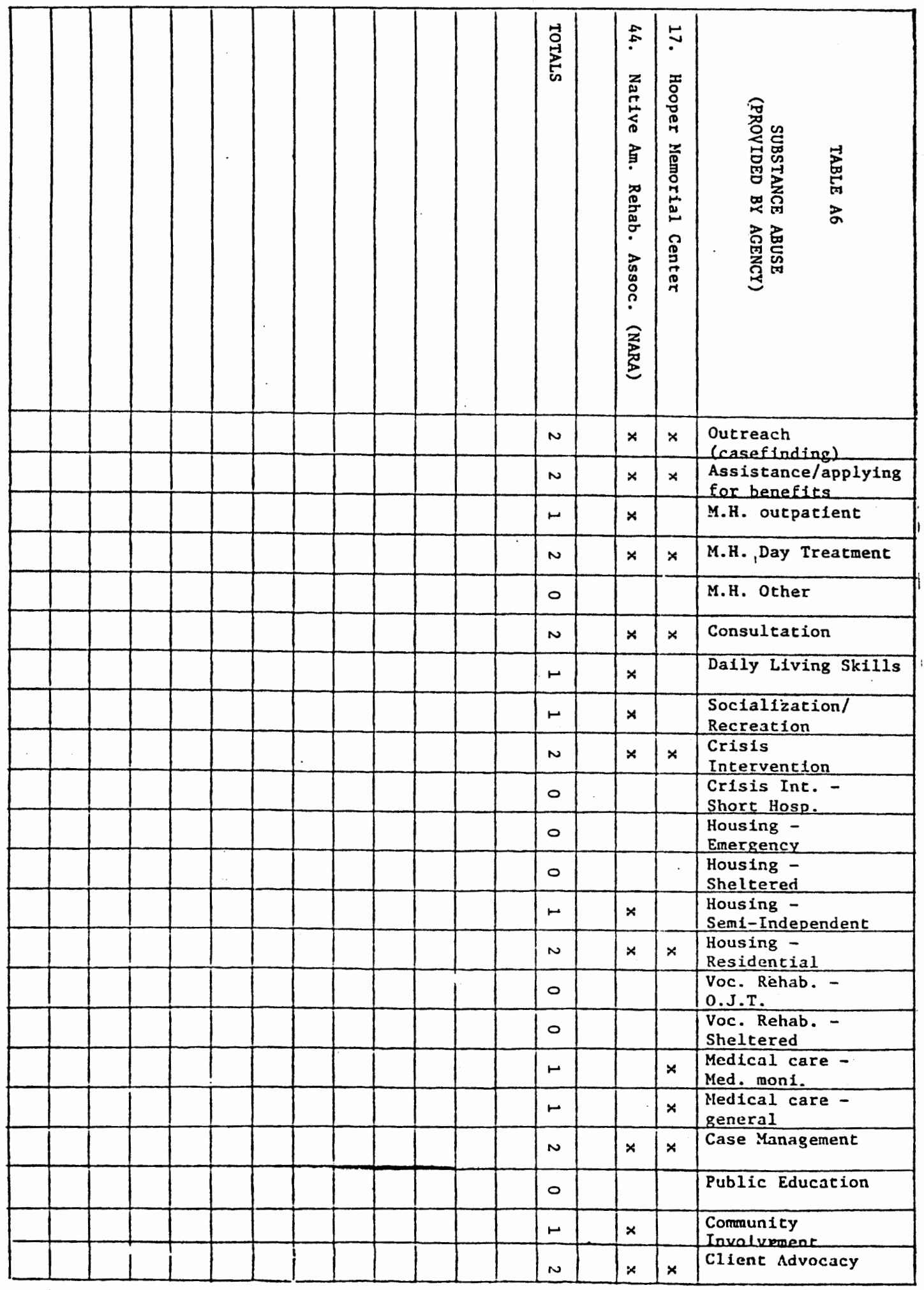




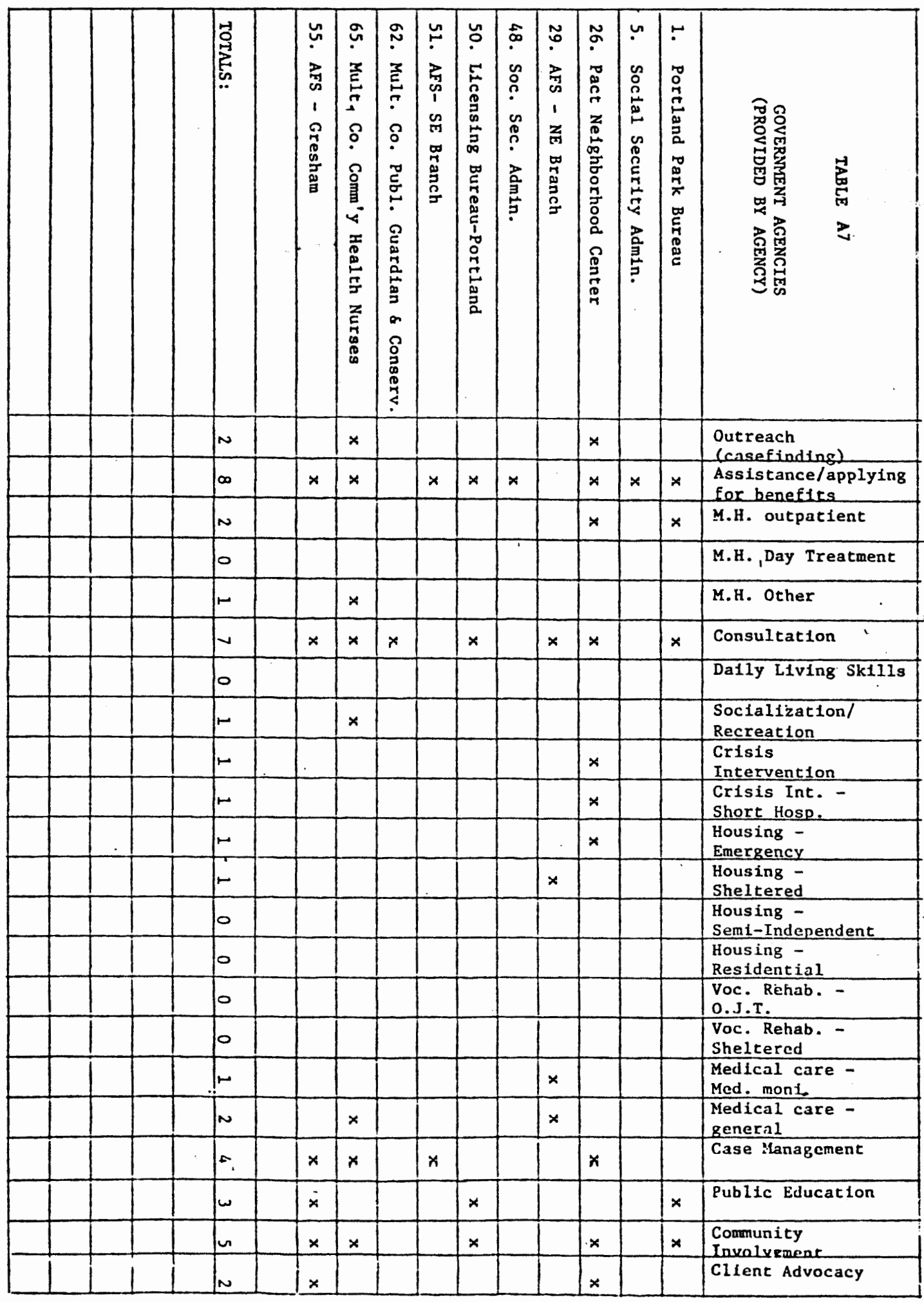




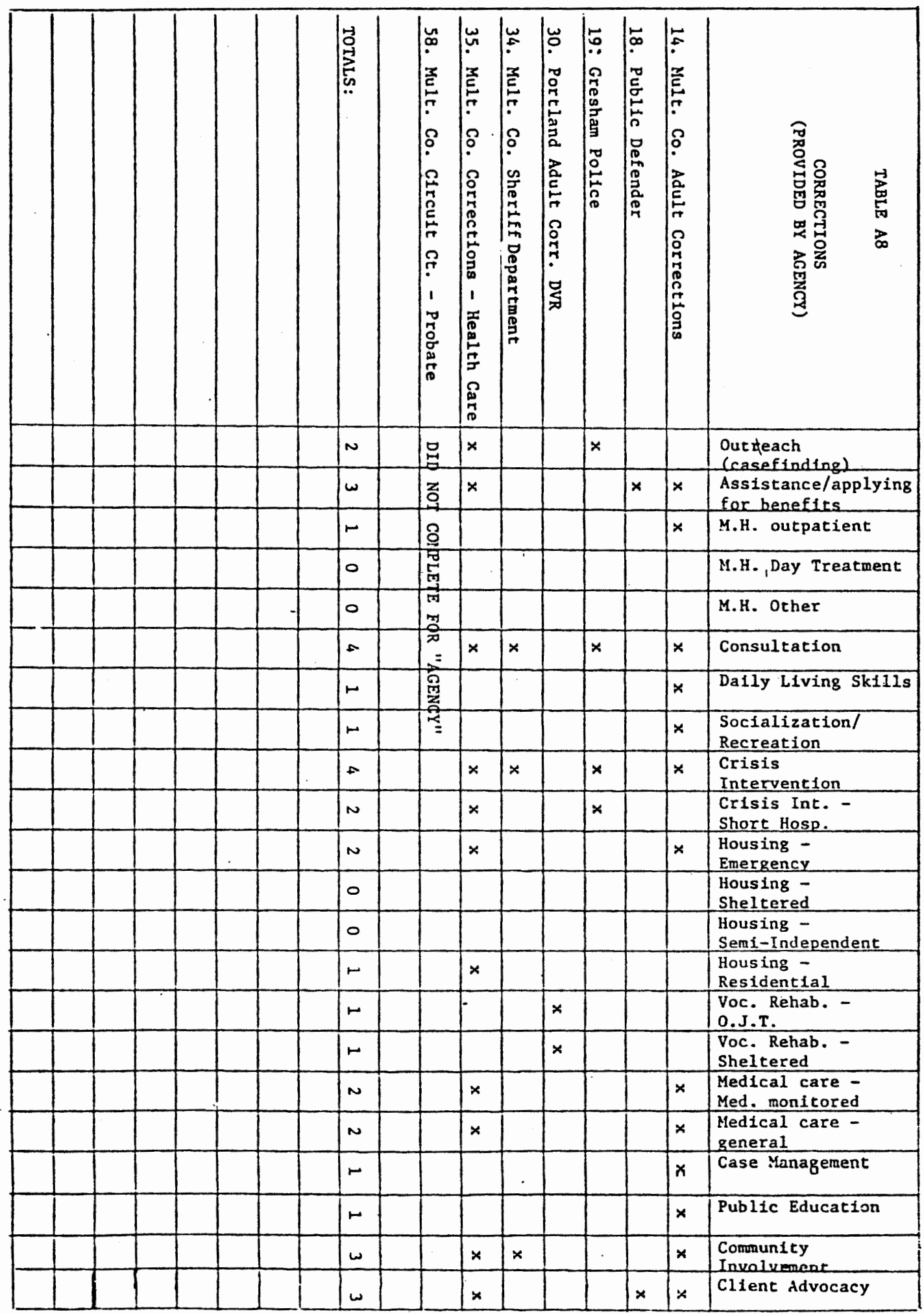




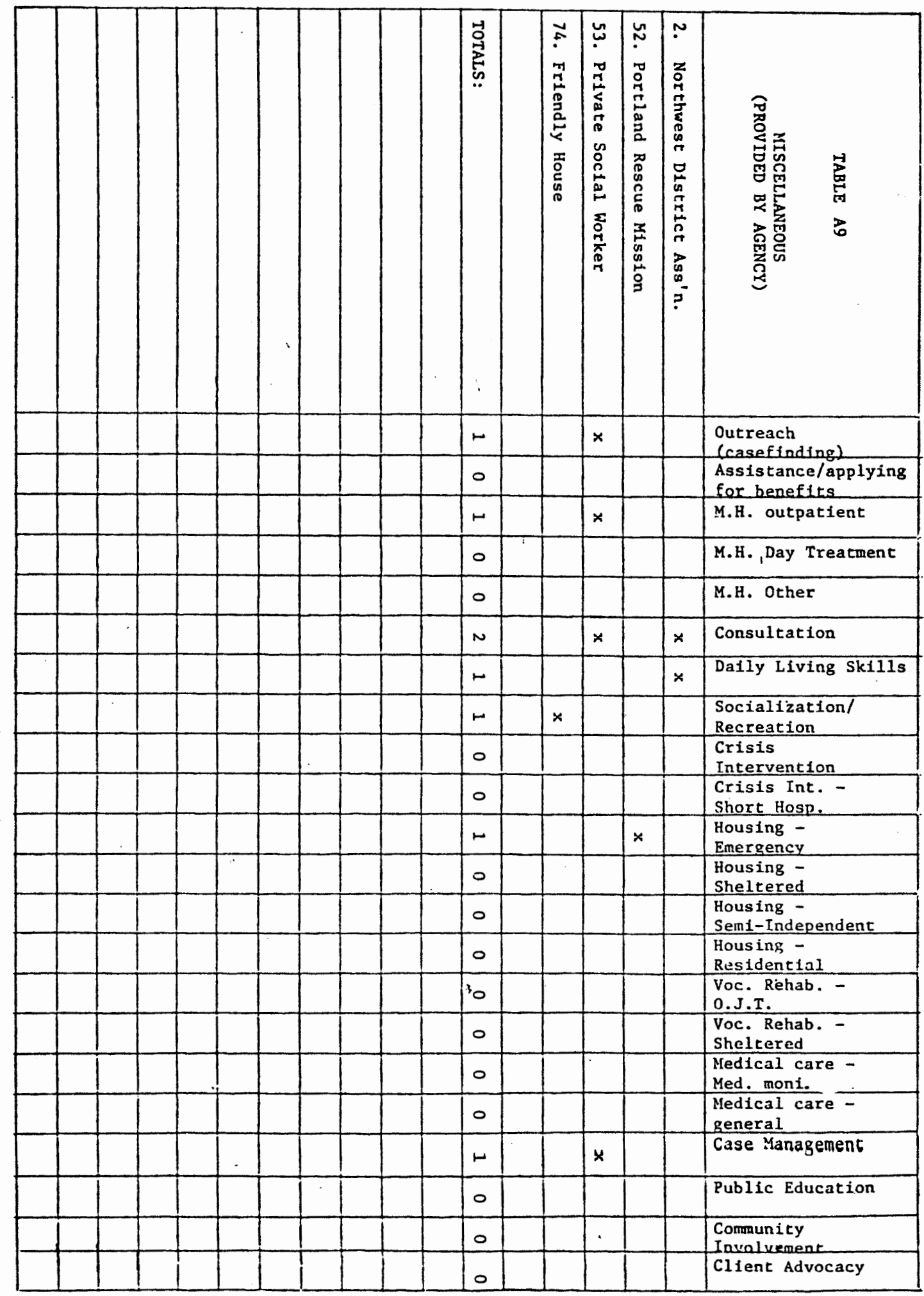




\begin{tabular}{|c|c|c|c|c|c|c|c|c|c|c|c|c|c|c|c|c|}
\hline 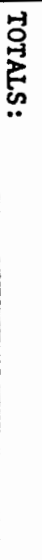 & $\begin{array}{l}n \\
0 \\
z \\
5 \\
\pi \\
8 \\
0 \\
3 \\
3 \\
3 \\
3 \\
3\end{array}$ & 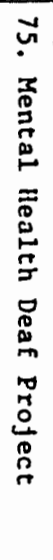 & $\begin{array}{l}9 \\
0 \\
0 \\
0 \\
0 \\
0 \\
0 \\
0 \\
-1 \\
0\end{array}$ & 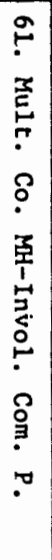 & 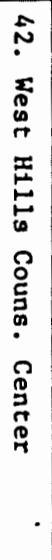 & 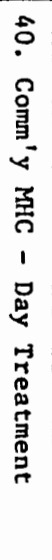 & 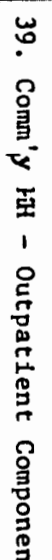 & 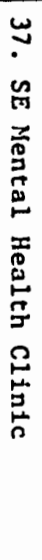 & 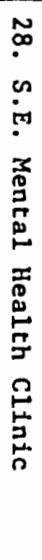 & 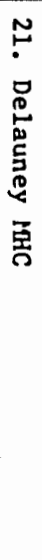 & 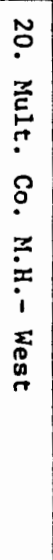 & 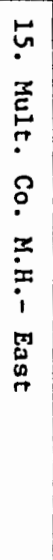 & 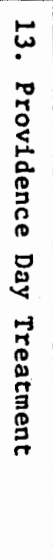 & 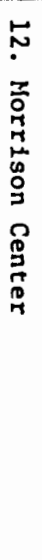 & 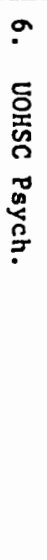 & 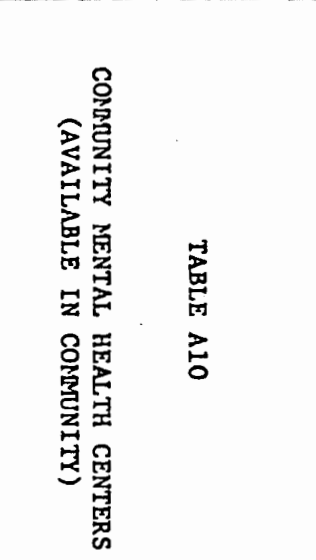 \\
\hline$\sim$ & $x$ & & & $z$ & $\circlearrowright$ & & & $x$ & $x$ & & & & & & $x$ & Outreach \\
\hline$a$ & & & & 象 & $\begin{array}{l}\text { की } \\
0 \\
0\end{array}$ & x & $x$ & $x$ & $x$ & $x$ & & & & & $x$ & Asslstance/applying \\
\hline$u$ & $x$ & & $x$ & 兽 & 要 & $x$ & $x$ & $x$ & & & & & $x$ & & & M.H. outpatient \\
\hline 0 & $x$ & & $x$ & 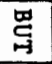 & 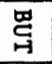 & & & $x$ & $x$ & $x$ & $\ddot{x}$ & $x$ & & $x$ & $x$ & M.H. Day Treatment \\
\hline$\omega$ & $x$ & & & $\underset{\sim}{\mathrm{O}}$ & $\underset{\sim}{z}$ & & $x$ & & & & & $x$ & & & & M.H. Other \\
\hline$\omega$ & $x$ & & & $\mathbf{z}$ & 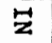 & & & $x$ & & $x$ & & & & & & Consultation \\
\hline a & $x$ & & & 올 & 是 & & & $x$ & & $x$ & $x$ & $x$ & & & $x$ & Dally Living Skills \\
\hline$\infty$ & $x$ & & $x$ & $\stackrel{7}{=}$ & $\stackrel{\pi}{\vdots}$ & & & $x$ & & $x$ & $x$ & $x$ & & $x$ & $\times$ & $\begin{array}{l}\text { Socialization/ } \\
\text { Recreation }\end{array}$ \\
\hline u & & & & 㞼 & 罳 & & & $x$ & $x$ & $x$ & $x$ & & & & $x$ & $\begin{array}{l}\text { Crisis } \\
\text { Intervention }\end{array}$ \\
\hline E & & $x$ & $x$ & 席 & 惫 & $x$ & $x$ & $x$ & $x$ & $x$ & $x$ & $x$ & & $\times$ & $x$ & $\begin{array}{l}\text { Crisis Int. - } \\
\text { Short Hosp. }\end{array}$ \\
\hline$\infty$ & $x$. & & & & & x & & $x$ & $x$ & $x$ & & & $x$ & $x$ & $x$ & $\begin{array}{l}\text { Housing - } \\
\text { Emergency }\end{array}$ \\
\hline N & $x$ & & $x$ & & & $x$ & $x$ & $x$ & $x$ & $x$ & $x$ & $x$ & $x$ & $x$ & $x$ & $\begin{array}{l}\text { Housing - } \\
\text { Sheltered }\end{array}$ \\
\hline$a$ & $x$ & & & & & & & & $x$ & $x$ & & & $x$ & $x$ & $x$ & $\begin{array}{l}\text { Housing - } \\
\text { Semi-Independent }\end{array}$ \\
\hline$a$ & $x$ & & & & & & & & $x$ & $x$ & & $x$ & & $x$ & $x$ & $\begin{array}{l}\text { Housing - } \\
\text { Residential }\end{array}$ \\
\hline$\infty$ & $x$ & & & & & $x$ & $x$ & $x$ & $x$ & $x$ & & $x$ & & $x$ & $x$ & $\begin{array}{l}\text { Voc. Rehab. - } \\
\text { O.J.T. }\end{array}$ \\
\hline 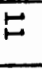 & $x$ & & $x$ & & & $x$ & $x$ & $x$ & $x$ & $x$ & & $x$ & $x$ & $x$ & $x$ & $\begin{array}{l}\text { Voc. Rehab. - } \\
\text { Shel cered }\end{array}$ \\
\hline n & $x$ & $x$ & $x$ & & & & $x$ & & & & & & & & $x$ & $\begin{array}{l}\text { Medical care - } \\
\text { Med. moni. }\end{array}$ \\
\hline 뭉 & $x$ & $x$ & $x$ & & & $x$ & $x$ & $x$ & $x$ & $x$ & & $x$ & & $x$ & & $\begin{array}{l}\text { Medical care - } \\
\text { general }\end{array}$ \\
\hline$\omega$ & & & & r & & & & $x$ & $x$ & $x$ & & & & & & Case Management \\
\hline un & $x$ & & & & & $\bar{x}$ & $x$ & $x$ & & $x$ & & & & & & Public Education \\
\hline un & $x$ & $x$ & & & & & & $x$ & & $x$ & & $x$ & . & & & $\begin{array}{l}\text { Community } \\
\text { Invalenent }\end{array}$ \\
\hline$a$ & $x$ & & $x$ & & & & & $x$ & $x$ & $x$ & $x$ & & & & & Cllent Advocacy \\
\hline
\end{tabular}




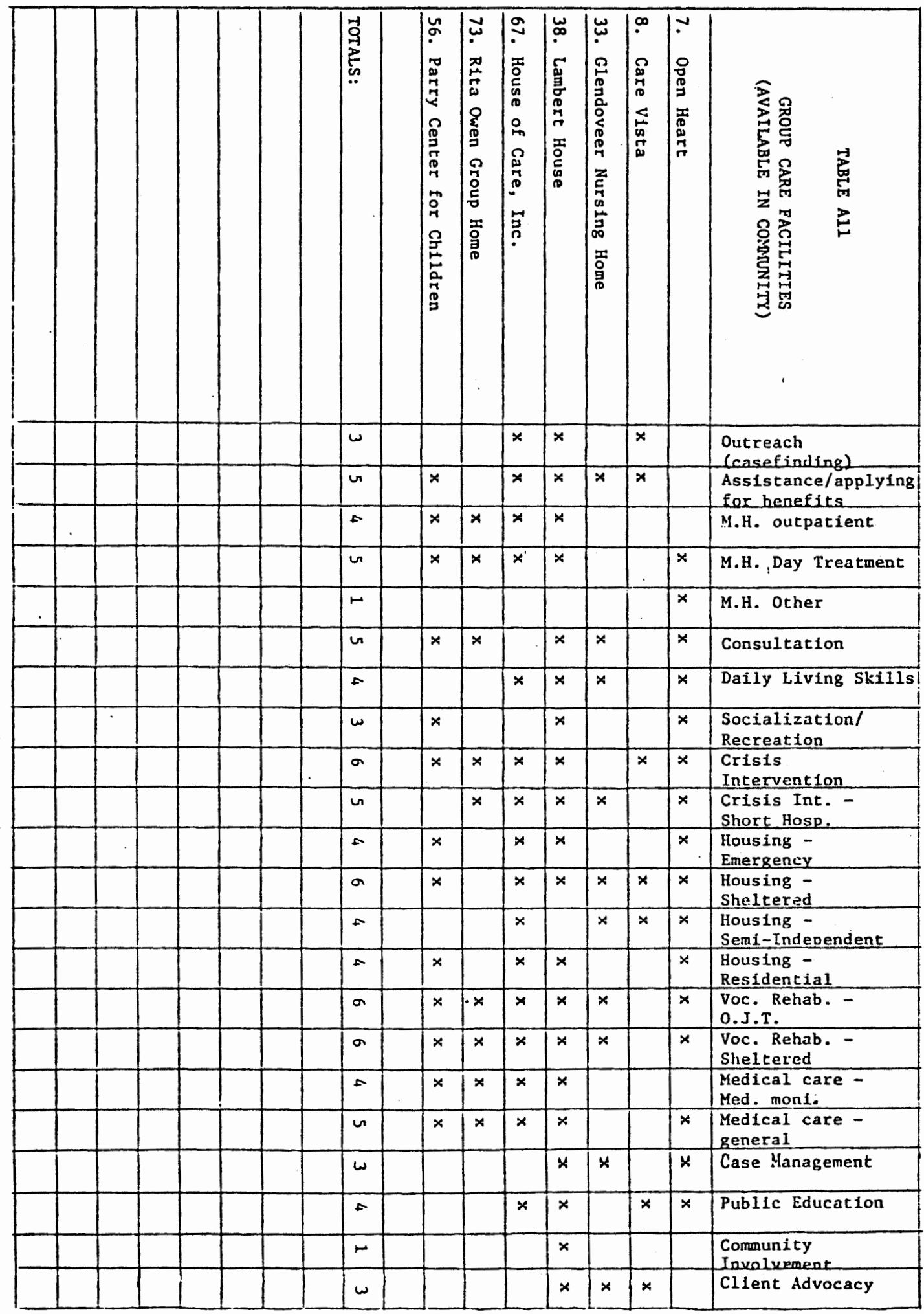




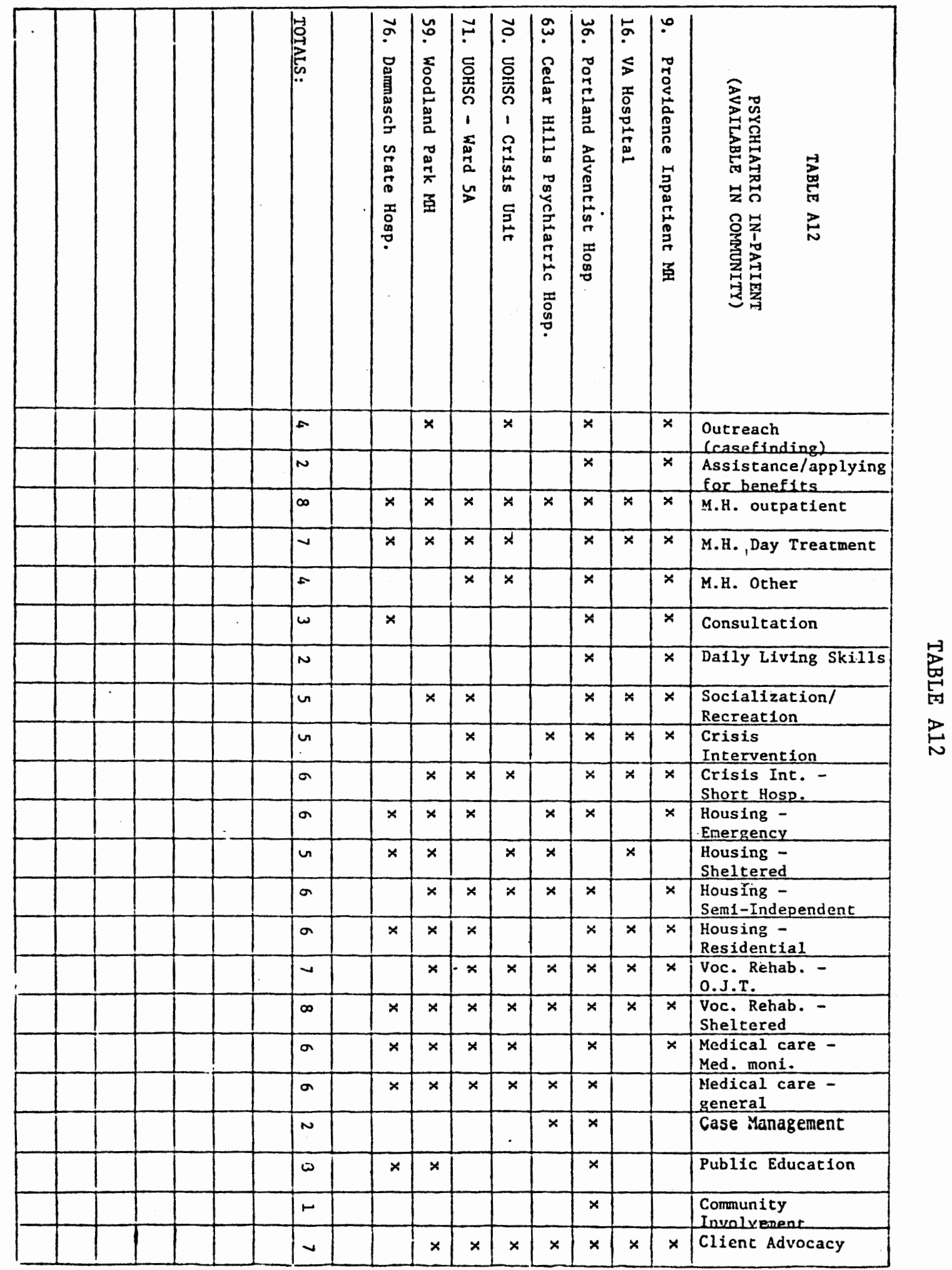




\begin{tabular}{|c|c|c|c|c|c|c|c|c|c|c|c|c|c|c|c|c|c|}
\hline 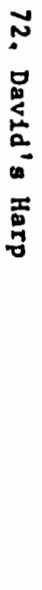 & 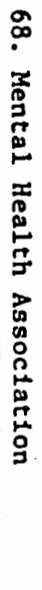 & 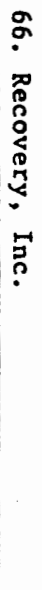 & 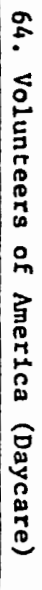 & $\begin{array}{l}\hat{0} \\
0 \\
z \\
z \\
0 \\
5 \\
50 \\
0 \\
0 \\
7 \\
0 \\
0 \\
0 \\
0 \\
0\end{array}$ & 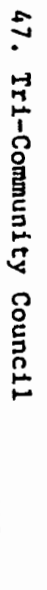 & 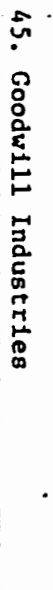 & 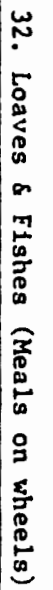 & 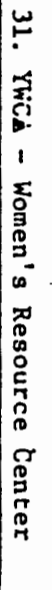 & 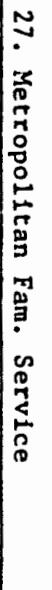 & 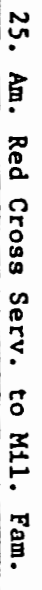 & 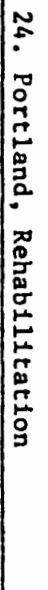 & 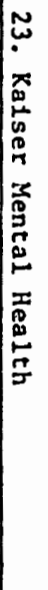 & 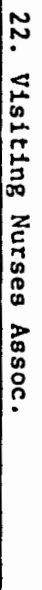 & 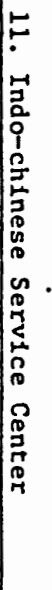 & 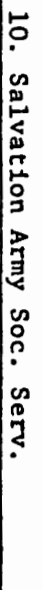 & $\begin{array}{l}- \\
0 \\
0 \\
0 \\
5 \\
5 \\
0 \\
0 \\
5 \\
\pi \\
0 \\
0 \\
0 \\
0 \\
5\end{array}$ & 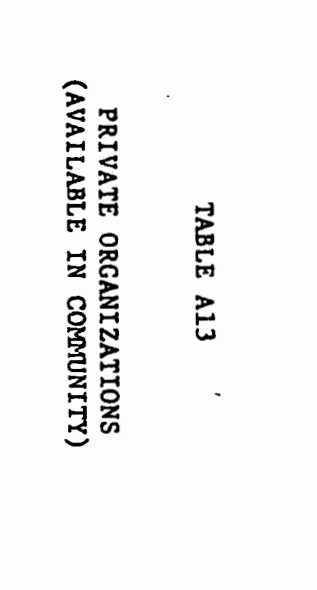 \\
\hline & & & $x$ & $x$ & & & & & $x$ & & & 赵 & & & & & $\begin{array}{l}\text { Outreach } \\
\text { (casefinding) }\end{array}$ \\
\hline & & & $x$ & $x$ & $x$ & $x$ & $x$ & $x$ & $x$ & & & $\frac{1}{10}$ & & $x$ & $x$ & $x$ & $\begin{array}{l}\text { Assistance/applyin\$ } \\
\text { fer benefits }\end{array}$ \\
\hline \multirow[t]{14}{*}{$x$} & $x$ & $\times$ & $x$ & $x$ & $x$ & & & $x$ & $x$ & & $x$ & 氮 & $x$ & & $x$ & $x$ & M.H. outpatient \\
\hline & $x$ & & & & & $x$ & & $x$ & $x$ & & $x$ & 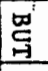 & $x$ & & & $x$ & M.H. Day Treatment \\
\hline & & & $x$ & & & & & $x$ & & & & 홉 & $x$ & & $x$ & 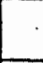 & M.H. Other \\
\hline & $x$ & $x$ & & $x$ & & $x$ & & & & & & 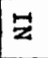 & $x$ & & $x$ & $x$ & Consultation \\
\hline & & & $x$ & $x$ & $x$ & $x$ & & & $x$ & $x$ & $x$ & $\overline{0}$ & & & & & Dafly Lfving Skfils \\
\hline & $x$ & 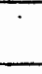 & $x$ & $x$ & & $x$ & & & $x$ & $x$ & $x$ & $\stackrel{2}{=}$ & & & $x$ & & $\begin{array}{l}\text { Soclalization/ } \\
\text { Recreation }\end{array}$ \\
\hline & & $x$ & $x$ & $x$ & & $x$ & $x$ & & & & & $\sum_{\substack{x \\
-1}}^{2}$ & $x$ & $x$ & $x$ & & $\begin{array}{l}\text { Crisis } \\
\text { Intervention }\end{array}$ \\
\hline & & $x$ & $x$ & $x$ & & $x$ & $x$ & & & & $x$ & 总 & $x$ & $x$ & $\times$ & $x$ & $\begin{array}{l}\text { Crisis Int. - } \\
\text { Short Hosp. }\end{array}$ \\
\hline & & & & $x$ & $x$ & $x$ & $x$ & $x$ & & $x$ & $x$ & & & & $x$ & $x$ & $\begin{array}{l}\text { Housing - } \\
\text { Emergency }\end{array}$ \\
\hline & & & & $x$ & $x$ & $x$ & $x$ & $x$ & $x$ & $x$ & $x$ & & $x$ & & & $x$ & $\begin{array}{l}\text { Housing - } \\
\text { Sheltered }\end{array}$ \\
\hline & & & & & & $x$ & & $x$ & $x$ & $x$ & $x$ & & & & & $x$ & $\begin{array}{l}\text { Housing - } \\
\text { Semi-Independent }\end{array}$ \\
\hline & & & & $x$ & & $x$ & & $x$ & & $x$ & $x$ & & $x$ & & & . & $\begin{array}{l}\text { Housing - } \\
\text { Residential } \\
\end{array}$ \\
\hline & & & & $x$ & & $x$ & & $x$ & & $x$ & $F$ & & $x$ & $x$ & $x$ & & $\begin{array}{l}\text { Voc. Rehab. - } \\
\text { O.J.T. }\end{array}$ \\
\hline & & & & $x$ & & $x$ & & $x$ & & $x$ & & & $x$ & & $x$ & . & $\begin{array}{l}\text { Voc. Rehab. - } \\
\text { Sheitered }\end{array}$ \\
\hline \multirow[t]{6}{*}{$x$} & $x$ & & & $x$ & $x$ & $x$ & & $x$ & $x$ & $x$ & $x$ & & $x$ & $x$ & $x$ & $x$ & $\begin{array}{l}\text { Medical care - } \\
\text { Med. moni. }\end{array}$ \\
\hline & & & & & & $x$ & & $x$ & & $x$ & $x$ & & & $x$ & $x$ & $x$ & $\begin{array}{l}\text { Medical care - } \\
\text { general }\end{array}$ \\
\hline & & & & $x$ & & $x$ & & $x$ & $\times$ & $x$ & & & & & & $x$ & Case Management \\
\hline & & $x$ & $x$ & $x$ & & $x$ & - & & $x$ & $x$ & & & $x$ & $x$ & & & Public Education \\
\hline & & $x$ & & $x$ & & $x$ & & $x$ & & & & & & & & & $\begin{array}{l}\text { Community } \\
\text { Involvement }\end{array}$ \\
\hline & & & & $x$ & $x$ & $x$ & & $x$ & & & $x$ & & & & $x$ & & Client Advocacy \\
\hline
\end{tabular}




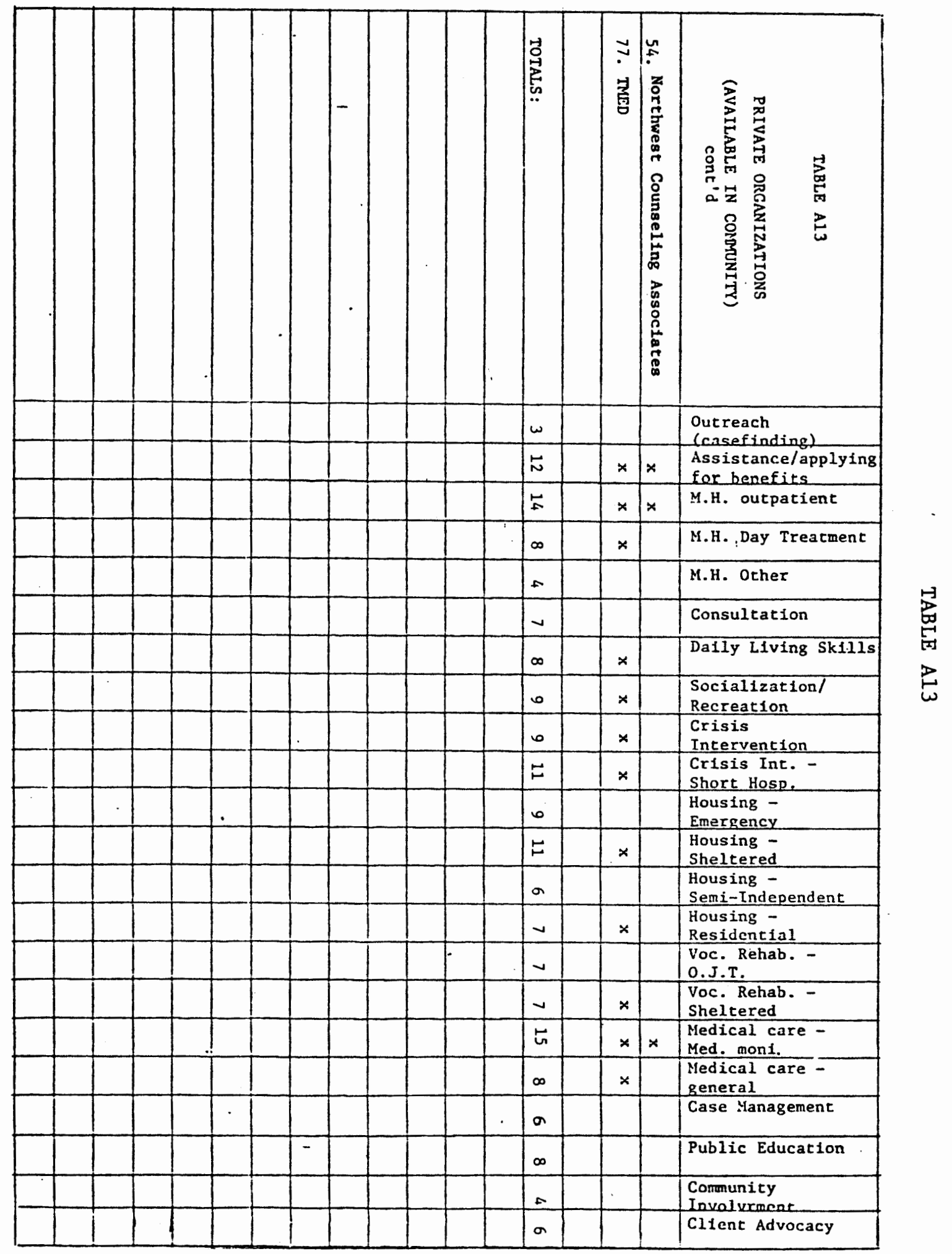




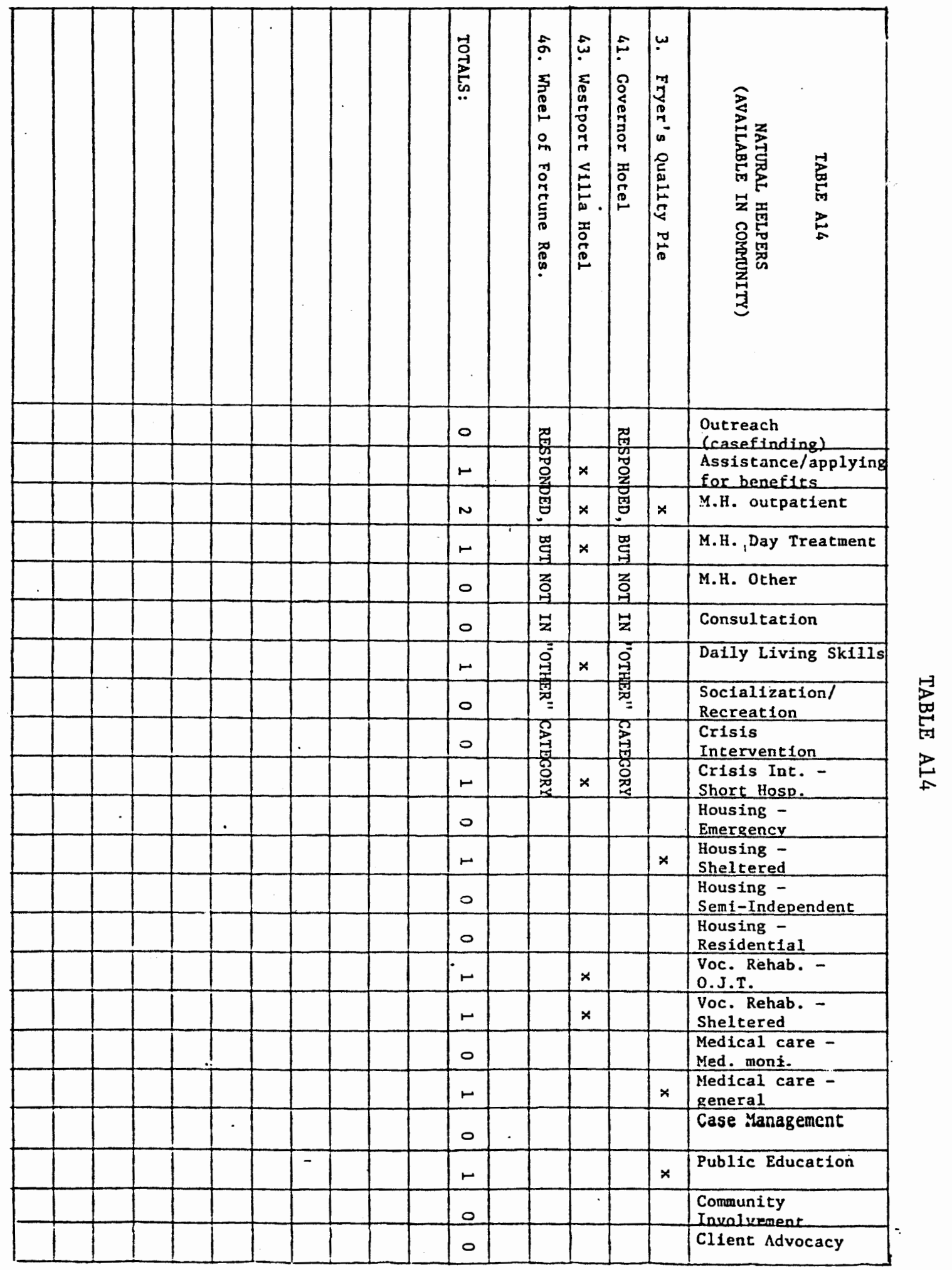




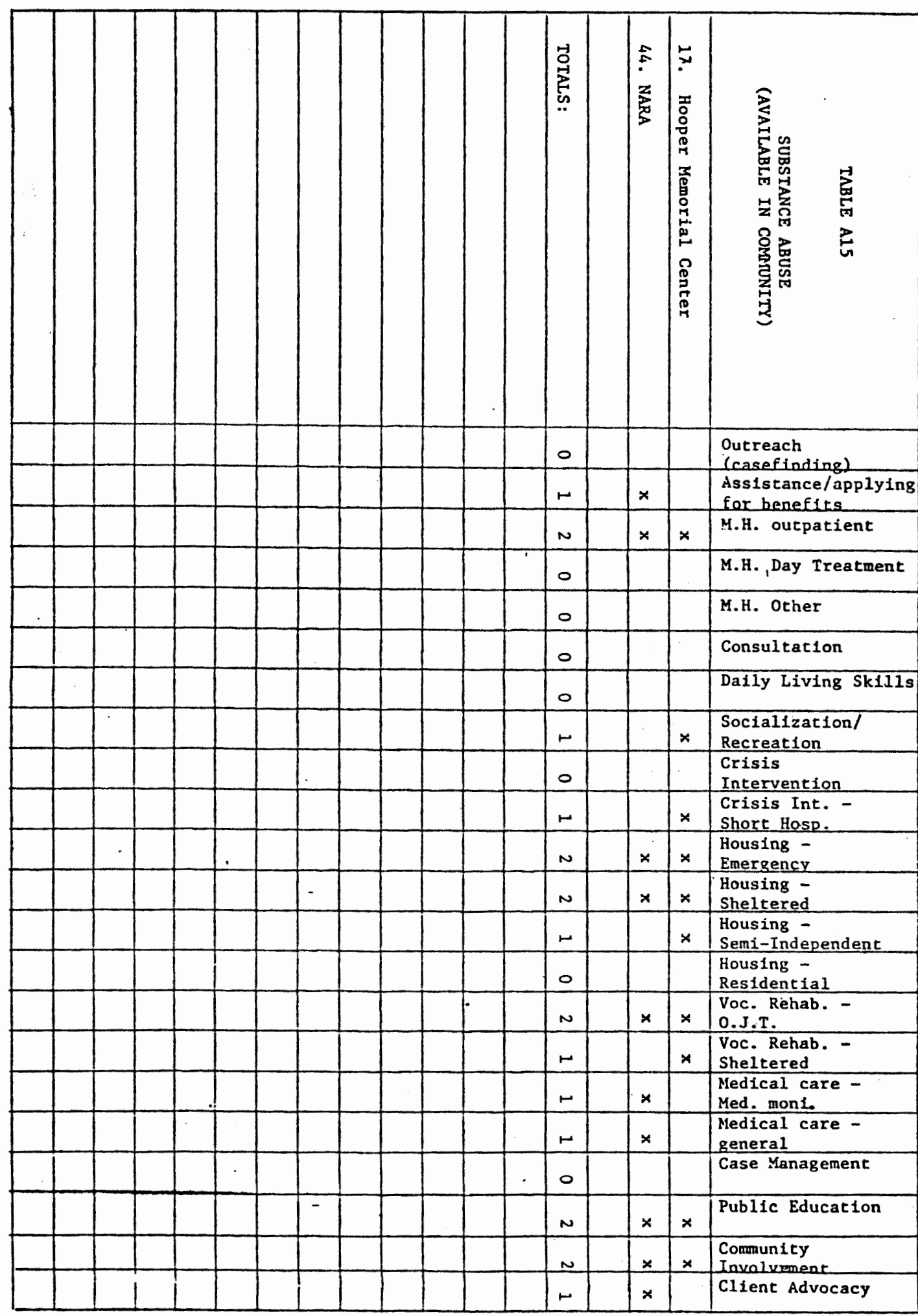




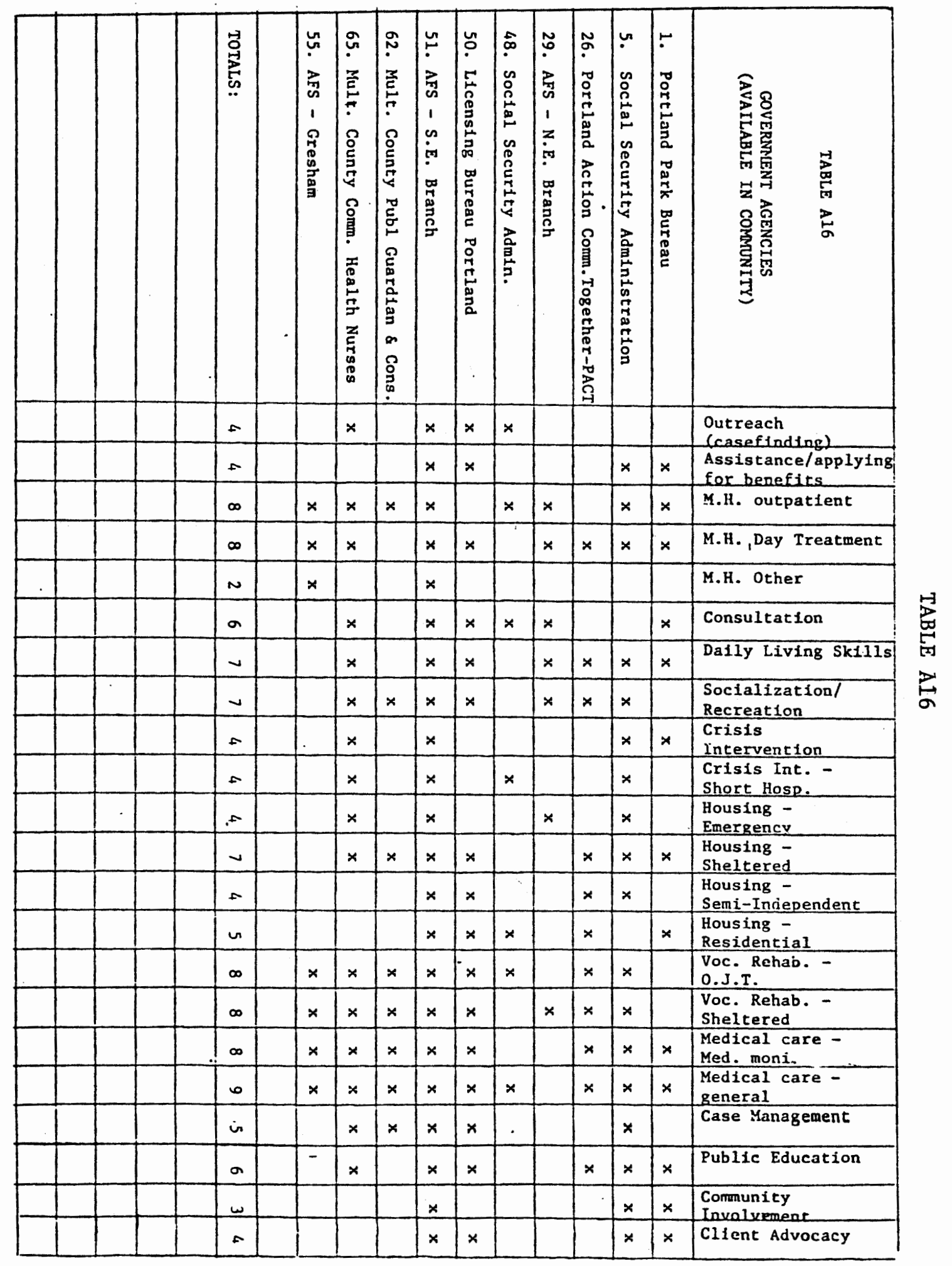




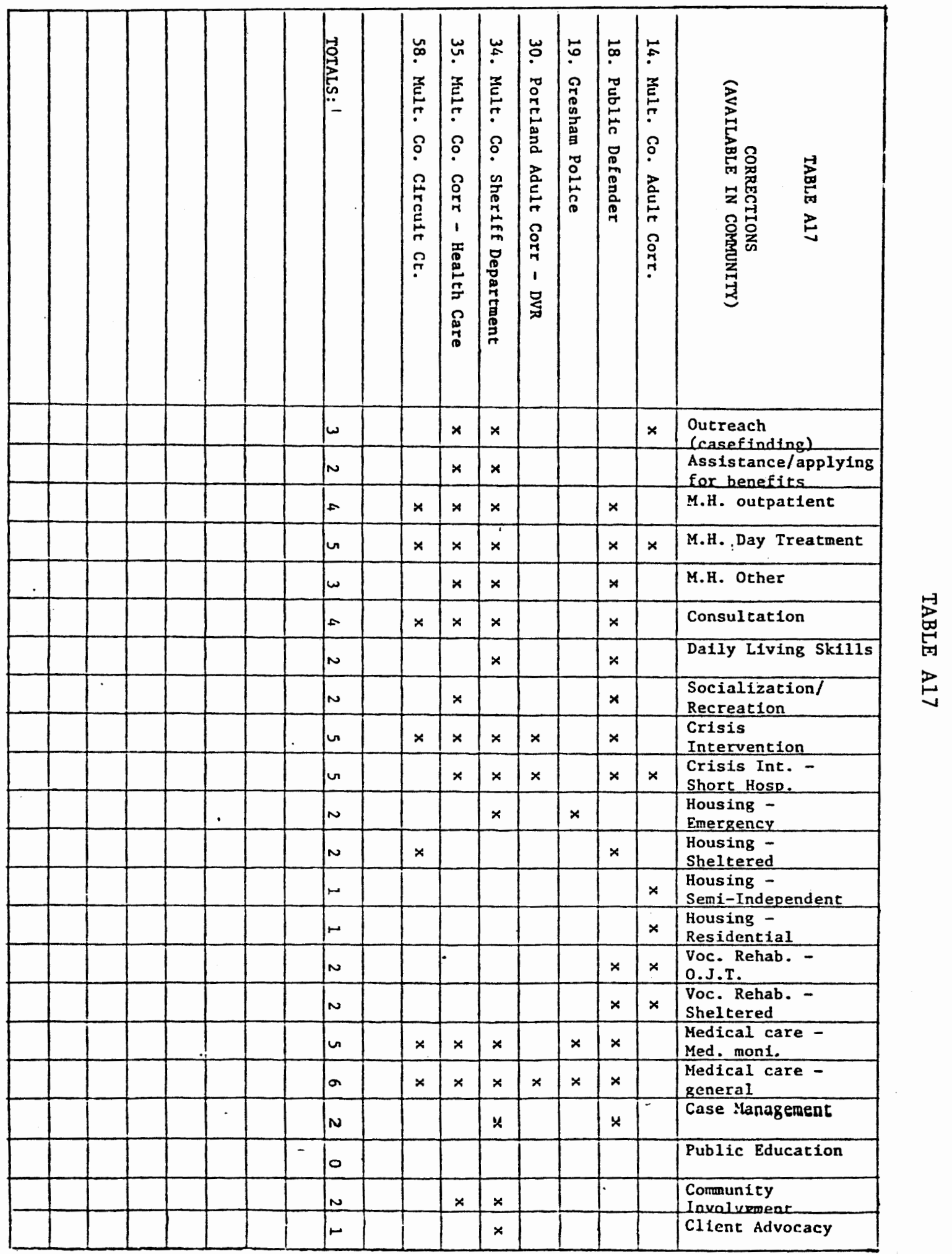




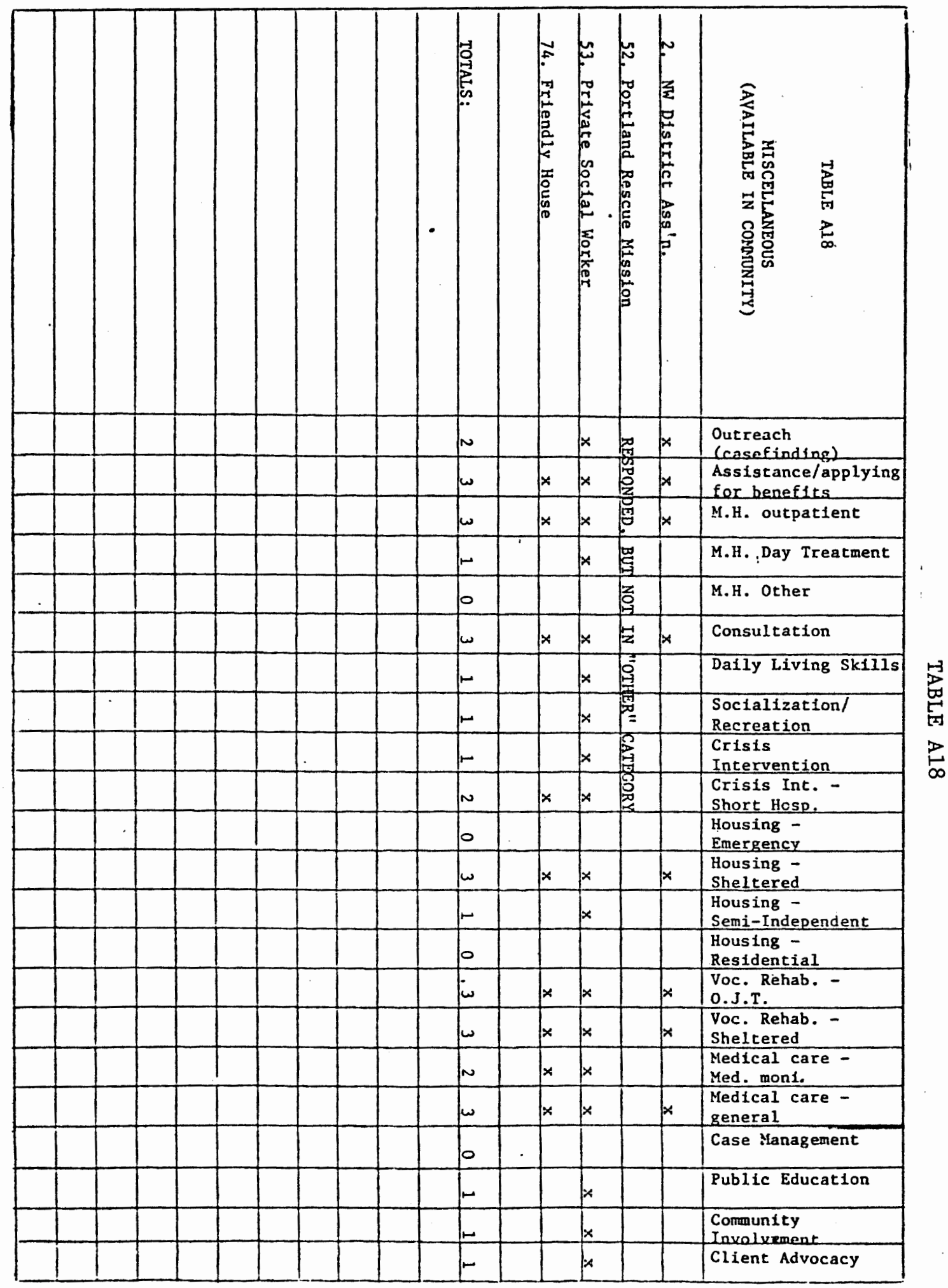


APPENDIX C

STATISTICAL SOURCES 
Age:

Sex:

Rural/Urban;

Ethnicity:

Economics :

Adult Education Level: United States Census, 1970.
Center for Population Research and Census (estimates for $7 / 1 / 77$ ) based upon 1970 Census, Portland State University, Portland, Oregon.

Socip-Economic Indicators 1978, State Community Services Program: Department of Human Resources, Salem, Oregon. p. 302.

Center for Population Research and Census (estimates for $7 / 1 / 77$ based upon 1970 Census, Portland State University, Portland, Oregon.

Community Mental Health Plan 1977-78, Multnomah County Mental Health Division, Portland, Oregon, p. 26.

Housing Division, Department of Commerce, State of Oregon, 1977.

Employment Division, Department of Human Resources, State of Oregon, 1977.

United States Census, 1970.

Public Assistance:

Supplemental Social Security Income:

Supplemental Security Income state and County Data, June, 1977, U.S. Department of Health, Education and Welfare publication, (SSA) 76-11 977 .

old Age Assistance Persons:

Adult and Family Services, Department of Human Resources, State of Oregon, Salem, Oregon, 1977.

Aid to the Blind and Disabled Persons:

Adult and Family Services, Department of Human Resources, State of Oregon, Salem, Oregon, 1977.

Food Stamp Recipients:

Adult and Family Services, Department of Human Resources, State of Oregon, Salem, Oregon, 1977. 
Congregate Care Recipients:

Adult and Family Services, Department of Human Resources, State of Oregon, Salem, Oregon, 1977.

Households:

Community Menta1 Health Plan 1977-78, Multnomah County Mental Health Division, Portland, Oregon, p. 26.

Disabled Population and Residents in need

of Alcohol Services. Residents in need

of Drug Services:

Community Mental Health Plan 1977-78, Multnomah County Mental Health Division, Portland, Oregon, p. 83 and p. 113.

Residents in need of Mental Retardation/

Developmental Disabilities Services:

Community Mental Health Plan 1977-78, Multnomah County Mental Health Division, Portland, Oregon, p. 140.

Residents in need of Services for

Mental and Emotional Disabilities:

Community Mental Health Plan 1977-78, Multnomah County Mental Health Division, Portland, Oregon, p. 170. 


\section{APPENDIX D}

DESCRIPTION OF A HOUSING AND URBAN DEVELOPMENT PROJECT 
HUD PROJECT DESCRIPTION

In 1978, the Department of Housing and Urban Development (HUD), in cooperation with the Department of Health and Welfare (HEW), created a special demonstration project to finance housing for the chronically mentally ill. The goals of this project are deinstitutionalization and the provision of quality housing for the chronically mentally ill. Housing may range from small group homes serving up to twelve residents to slightly larger apartment complexes of up to ten units. HUD estimates that 488 units of housing will be developed depending upon the blend of new construction and substantially rehabilitated approved housing.

HUD will provide $\$ 15$ million in funds drawn from its Section 202 direct loan program for the housing construction and/or renovation. In addition to this, approximately $\$ 3$ million in rental assistance funds will be set aside to insure that occupants pay no more than 25 percent of their income for rent.

Under project regulations only private, non-profit groups at the community level are eligible sponsors of the housing project. States are requested to submit plans for housing development to HUD.

In June, 1978, the Community Support Project staff learned of this special demonstration project. The staff then initiated a process which resulted in Oregon's selection as one of the fourteen states that will participate in the HUD project. 
Within Oregon, ten non-profit corporations submitted applications to sponsor a housing development project. Representatives of the Department of Human Resources, Mental Health Division, Vocational Rehabilitation Division, County Mental Health programs, and the Housing Authority selected the private, non-profit agencies to carry out the project. Five of the agencies, from five counties, were awarded a total of $\$ 1.3$ million in loans for the construction and or renovation of housing.

Representatives of the state agencies mentioned will also determine eligibility for potential residents. In addition, the Mental Health Division and AFS will provide the necessary support services.

In Multnomah County, ten housing units for the chronically mentally ill will be built through this HUD demonstration project. The CSP staff and MHD staff were instrumental in encouraging private, non-profit agencies to apply and have provided technical assistance to those agencies awarded the loans. 
APPENDIX E

BASIC POPULATION CHARACTERISTICS 
APPENDIX E ${ }^{1}$

POPULATION

\begin{tabular}{|c|c|c|}
\hline $\begin{array}{l}\text { MULTNOMAH } \\
\% \text { of County } \\
\text { Population }\end{array}$ & $\begin{array}{l}\text { STATE } \\
\% \text { of State } \\
\text { Population }\end{array}$ & $\begin{array}{c}\text { State Rank } \\
\text { of } \\
\text { percent }\end{array}$ \\
\hline
\end{tabular}

SEX

Male

Female

ETHNICITY

White

Non-White

AGE GROUP ESTIMATES

17 Years and Under

18 to 64 Years

65 Years and 01der

URBAN AND RURAL PEOPLE (1977)

Total Population in Cities

Total Population Not in Cities

POPULATION CHANGE (1976-77)

Percent Population Net Change

Percent Change Due to Natural Increase

Percent Change Due to Net Migration

PERCENT OF POOR

Percent of Population (1970 Census)
48.3

51.7

93.0

7.0

26.3

61.0

12.7

29.2

59.9

10.9

49.0

51.0

97.2

2.8

-

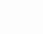

36

4.5*

9
75.2

24.8

59.1

40.9

1

36

2.3

33

31.3

68.7

35

27.7

11.1

11.2

25

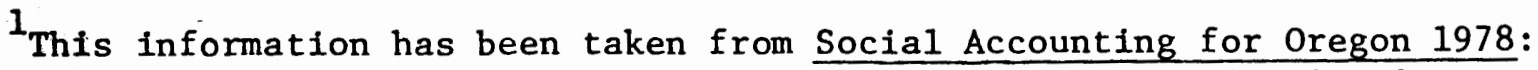

Socio-Economic Indicators. Salem, oregon: State Community Services Program, Department of Human Resources, 1978.

* Rank shared with other County(ies) 
PUBLIC ASSISTANCE

(SSI only)
MULTNOMAH

$\%$ of County

population
STATE

$\%$ of State

population
State Rank

of

percent

SUPPLEMENTAL SECURITY INCOME

PAYMENTS - 1977

Total - Adults and Children

1.33

1.0

$5.5 *$

Adult Recipients:

1.3

0.9

Aged Adults

0.5

Blind Adults

0.03

0.4

Disabled Adults

0.8

0.02

0.5 
EDUCATION

MULTNOMAH

STATE

$\%$ of County

$\%$ of State

State Rank

Population

Population 